\title{
Psychological interventions for parents of children and adolescents with chronic illness
}

\author{
Christopher Eccleston ${ }^{1}$, Tonya M Palermo ${ }^{2}$, Emma Fisher ${ }^{3}$, and Emily Law ${ }^{4}$ \\ ${ }^{1}$ Cochrane Pain, Palliative and Supportive Care Review Group, Centre for Pain Research, \\ University of Bath, Bath, UK \\ ${ }^{2}$ Anesthesiology and Pain Medicine, University of Washington, Washington, Seattle, USA \\ ${ }^{3}$ Department of Health, University of Bath, Bath, UK \\ ${ }^{4}$ Child Health, Behaviour \& Development, Seattle Children's Research Institute, WA, Seattle, USA
}

\begin{abstract}
Background-Psychological therapies have been developed for parents of children and adolescents with a chronic illness. Such therapies include parent only or parent and child/ adolescent, and are designed to treat parent behaviour, parent mental health, child behaviour/ disability, child mental health, child symptoms and/or family functioning. No comprehensive, meta-analytic reviews have been published in this area.
\end{abstract}

Objectives-To evaluate the effectiveness of psychological therapies that include coping strategies for parents of children/adolescents with chronic illnesses (painful conditions, cancer, diabetes mellitus, asthma, traumatic brain injury, inflammatory bowel diseases, skin diseases or gynaecological disorders). The therapy will aim to improve parent behaviour, parent mental health, child behaviour/disability, child mental health, child symptoms and family functioning.

Search methods-We searched CENTRAL, MEDLINE, EMBASE and PsyclNFO for randomised controlled trials (RCTs) of psychological interventions that included parents of children and adolescents with a chronic illness. The initial search was from inception of these databases to June 2011 and we conducted a follow-up search from June 2011 to March 2012. We identified additional studies from the reference list of retrieved papers and from discussion with investigators.

Contact person: Emma Fisher, Research Assistant, Department of Health, University of Bath, Bath, BA2 7AY UK,

e.a.fisher@bath.ac.uk

Contributions of authors: CE oversaw authoring of the manuscript, arbitrated the selection of studies, interpreted the analyses, was responsible for the methodology and will be responsible for updating the review in the future.

TP interpreted the analyses, drafted the final manuscript and will update the review in the future.

EF developed the search strategy, searched the electronic databases and reference lists, obtained studies, selected relevant studies, extracted data and entered data into RevMan (RevMan 2011), interpreted the analyses and drafted the review.

EL selected the studies to include and extracted data, interpreted the analyses and drafted the review.

Declarations of interest: None known.

Differences between protocol and review: Language throughout the protocol has been altered to improve the flow and increase the accuracy.

The tense of the language used in the methodology has been changed to past in line with Cochrane guidelines. Measures of treatment effect: this section has been added to provide a clearer description of intended analyses.

The order of the four main analyses has been re-worded for a clearer understanding of the analysis plan. Parent outcomes have been listed before child outcomes as this is the focus of the review. Appendices were added for other search strategies.

Assessment of risk of bias in included studies: this has been expanded to include a fuller description. 
Selection criteria-Included studies were RCTs of psychological interventions that delivered treatment to parents of children and adolescents (under 19 years of age) with a chronic illness compared to active control, wait list control or treatment as usual. We excluded studies if the parent component was a coaching intervention, the aim of the intervention was health prevention/ promotion, the comparator was a pharmacological treatment, the child/adolescent had an illness not listed above or the study included children with more than one type of chronic illness. Further to this, we excluded studies when the sample size of either comparator group was fewer than 10 at post-treatment.

Data collection and analysis-We included 35 RCTs involving a total of 2723 primary trial participants. Two review authors extracted data from 26 studies. We analysed data using two categories. First, we analysed data by each medical condition across all treatment classes at two time points (immediately post-treatment and the first available follow-up). Second, we analysed data by each treatment class (cognitive behavioural therapy (CBT), family therapy (FT), problem solving therapy (PST) and multisystemic therapy (MST)) across all medical conditions at two time points (immediately post-treatment and the first available follow-up). We assessed treatment effectiveness on six possible outcomes: parent behaviour, parent mental health, child behaviour/ disability, child mental health, child symptoms and family functioning.

Main results-Across all treatment types, psychological therapies that included parents significantly improved child symptoms for painful conditions immediately post-treatment. Across all medical conditions, cognitive behavioural therapy (CBT) significantly improved child symptoms and problem solving therapy significantly improved parent behaviour and parent mental health immediately post-treatment. There were no other effects at post-treatment or follow-up. The risk of bias of included studies is described.

Authors' conclusions-There is no evidence on the effectiveness of psychological therapies that include parents in most outcome domains of functioning, for a large number of common chronic illnesses in children. There is good evidence for the effectiveness of including parents in psychological therapies that reduce pain in children with painful conditions. There is also good evidence for the effectiveness of CBT that includes parents for improving the primary symptom complaints when available data were included from chronic illness conditions. Finally, there is good evidence for the effectiveness of problem solving therapy delivered to parents on improving parent problem solving skills and parent mental health. All effects are immediately post-treatment. There are no significant findings for any treatment effects in any condition at follow-up.

\section{Plain language summary}

\section{Psychological therapy for parents of children with a longstanding or life-threatening physical illness}

Parenting a child with a longstanding or life-threatening illness is very difficult, and can have a negative impact on many aspects of the parent's life. Parents of these children often have difficulty balancing caring for their child with other responsibilities such as work, social life, finance and other household tasks. As a result they may experience more stress, worries, sad feelings, family arguments and troubling child behaviour. Parents also have a major influence on their child's well-being and adjustment, and play an important role in how their child adapts to living with an illness. Treatments for parents of children with a longstanding illness aim to improve parent distress, parenting behaviours, family conflict, child distress, child disability and the child's medical symptoms.

Thirty-five studies were found in the search, but only 26 of these had data that could be used in the analyses. We found studies for six child illnesses (painful conditions, cancer, diabetes, asthma, traumatic brain injury and eczema) and four types of psychological therapies (cognitive behavioural therapy, family therapy, problem solving therapy and multisystemic 
therapy). We looked at the effects of the treatments on parent distress, parenting behaviours, family conflict, child distress, child disability and symptoms of the child's illness immediately after the treatment and at the first available follow-up time point after the treatment had ended. We analysed the data in two ways; first we grouped the studies by each individual illness and then we grouped the studies by each individual psychological therapy.

Psychological therapies can help reduce pain in children with painful conditions. Where there were results available from studies of different chronic illnesses, we found that cognitive behavioural therapy can improve the child's medical symptoms. Problem solving therapy can improve parent's distress and their ability to solve problems. More studies of psychological treatments for parents of children with a longstanding illness are needed.

\section{Background}

\section{Description of the condition}

Chronic illness affects the lives of many children and their families. The prevalence of illness and disability differs by geographical and economical context. In the USA, Canada, Northern Europe, UK and Australia chronic activity-limiting conditions are reported to be frequent, with painful illness, allergy, asthma and obesity being common (McDougall 2004). The changing demographic of childhood illness in economically wealthy countries has prompted a re-analysis of the role of paediatric medicine, as chronic illness becomes more prevalent than acute (e.g. Halfon 2010; Van Cleave 2010). Other parts of the world present different clinical challenges. In Africa, for example, life expectancy is 54 years and shorter in sub-Saharan Africa where almost half the population are children and the most prevalent chronic conditions are related to communicable diseases, in particular HIV-related disease, malaria and tuberculosis (WHO 2011).

The existing published literature shows a bias towards the medical management of chronic illness related to environment or lifestyle. Chronic pain in childhood is known to have widespread negative outcomes for children and parents (Palermo 2000). Psychological intervention reviews have also been undertaken on the impact of sickle cell disease (Anie 2012), recurrent abdominal pain/irritable bowel syndrome (Huertas-Ceballos 2008), type 1 diabetes (McBroom 2009), traumatic brain injury in children (Soo 2007) and asthma (Yorke 2009).

The impact of childhood chronic illness on other family members, including parents, has been of growing interest for two reasons. First, it is now recognised that parents who have significant emotional distress of their own and poor family functioning can indirectly affect child outcomes (Logan 2005; Palermo 2007). Second, it is now recognised that parents can have a positive effect on child adjustment to chronic illness (Logan 2005).

\section{Description of the intervention}

Addressing the mental health problems of parents, and enabling parents to be agents of change in the management of their child's chronic illness, have recently been promoted as viable treatment approaches (Jordan 2007; Palermo 2009b). Studies have focused on the education of parents about the specific condition or treatment (e.g. Savage 2011), whilst others concern lay- or nurse-mediated social support (e.g. Lewin 2010). In psychological science, specific treatment approaches have been developed that focus on reducing the emotional distress expressed by parents, or on altering parenting behaviours to promote better child outcomes, whether this be decreasing emotional distress, or improving physical symptoms or behaviour. 
Psychological interventions of interest are defined as any psychotherapeutic treatment specifically designed to change parent cognition or behaviour, or both, with the intention of improving child outcomes. Psychological interventions are varied in their approaches and there is still debate surrounding which treatment is most effective at improving mental health and behaviour in parents and children with chronic illnesses. Such interventions include cognitive behavioural therapy (CBT) which has been found to be effective with children with painful conditions (e.g. Eccleston 2009a; Palermo 2009a). Problem solving therapy (PST) has also been used with parents and children with various chronic illnesses (D'Zurilla 1995; Sahler 2002). Other treatments have emerged from a family systems approach that focuses explicitly on the family as a unit of intervention (Ellis 2005; Wysocki 2000) such as multisystemic therapy (MST) or family therapy (FT).

\section{How the intervention might work}

There are a variety of interventions described as psychological. Cognitive and cognitive behavioural therapies dominate, but therapies with a psychodynamic or systemic tradition are also represented. Family and couple therapies have also been developed. All psychological interventions include a rationale for therapy. Common is education around illness and behaviour. Establishing the therapy and the therapist as credible is an important general stage (Nock 2001). Next, a therapeutic relationship is established that will enable a confidential, non-blaming investigation of behaviour. Then, depending on the illness and behavioural presentation, specific components may include anxiety management, exposure for phobic targets, problem solving skills, cognitive therapy for depression and relationship management. Finally, most treatments will include a maintenance component that focuses on robust behavioural change within a normal home environment outside the clinic, over time. Such components can be seen in parent interventions using different therapies to improve parental functioning, child behaviour and mental health.

Cognitive behavioural interventions specifically are based on a number of foundational assumptions. First, behaviour is socially and historically contingent (Skinner 1953). Second, cognition is an emergent property of behavioural context (James 1980). Third, behaviour is regulated by cognitive goals (Bandura 1989). Fourth, emotions influence both behaviour and cognition (Ashby 1999; Gilliom 2002). Fifth, most behaviour is deployed outside of conscious awareness or control (Bargh 2008). Finally, some attempts to control cognition and behaviour can have paradoxical negative effects on desired outcomes (Wegner 1994).

Other interventions such as PST (D'Zurilla 1995) provide a specific framework that includes positive problem orientation towards an issue. Cognitive-behavioural strategies are used in PST and include the following steps: Identify the problem, Define your options, Evaluate your options, Act, and finally See if it worked. PST has previously been effective with depression, anxiety and stress-related syndromes (D'Zurilla 1999).

Family and systemic therapies specifically focus on a contextual and relational view of the aetiology and maintenance of behaviour. In particular, the target of health behaviour change is typically related to family functioning, or in the cognitive representation of the family, rather than on individual attitudes, beliefs or behaviour. Typically, family or systems therapy approaches will include multiple family members and outcomes are often expressed on behalf of the family or dyad (two individuals regarded as a pair).

\section{Why it is important to do this review}

The prevalence of childhood chronic illness has more than doubled in the last 20 years (Perrin 2007). Parents provide a major influence in children's lives, influence that can have both a positive or negative effect on child outcomes. Psychological interventions are being 
developed that focus on helping parents to help both themselves and their children.

Establishing the evidence at this stage of development will provide comment on current best practice, and serve to guide new treatment development.

\section{Objectives}

1. To evaluate the effectiveness of psychological parent interventions on reducing the distress associated with parenting a child with a chronic illness.

2. To evaluate the effectiveness of psychological parent interventions on reducing the primary symptom or behavioural expression of illness for the child.

3. To assess primary outcomes and adverse events of different parent interventions in the 14 different conditions (see 'Types of participants').

\section{Methods}

\section{Criteria for considering studies for this review}

Types of studies-Randomised controlled trials (RCTs) that compared parental psychological interventions with attention control, other active treatment or waiting list control were considered for this review. The parent intervention had to be primarily psychological in nature. Studies that met the inclusion criteria consisted of the following:

- RCT, published in full in a peer-reviewed journal;

- primary aim of the trial was an evaluation of a psychological intervention;

- involved parents of children who have an illness for three months or more (Van der Lee 2007);

- involved parents of children adjusting to a diagnosis of cancer;

- had a $\mathrm{n}$ of 10 or more in both the treatment and control arm at end of treatment or follow-up.

Types of participants-Parents of children who have endured a chronic illness for three months or more. Parents were regarded as the primary caregiver of a child or adolescent under the age of 19 years. Parents were defined, for the purposes of this review as any adult who adopts the responsibility for the role of parenting the child (this could include biological parent, guardian, other adult family member). There was no lower age limit for the children, however, by the definition of 'chronic illness', the child must be three months or more. The children must also be experiencing one (or more) of the following physical illnesses:

- headache;

- recurrent abdominal pain;

- back pain;

- idiopathic pain conditions;

- complex regional pain syndrome (CRPS);

- rheumatological conditions (e.g. arthritis and fibromyalgia);

- $\quad$ sickle cell disease;

- cancer;

- diabetes mellitus; 
- $\quad$ asthma;

- $\quad$ traumatic brain injury;

- $\quad$ inflammatory bowel diseases;

- $\quad$ skin diseases (e.g. eczema);

- gynaecological disorders (e.g. chronic dysmenorrhoea and endometriosis).

Chronic illnesses were selected from the National Survey of Children with Special Health Care Needs 2009 to 2010 (Data Resource Center 2010). It was impractical to include all chronic illnesses on this list, therefore, we selected the most common. However, three illnesses (cancer, inflammatory bowel diseases and gynaecological disorders) were not included in the Current Health Conditions and Functional Difficulties but were added for the purposes of this review. Cancer has a high incidence level and it was predicted that in 2007, there were 10,400 children with cancer in the US alone under the age of 14 (Linabery 2007). Studies that investigate interventions with parents of children who have 'survived' an illness such as childhood survivors of cancer were also eligible for inclusion. Inflammatory bowel diseases and gynaecological disorders are also common conditions in childhood and adolescence and were included because they are thought to be prevalent but underrepresented in the academic literature.

Types of interventions-Studies were included if the interventions were primarily psychological, and had credible, recognisable psychological/psychotherapeutic content, and were specifically for, or included parents. Psychological interventions were defined as any psychotherapeutic treatment specifically designed to change parent cognition or behaviour, or both, and had the intention of improving parent or child outcomes. However, studies in which parents acted as 'coaches' were excluded from this review. The intervention had to aim to provide treatment to the parent rather than teach them to deliver an intervention to their child. Similarly, we also excluded health promotion therapies such as intervening with the parent to cease smoking to improve their child's asthma. We have excluded studies that combine psychological interventions with pharmacological interventions or are qualitative in nature as it is difficult to combine qualitative and quantitative data.

Types of outcome measures-Primarily, parent outcomes were the target of our review. However, if the study also reported child outcomes as stated below, we also analysed and reported these data. We analysed data at post-treatment and the first available follow-up period, where reported.

Primary outcomes, depending on specific treatment, were: parent behaviour, parent mental health, child behaviour/disability, child mental health, child primary symptom, family function and adverse events.

We made a judgement when studies reported multiple measures within one of the six outcome domains without defining their primary or secondary outcome measure. The rules of this judgement were to select the most generic, reliable and most frequently used measure within the field, and most appropriate for the given outcome category. When both parents and children reported on a measure, we extracted the self report item unless the non-self report measure was a more generic measure. For family functioning measures, we extracted parent data over child data as the review is focused on whether interventions can help parents of children with a chronic illness. 


\section{Search methods for identification of studies}

We searched electronic databases and reference lists to identify studies matching the criteria. In addition, we also contacted experts and study authors for additional studies.

Electronic searches-We searched four databases for studies from inception to June (week 4) 2011 and again in March (week 1) 2012:

- The Cochrane Central Register of Controlled Trials (CENTRAL, beginning 1968);

- MEDLINE via Ovid (beginning 1946);

- EMBASE via Ovid (beginning 1974);

- PsyclNFO via Ovid (beginning 1806).

We adapted the search strategies from the MEDLINE search (see Appendix 1) and they are included in Appendix 2. There was no language restriction imposed and no unpublished literature or grey material was included. The search strategy included four categories of words: psychological interventions, parents, children/adolescents and chronic illnesses (as stated above), and was refined by a methodological filter used to identify RCTs according to Cochrane guidance (Higgins 2011).

Searching other resources-We performed a reference list and citation search of each selected study which identified further studies meeting the inclusion criteria. We then repeated this stage for such studies. We also checked meta-analyses and systematic reviews that met the inclusion criteria for appropriate studies and included them if they met the inclusion criteria. We also contacted authors of selected studies and experts in the field for further studies that had not already been identified from the search.

\section{Data collection and analysis}

Selection of studies-EF performed the searches of each database and collated results. Two review authors (EF, EL) then sifted through potential studies and identified those eligible to be included with CE acting as arbiter. No blinding of study authors' names, institutions or journals occurred during this process. We resolved any disagreements by discussion between all review authors.

We made selection of abstracts using the following criteria.

1. Participants

- Parents must be referred to in the title or abstract of each study

- The parent must be the primary caregiver of the child

- Children must have one or more of the chronic illnesses listed above

- Children must be in the age range three months to 19 years

- There must be 10 or more participants in each condition at the end of the treatment assessment

2. Intervention

- The intervention must be primarily psychological in at least one condition

- Must be of RCT in design

- One or more parents must be treated by the intervention 
- The parents and/or child must be measured at baseline and at a point in time during or after the intervention

3. Comparison groups

- Attention control group

- Active treatment group

- Treatment as usual group: this would consist of usual doctors' appointments and treatment without added psychological therapy

- Wait list control

4. Numerical outcomes presented

We then obtained the selected studies meeting the criteria in full and EF and EL read and assessed them independently.

Data extraction and management-Two review authors (EF and EL) carried out data extraction from studies that were identified by all review authors as appropriate for inclusion. The data extraction sheet was adapted from Eccleston 2009a and Eccleston 2009b. It included references, the diagnosis of the child's chronic illness, aspects of the intervention or therapy, characteristics of the treatment team, the setting of the intervention and outcome measures.

Assessment of risk of bias in included studies-We assessed risk of bias using the recommended Cochrane guidance (Higgins 2011). Of the five suggested risk of bias categories, we judged studies on random sequence generation (selection bias), allocation concealment (selection bias), blinding of outcome assessment (detection bias), incomplete outcome data (attrition bias) and selective reporting (reporting bias). We excluded the option of 'blinding participants and personnel' because we deemed it redundant as neither therapists nor patients can be blinded to whether they deliver or receive treatment.

Decisions about random sequence generation were based on whether authors gave a convincing method of randomisation. Allocation concealment judgements were based on whether sufficient methods were employed for random allocation to take place. Participants being stratified by age or gender did not count as bias but are noted in the tables. We judged risk of blinding of outcome assessment on whether the measures were administered and collected by an assessor who was blind to the treatment allocation. We judged high risk of attrition bias when no description of attrition was reported. We made an unclear decision when there was an adequate decision given but authors did not report whether there were significant differences between completers and non-completers. We concluded low risk of bias when authors gave both a description of attrition and stated that there were no significant differences between completers and non-completers. Third, we judged selective reporting bias in two parts. First, we judged studies on whether data were fully reported in the study or if authors later responded to data requests. Second, we rated each study on a three-point scale for concordance (two points $=$ full concordance, one point $=$ partial concordance, zero points $=$ no concordance) . We rated studies for concordance between study aims and measures (i.e. if aims corresponded to measures stated in methods section) and between measures and results (i.e. if all measures were reported in results, and no additional measures were added to results that were not stated in the methods section).

Assessment of quality in included studies: We assessed quality of studies using the method advocated by Yates 2005. Two authors (EF, EL) rated study quality for each study and disagreements were settled by discussion between all authors. The rating scale consists 
of two sections which creates an overall quality of study score of 35 . The first section measures treatment quality ( 0 to 9 ) which assesses the treatment rationale, duration of treatment, manualisation, therapist training and engagement of patients. The second section measures the quality of the study design and methods used (0 to 26). This section measures the inclusion/exclusion criteria, rates of attrition, description of patient sample, steps taken to minimise bias (randomisation, allocation bias, measurement bias and treatment expectations), justification of outcomes and whether they are reliable and valid, follow-up, adequate statistical analyses (power, sufficient sample size, planned data analysis, statistical reporting and intention-to-treat analysis) and finally choice of control group. The studies are then categorised as ' high quality' or ' low quality' of being biased. The boundary between high and low quality was defined as the mid-point (quality of study high quality $\geq 18$, low quality $\leq 17$, treatment quality high quality $\geq 5$, low quality $\leq 4$, quality of study design and methods used high quality $\geq 15$, low quality $\leq 14$ ).

Measures of treatment effect-We investigated four classes of psychological therapies: cognitive behavioural therapy (CBT), family therapy (FT), problem solving therapy (PST) and multisystemic therapy (MST). CBT is based on theories of behavioural analysis (Bergin 1975), cognitive theory (Beck 1979) and social learning theory (Bandura 1977). CBT therefore includes a range of strategies with the goals of modifying social/environmental and behavioural factors that may exacerbate or cause symptoms, and modifying maladaptive thoughts, feelings and behaviours to reduce symptoms and prevent relapse. FT is based on family systems theory (Haley 1976; Minuchin 1974), which emphasises the role of the family context in an individual's emotional functioning. FT interventions typically focus on altering patterns of interactions between family members, and include structural family therapy (Minuchin 1974), strategic family therapy (Haley 1976) and behavioural systems family therapy (Robin 1989). PST is based on the D'Zurilla 1982 social problem solving model, which defines problem solving in terms of an individual's ability to recognise problems and use cognitive and behavioural skills to solve them. PST includes didactic instruction in problem solving skills, followed by in-session modelling, behavioural rehearsal and performance feedback, as well as homework assignments (D'Zurilla 2007). Finally, MST is an intensive family and community-based intervention based on the Bronfenbrenner 1979 social ecological model and family systems theory (Haley 1976; Minuchin 1974). MST therefore targets the patient, their family and broader systems such as the patient's school, work or medical team as needed. MST incorporates a wide range of evidence-based intervention techniques based on the individual needs of the patient and family (Henggeler 2003), including cognitive-behaviour approaches, parent training and family therapies.

We extracted data immediately post-treatment (i.e. immediately after the treatment programme had finished). Where data were available, we also analysed studies at follow-up, which is classed as the first available time point after post-treatment. We categorised outcomes into one of six outcome domains: parent behaviour, parent mental health, child behaviour/disability, child mental health, child symptoms and family functioning. Where studies had more than one comparator group, we chose the 'active control group' over 'standard treatment' or 'wait list control' groups.

There are four therapies (CBT, FT, PST and MST), eight conditions (asthma, cancer, diabetes, gynaecological disorders, inflammatory bowel syndrome, painful conditions (these were grouped together due to the homogeneous nature of the trials), skin diseases and traumatic brain injury), two time points (post-treatment and follow-up) and six possible outcomes (parent behaviour, parent mental health, child behaviour/disability, child mental health, child symptoms and family functioning). There are six categories by which we analysed data. 
1. For each condition, across all types of psychological therapy, what is the effectiveness for the six outcomes immediately post-treatment?

2. For each condition, across all types of psychological therapy, what is the effectiveness for the six outcomes at follow-up?

3. For each psychological therapy, across all conditions, what is the effectiveness for the six outcomes immediately post-treatment?

4. For each psychological therapy, across all conditions, what is the effectiveness for the six outcomes at follow-up?

5. The interaction between the condition and the psychological therapy effectiveness.

6. Investigation of characteristics of particularly effective treatments.

Analyses are presented for each of the six outcomes, however, due to the heterogeneous nature of the conditions and studies, this was not always possible. We pooled data using standardised mean difference and random-effect models as studies did not consistently use the same scales when measuring the same outcomes. Cohen's d effect sizes can be interpreted as follows: $0.2=$ small, $0.5=$ medium, $0.8=$ large (Cohen 1992). Where possible, we combined data in a metaanalysis and, following Cochrane guidance (Higgins 2011), presented data in the form of numbers needed to treat and numbers needed to harm.

Dealing with missing data-We contacted authors of studies when data were not reported fully in publications. However, when authors could not send data to the review authors or were non-responsive to emails, we excluded data.

Assessment of heterogeneity-Subgroup analysis explored the possible sources of heterogeneity (see Results).

Assessment of reporting biases-Biases are reported within the results section of the review following Cochrane guidance on bias reporting (Higgins 2011). When possible, we attempted to use a failsafe $\mathrm{N}$ to control for publication bias.

Subgroup analysis and investigation of heterogeneity-When there were multiarm trials or trials that compared more than one active treatment, we used the primary active treatment and compared with the least biased comparator (typically standard care or treatment as usual). Analyses of the following subgroups are presented where data permitted:

- parent-only interventions versus family-based interventions;

- intervention effects within specific illnesses;

- intervention effects across specific types of psychological interventions.

We also explored heterogeneity through subgroup analysis (see 'Results').

\section{Results}

\section{Description of studies}

See: 'Characteristics of included studies' and 'Characteristics of excluded studies'.

Results of the search-We extracted a total of 114 papers to identify whether they met the full inclusion criteria; 107 papers were found in the initial search, and a further seven studies were identified later in an updated search before publication. Of these 114 papers, 99 
were found from the search of databases, six papers from the citation search, four papers from reference searches and five papers from authors of included studies. We deemed 35 studies (45 papers) to meet the inclusion criteria for the review, whilst 61 studies (69 papers) were excluded (Aleman 1992; Anderson 1999; Betancourt 2004; Braga 2005; Bruzzese 2008; Burke 1997; Burke 2001; Cakan 2007; Canino 2008; Carey 2008; Chernoff 2002; Chiang 2009; Ellis 2007; Ellis 2008; Evans 1999; Field 1998; Forsander 1995; Forsander 2003; Garbutt 2010; Gerber 2010; Giallo 2008; Glang 2007; Gustafsson 1986; Harris 2001; Haus 1976; Hernandez 1998; Hommel 2012; Hovell 1994; Humphreys 2000; Ireys 1996; Ireys 2001; Jay 1990; Johnson 1987; Kamps 2008; Kaslow 2000; Kazak 1996; Kazak 2005; Ketchen 2006; Klinnert 2005; Klinnert 2007; Kroner-Herwig 1998; Kupfer 2010; Lasecki 2008; Logan 1997; Mendez 1997; Nelson 2011; Perez 1999; Rasoli 2008; Sanders 1989; Sanders 1996; Satin 1989; Scholten 2011; Sieberg 2011; Staab 2002; Sullivan-Bolyai 2010; Szczepanski 2010; Wade 2010; Walders 2006; Walker 1996; Warner 2011; Wysocki 1997).

Included studies-Of the 35 studies (45 papers) included in this review, 31 had two comparator arms and four studies had three comparator arms. Of the 31 studies that had two arms, 15 studies used active controls where patients had to actively engage in another type of treatment (e.g. education) whilst 19 used wait list or "treatment as usual controls". The total number of participants at the end of treatment was 2723 (mean $=80$ per study). The total number of participants entering treatment was 3214 (mean $=95$ per study). Therefore, the completion rate for all studies was $85 \%$, making the attrition percentage $15 \%$. The proportion of completers across studies ranged from $59 \%$ to $100 \%$.

We categorised the studies by the primary illness of the children. There were 12 painful condition studies (Allen 1998; Barakat 2010; Barry 1997; Connelly 2006; Duarte 2006; Hicks 2006; Kashikar-Zuck 2005; Kashikar-Zuck 2012; Levy 2010; Palermo 2009; Robins 2005; Sanders 1994). Six studies with the primary illness of cancer met the inclusion criteria (Askins 2009; Hoekstra-Weebers 1998; Kazak 2004; Sahler 2002; Sahler 2005; Stehl 2009), nine diabetes studies (Ambrosino 2008; Ellis 2004; Ellis 2005; Grey 2011; Laffel 2003; Lehmkuhl 2010; Olivares 1997; Wysocki 1999; Wysocki 2006), four asthma studies (Celano 2012; Lask 1979; Ng 2008; Seid 2010), three traumatic brain injury studies (Wade 2006; Wade 2006b; Wade 2011) and one atopic eczema study (Niebel 2000). However, no studies met the inclusion criteria for inflammatory bowel disease or gynaecological disorders.

Similarly, we also categorised studies by the type of psychological therapy delivered. There were 19 studies that delivered CBT (Allen 1998; Ambrosino 2008; Barakat 2010; Barry 1997; Connelly 2006; Duarte 2006; Grey 2011; Hicks 2006; Hoekstra-Weebers 1998; Kashikar-Zuck 2005; Kashikar-Zuck 2012; Laffel 2003; Levy 2010; Niebel 2000; Olivares 1997; Palermo 2009; Robins 2005; Sanders 1994; Stehl 2009), seven studies that delivered FT (Celano 2012; Kazak 2004; Lask 1979; Lehmkuhl 2010; Ng 2008; Wysocki 1999; Wysocki 2006), seven studies that delivered PST (Askins 2009; Sahler 2002; Sahler 2005; Seid 2010; Wade 2006; Wade 2006b; Wade 2011) and two studies that delivered MST (Ellis 2004; Ellis 2005).

We were unable to extract quantitative data from nine of the 35 studies (Barry 1997; Celano 2012; Duarte 2006; Grey 2011; Kazak 2004; Lask 1979; Lehmkuhl 2010; Olivares 1997; Robins 2005). These studies did not present means or standard deviations, or combined data with another study already included in the review (Grey 2011). Therefore 26 studies (36 papers, 2253 participants at end of treatment) presented data that were included in at least one analysis (Allen 1998; Ambrosino 2008; Askins 2009; Barakat 2010; Connelly 2006; Ellis 2004; Ellis 2005; Hicks 2006; Hoekstra-Weebers 1998; Kashikar-Zuck 2005; Kashikar-Zuck 2012; Laffel 2003; Levy 2010; Ng 2008; Niebel 2000; Palermo 2009; Sahler 
2002; Sahler 2005; Sanders 1994; Seid 2010; Stehl 2009; Wade 2006; Wade 2006b; Wade 2011; Wysocki 1999; Wysocki 2006).

The proportion of therapy received by parent and child varied between studies. The majority of studies gave equal attention to both parent and child (22 studies). In seven studies only the parent received therapy, four of which studies were delivering treatment to parents whose children had been diagnosed with cancer. Four further studies spent the majority of treatment time with the child. The final two studies did not specify how much therapy the parent and child received. Twenty-eight studies treated patients in-person with the therapist, and seven studies used online programmes to deliver part or all of the therapy to patients. Twenty-five studies carried out therapy with individuals or with individual families, whilst eight studies used a group format. One further study used a combination of group and individual work. One study did not specify how treatment was carried out. A summary of the characteristics of therapy, and a narrative summary of treatment content, are presented in Table 1 and Table 2 respectively.

Excluded studies-Sixty-one studies did not meet the inclusion criteria for this study. Thirty-one studies had insufficient psychotherapeutic content, such as instruction, education, parents trained as 'coaches' for their children or health prevention interventions (Aleman 1992; Anderson 1999; Braga 2005; Burke 1997; Burke 2001; Chernoff 2002; Chiang 2009; Evans 1999; Field 1998; Garbutt 2010; Giallo 2008; Glang 2007; Hovell 1994; Humphreys 2000; Ireys 1996; Ireys 2001; Johnson 1987; Kaslow 2000; Kazak 1996; Ketchen 2006; Klinnert 2005; Klinnert 2007; Kupfer 2010; Logan 1997; Mendez 1997; Nelson 2011; Perez 1999; Staab 2002; Sullivan-Bolyai 2010; Szczepanski 2010; Walders 2006). Sixteen studies had an aim that was irrelevant to the aim of the review such as fidelity studies, mixed illnesses or the intervention focusing on the parents communication with professionals (Bruzzese 2008; Cakan 2007; Canino 2008; Carey 2008; Ellis 2007; Ellis 2008; Forsander 1995; Gerber 2010; Harris 2001; Hommel 2012; Jay 1990; Rasoli 2008; Scholten 2011; Wade 2010; Walker 1996; Wysocki 1997). Thirteen studies had an insufficient number of participants $(\mathrm{n}<10)$ at post-treatment in or one more arms of treatment (Forsander 2003; Gustafsson 1986; Haus 1976; Hernandez 1998; Kamps 2008; Kazak 2005; Kroner-Herwig 1998; Lasecki 2008; Sanders 1989; Sanders 1996; Satin 1989; Sieberg 2011; Warner 2011) and one paper recruited participants prospectively (Betancourt 2004). These judgements were often difficult to make and led to extended discussion between review authors.

\section{Risk of bias in included studies}

We used five 'Risk of bias' categories: random sequence generation (selection bias), allocation concealment (selection bias), blinding of outcome assessment (detection bias), incomplete outcome data (attrition bias) and selective reporting (reporting bias) (Figure 1; Figure 2). Sixteen studies described a convincing method of randomisation and we judged them to have a low risk of bias, a further 19 studies did not provide an adequate description and we judged them to be unclear. We rated no studies as high risk of bias for random allocation. There were 12 studies that described a convincing method of allocation and we judged them to have a low risk of allocation bias, a further 22 studies did not provide an adequate description and we judged them to be unclear. We rated ne study as high risk of allocation bias. Thirteen studies reported outcome assessors that were blinded to treatment allocation and we judged them to have a low risk of bias, a further 21 studies did not provide an adequate description and we judged them to be unclear, and we judged one study to have a high risk of outcome bias. Eleven studies reported attrition and found no significant differences between completers and non-completers, so we judged them to have a low risk of bias. Five studies reported attrition but did not report differences between completers and non-completers and so we judged them to be unclear and nine studies did not give an 
adequate description of attrition and so we judged them to be of high risk. Data could be fully extracted in 12 studies and were fully concordant between aims, measures and results and we judged them to have low risk of selective reporting bias. A further 13 studies were unclear, meaning data could not be extracted or aims, measures and results were only partially concordant. We found 10 studies to have high risk of selective reporting bias because data could not be extracted and they were only partially concordant.

Assessment of quality in included studies-For the 35 studies that met the inclusion criteria, the mean overall quality of the study was 21.49 (standard deviation $(\mathrm{SD})=6.09$, range seven to 32). This score is made up of the treatment quality score ( $M=6.74$, SD 2.06, range one to nine) and the quality of design and methods $(\mathrm{M}=14.74, \mathrm{SD}=4.52$, range three to 23). The 'Risk of bias' figures show the overall quality total, treatment quality and quality of design and methods. We performed a Spearman's correlation to investigate whether the total study quality, treatment quality, design quality or $n$ at the end of treatment were correlated to the year of study. Year of publication was significantly and positively associated with total study quality (rho $=0.581, \mathrm{P}<0.001)$, design quality of the study (rho $=0.525, \mathrm{P}<0.01$ ) and treatment quality of the study (rho $=0.566, \mathrm{P}<0.01$ ). Treatment quality was significantly associated with design quality (rho $=0.665, \mathrm{P}<0.001$ ). End of treatment $\mathrm{n}$ was not significantly associated with year of publication, treatment quality or design quality $(\mathrm{rho}=0.169, \mathrm{P}>0.05 ;$ rho $=0.066, \mathrm{P}>0.05 ;$ rho $=0.136, \mathrm{P}>0.05$ ), respectively.

When assessing all 45 analyses reported at post-treatment and follow-up, 15 showed low heterogeneity $\left(\mathrm{I}^{2}=<25 \%\right), 16$ showed moderate heterogeneity $\left(\mathrm{I}^{2}=>25 \%\right.$ to $\left.<50 \%\right)$ and 14 showed high heterogeneity $\left(\mathrm{I}^{2}=>50 \%\right)$.

\section{Effects of interventions}

We analysed data in two categories. In the first, outcomes for each individual condition across all psychological therapies are analysed at post-treatment and follow-up. For the second, outcomes for each psychological therapy across all conditions at post-treatment and follow-up are presented. No analyses could be presented for gynaecological disorders or inflammatory bowel syndrome due to lack of studies meeting the inclusion criteria, and no adverse events were reported in any study reviewed.

\section{Individual conditions across all psychological therapies}

Painful conditions at post-treatment: We entered two studies of children with chronic pain, containing a total of 92 participants, into an analysis of parent behaviour. The overall effect of all psychological therapies on parent behaviour was not significant $(Z=0.80, P>$ 0.05) (Analysis 1.1). We entered six studies of children with chronic pain, containing a total of 429 participants, into an analysis of child behaviour/disability. The overall effect of all psychological therapies on child behaviour/disability was not significant $(\mathrm{Z}=1.39, \mathrm{P}>0.05)$ (Analysis 1.2). We entered four studies of children with chronic pain, containing a total of 356 participants, into an analysis of child mental health. The overall effect of all psychological therapies on child mental health was not significant $(Z=0.14, P>0.05)$ (Analysis 1.3). We entered eight studies of children with chronic pain, containing a total of 512 participants, into an analysis of child symptoms. The overall effect of all psychological therapies on child symptoms was significant $(Z=2.23, \mathrm{P}<0.05)$ with a small effect size of standardised mean difference (SMD) -0.29 (95\% confidence interval (CI) -0.55 to -0.03) (Analysis 1.4; Figure 3). There was only one study of children with chronic pain that could be entered into an analysis of family functioning, therefore no conclusion could be drawn.

No studies presented extractable data on parent mental health. 
Painful conditions at follow-up: There was only one study of children with chronic pain that could be entered into an analysis of parent behaviour at follow-up, therefore no conclusions could be drawn. We entered three studies of children with chronic pain, containing a total of 289 participants, into an analysis of child behaviour/disability at followup. The overall effect of all psychological therapies on child behaviour/disability at followup was not significant $(Z=0.29, P>0.05)$ (Analysis 2.1). We entered two studies of children with chronic pain, containing a total of 255 participants, into an analysis of child mental health at follow-up. The overall effect of all psychological therapies on child mental health at follow-up was not significant $(\mathrm{Z}=0.28, \mathrm{P}>0.05)$ (Analysis 2.2). We entered six studies of children with chronic pain, containing a total of 391 participants, into an analysis of child symptoms at follow-up. The overall effect of all psychological therapies on child symptoms at follow-up was not significant $(\mathrm{Z}=1.64, \mathrm{P}>0.05)$ (Analysis 2.3 ). There was only one study of children with chronic pain that could be entered into an analysis of family functioning at follow-up, therefore no conclusions could be drawn.

No studies presented extractable data on parent mental health.

Cancer at post-treatment: We entered four studies of children with cancer, containing a total of 629 participants, into an analysis of parent behaviour. The overall effect of all psychological therapies on parent behaviour was not significant $(\mathrm{Z}=1.28, \mathrm{P}>0.05)$ (Analysis 3.1). We entered five studies of children with cancer, containing a total of 706 participants, into an analysis of parent mental health. The overall effect of all psychological therapies on parent mental health was not significant $(\mathrm{Z}=1.36, \mathrm{P}>0.05)$ (Analysis 3.2).

No studies presented extractable data on child behaviour/disability, child mental health, child symptoms or family functioning.

Cancer at follow-up: We entered four studies of children with cancer, containing a total of 597 participants, into an analysis of parent behaviour at follow-up. The overall effect of all psychological therapies on parent behaviour at follow-up was not significant $(Z=0.54, P$ > 0.05) (Analysis 4.1). We entered four studies of children with cancer, containing a total of 598 participants, into an analysis of parent mental health at follow-up. The overall effect of all psychological therapies on parent mental health at follow-up was not significant $(\mathrm{Z}=$ $1.20, \mathrm{P}>0.05$ ) (Analysis 4.2).

No studies presented extractable data on child behaviour/disability, child mental health, child symptoms or family functioning.

Diabetes at post-treatment: There was only one study of children with diabetes that could be entered into analyses of parent mental health, therefore no conclusions could be drawn. We entered two studies of children with diabetes, containing a total of 198 participants, into an analysis of child mental health. The overall effect of all psychological therapies on child mental health was not significant $(Z=0.28, P>0.05)$ (Analysis 5.1). There was only one study of children with diabetes that could be entered into analyses of child behaviour/ disability, therefore no conclusions could be drawn. We entered six studies of children with diabetes, containing a total of 455 participants, into an analysis of child symptoms. The overall effect of all psychological therapies on child symptoms was not significant $(\mathrm{Z}=$ $1.70, \mathrm{P}>0.05$ ) (Analysis 5.2). We entered four studies of children with diabetes, containing a total of 306 participants, into an analysis of family functioning. The overall effect of all psychological therapies on family functioning was not significant $(\mathrm{Z}=0.09, \mathrm{P}>0.05)$ (Analysis 5.3).

No studies presented extractable data on parent behaviour. 
Diabetes at follow-up: There was only one study of children with diabetes that could be entered into an analysis of parent mental health at follow-up, therefore no conclusion could be drawn. We entered three studies of children with diabetes, containing a total of 239 participants, into an analysis of child symptoms at follow-up. The overall effect of all psychological therapies on child symptoms at follow-up was not significant $(\mathrm{Z}=1.58, \mathrm{P}>$ 0.05) (Analysis 6.1).

No studies presented extractable data on parent behaviour, child behaviour/disability, child mental health or family functioning.

Asthma at post-treatment: There was only one study of children with asthma that could be entered into analyses on parent behaviour, therefore no conclusions could be drawn. We entered two studies of children with asthma, containing a total of 74 participants, into an analysis of parent mental health. The overall effect of all psychological therapies on parent mental health was not significant $(Z=0.86, P>0.05)$ (Analysis 7.1). There was only one study of children with diabetes that could be entered into analyses of child behaviour/ disability, therefore no conclusions could be drawn. We entered three studies of children with asthma, containing a total of 170 participants, into an analysis of child symptoms. The overall effect of all psychological therapies on child symptoms was not significant $(\mathrm{Z}=$ $1.51, \mathrm{P}>0.05$ ) (Analysis 7.2).

No studies presented extractable data on child mental health or family functioning.

Asthma at follow-up: We entered two studies of children with asthma, containing a total of 132 participants, into an analysis of child symptoms at follow-up. The overall effect of all psychological therapies on child symptoms at follow-up was not significant $(\mathrm{Z}=0.55, \mathrm{P}$ > 0.05) (Analysis 8.1).

No studies presented extractable data on parent behaviour, parent mental health, child behaviour/disability, child mental health or family functioning.

Traumatic brain injury at post-treatment: We entered two studies of children with traumatic brain injury, containing a total of 72 participants, into an analysis of parent mental health. The overall effect of all psychological therapies on parent mental health was not significant $(\mathrm{Z}=1.49, \mathrm{P}>0.05)$ (Analysis 9.1). We entered two studies of children with traumatic brain injury, containing a total of 72 participants, into an analysis of child behaviour/disability. The overall effect of all psychological therapies on child behaviour/ disability was not significant $(Z=0.65, P>0.05)$ (Analysis 9.2). We entered two studies of children with traumatic brain injury, containing a total of 67 participants, into an analysis of family functioning. The overall effect of all psychological therapies on family functioning was not significant $(Z=0.33, P>0.05)$ (Analysis 9.3).

No studies presented extractable data on parent behaviour, child mental health or child symptoms.

Traumatic brain injury at follow-up: No studies presented extractable data on parent behaviour, parent mental health, child behaviour/disability, child mental health, child symptoms or family functioning.

Skin diseases at post-treatment: There was only one study of children with skin diseases that could be entered into an analysis of parent behaviour, parent mental health, child behaviour and child symptoms at post-treatment, therefore no conclusions could be drawn. 
No studies presented extractable data on child mental health or family functioning.

\section{Individual psychological therapies across all conditions}

Cognitive behavioural therapy at post-treatment: We entered four studies, containing a total of 166 participants, into an analysis of the effects of cognitive behavioural therapy (CBT) across all conditions on parent behaviour. The overall effect of CBT on parent behaviour was not significant $(Z=0.08, P>0.05)$ (Analysis 10.1). We entered four studies, containing a total of 224 participants, into an analysis of the effects of CBT on parent mental health. The overall effect of CBT on parent mental health was not significant $(\mathrm{Z}=1.05, \mathrm{P}$ > 0.05) (Analysis 10.2). We entered seven studies, containing a total of 459 participants, into an analysis of the effects of CBT on child behaviour/disability. The overall effect of CBT on child behaviour/disability was not significant $(\mathrm{Z}=0.84, \mathrm{P}>0.05)$ (Analysis 10.3$)$. We entered five studies, containing a total of 439 participants, into an analysis of the effects of CBT on child mental health. The overall effect of CBT on child mental health was not significant $(Z=0.21, P>0.05)$ (Analysis 10.4). We entered 11 studies, containing a total of 726 participants, into an analysis of the effects of CBT on child symptoms. The overall effect of CBT on child symptoms was significant $(Z=2.61, P<0.05)$ with a small effect size of SMD -0.25 (95\% CI -0.44 to -0.06) (Analysis 10.5; Figure 4). We entered three studies, containing a total of 211 participants, into an analysis of the effects of CBT on family functioning. The overall effect of CBT on family functioning was not significant $(\mathrm{Z}=$ $0.40, \mathrm{P}>0.05$ ) (Analysis 10.6).

Cognitive behavioural therapy at follow-up: We entered two studies, containing a total of 85 participants, into an analysis of the effects of CBT across all conditions on parent behaviour at follow-up. The overall effect of CBT on parent behaviour at follow-up was not significant $(Z=0.56, P>0.05)$ (Analysis 11.1). We entered two studies, containing a total of 115 participants, into an analysis of the effects of CBT on parent mental health at followup. The overall effect of CBT on parent mental health at follow-up was not significant $(\mathrm{Z}=$ 1.26, P > 0.05) (Analysis 11.2). We entered three studies, containing a total of 289 participants, into an analysis of the effects of CBT on child behaviour/disability at followup. The overall effect of CBT on child behaviour/disability at follow-up was not significant $(\mathrm{Z}=0.29, \mathrm{P}>0.05)$ (Analysis 11.3). We entered two studies, containing a total of 257 participants, into an analysis of the effects of CBT on child mental health at follow-up. The overall effect of CBT on child mental health at follow-up was not significant $(Z=0.27, P$ > 0.05) (Analysis 11.4). We entered seven studies, containing a total of 472 participants, into an analysis of the effects of CBT on child symptoms at follow-up. The overall effect of CBT on child symptoms at follow-up was not significant $(Z=1.78, \mathrm{P}>0.05)$ (Analysis 11.5). We entered two studies, containing a total of 107 participants, into an analysis of the effects of CBT on family functioning at follow-up. The overall effect of CBT on family functioning at follow-up was not significant $(Z=0.61, P>0.05)$ (Analysis 11.6).

Family therapy at post-treatment: There was only one study that could be entered into an analysis on the effects of family therapy (FT) across all conditions on parent behaviour, therefore no conclusions could be drawn. We entered two studies, containing a total of 74 participants, into an analysis of the effects of FT on parent mental health. The overall effect of FT on parent mental health was not significant $(Z=0.86, P>0.05)$ (Analysis 12.1). We entered two studies, containing a total of 107 participants, into an analysis of the effects of FT on child behaviour/disability. The overall effect of FT on child behaviour/disability was not significant $(\mathrm{Z}=1.44, \mathrm{P}>0.05$ ) (Analysis 12.2). We entered four studies, containing a total of 202 participants, into an analysis of the effects of FT on child symptoms. The overall effect of FT on child symptoms was not significant $(Z=0.94, P>0.05)$ (Analysis 12.3). We entered two studies, containing a total of 132 participants, into an analysis of the effects of 
FT on family functioning. The overall effect of FT on functioning was not significant $(\mathrm{Z}=$ $0.45, \mathrm{P}>0.05$ ) (Analysis 12.4).

No studies presented extractable data on child mental health.

Family therapy at follow-up: There was only one study that could be entered into an analysis on the effects of FT across all conditions on parent mental health at follow-up, therefore no conclusions could be drawn. We entered two studies, containing a total of 96 participants, into an analysis of the effects of FT on child symptoms at follow-up. The overall effect of FT on child symptoms was not significant $(Z=0.12, P>0.05)$ (Analysis 13.1).

No studies presented extractable data on parent behaviour, child behaviour/disability, child mental health or family functioning.

Problem solving therapy at post-treatment: We entered three studies, containing a total of 588 participants, into an analysis of the effects of problem solving therapy (PST) across all conditions on parent behaviour. The overall effect of PST on parent behaviour was significant $(Z=2.64, \mathrm{P}<0.05)$ with a small effect size of SMD $-0.22(95 \% \mathrm{CI}-0.38$ to -0.06) (Analysis 14.1; Figure 5). We entered five studies, containing a total of 660 participants, into an analysis of the effects of PST on parent mental health. The overall effect of PST on parent mental health was significant $(\mathrm{Z}=2.14, \mathrm{P}<0.05)$ with a small effect size of SMD -0.27 (95\% CI -0.53 to -0.02) (Analysis 14.2; Figure 6). We entered two studies, containing a total of 72 participants, into an analysis of the effects of PST on child behaviour/disability. The overall effect of PST on child behaviour/disability was not significant $(Z=0.65, P>0.05)$ (Analysis 14.3 ). There was only one study that could be entered into an analysis on the effects of PST on child symptoms, therefore no conclusions could be drawn. We entered two studies, containing a total of 67 participants, into an analysis of the effects of PST on family functioning. The overall effect of PST on family functioning was not significant $(Z=0.33, P>0.05)$ (Analysis 14.4).

No studies presented extractable data on child mental health.

Problem solving therapy at follow-up: We entered three studies, containing a total of 556 participants, into an analysis of the effects of PST on parent behaviour at follow-up. The overall effect of all psychological therapies on parent behaviour at follow-up was not significant $(Z=0.77, P>0.05)$ (Analysis 15.1$)$. We entered three studies, containing a total of 557 participants, into an analysis of the effects of PST on parent mental health at followup. The overall effect of all psychological therapies on parent mental health at follow-up was not significant $(Z=1.02, P>0.05)$ (Analysis 15.2). There was only one study that could be entered into an analysis on the effects of PST on child symptoms at follow-up, therefore no conclusions could be drawn.

No studies presented extractable data on child behaviour/disability, child mental health or family functioning.

Multisystemic therapy at post-treatment: There was only one study that could be entered into an analysis on the effects of multisystemic therapy (MST) across all conditions on child mental health, therefore no conclusions could be drawn. We entered two studies, containing a total of 142 participants, into an analysis of the effects of MST on child symptoms. The overall effect of MST on child symptoms was not significant $(Z=1.81, P>0.05)$ (Analysis 16.1). 
No studies presented extractable data on parent behaviour, parent mental health, child behaviour/disability or family functioning.

Multisystemic therapy at follow-up: There was only one study that could be entered into an analysis on the effects of MST across all conditions on child symptoms at follow-up, therefore no conclusions could be drawn.

No studies presented extractable data on parent behaviour, parent mental health, child behaviour/disability, child mental health or family functioning.

\section{Discussion}

There were three objectives of this review. First, results show that only problem solving therapy (PST) interventions that include parents of children with chronic conditions are effective in reducing the distress (improving mental health and behaviour) associated with parenting a child with a chronic illness. Second, cognitive behavioural therapy (CBT) is effective at reducing the primary symptom of a child experiencing chronic illness, in particular chronic pain. Third, we were unable to assess adverse events of interventions for the 14 chronic conditions.

\section{Evidence base}

Parents are commonly included in the psychological treatment of children with chronic illness. Many psychological treatments do more than simply include parents, rather they actively focus on them, aiming to help parents improve their own coping, their ability to improve their child's coping, or both. We included 35 randomised controlled trials (RCTs) involving a total of 2723 primary trial participants. Over a third of the studies $(n=12)$ included in this review investigated conditions in which pain was the primary complaint. A further nine investigated diabetes, six examined cancer patients, four examined children with asthma, three trials investigated children with a traumatic brain injury (TBI) and one trial investigated eczema. There were no RCTs that met the inclusion criteria for gynaecological disorders or inflammatory bowel disease. The majority of studies could be classified within one of four broad treatment approaches: CBT, family therapy (FT), PST and multisystemic therapy (MST). The largest evidence base is of 19 studies in CBT, 18 of which had data that were available for extraction. We are currently able to draw few conclusions about PST, which had seven studies available of which six were included in our analyses. We are unable to draw any conclusions about FT and MST. FT had seven studies available, three of which were included in our analyses, and MST had two studies available, both of which were included in our analyses. Other psychotherapeutic approaches with parents and families have been discussed (e.g. Shapiro 2003) but we could find no studies or evaluations.

\section{Summary of main results}

There were a number of analyses which could not be run due to missing data, either because no study measured the selected outcome or because we were unable to extract the data from the study. This reflects the status of this developing field that has not yet met a consensus of agreed scales and questionnaires to measure relevant outcomes.

Combined psychological therapies for each illness condition-First, we analysed data by each medical condition across all treatment classes, giving 72 possible analyses. There were no effects for follow-up data, leaving 36 possible analyses (Table 3 ). For 22 of the 36 analyses, there were insufficient data to attempt a meta-analysis and so the findings are unknown (i.e. one or no studies available within a given outcome domain). Six analyses should be interpreted with caution because the total number of studies entering the meta- 
analysis was two. However, we have included these six analyses in this review for transparency; all six had no effect. Of the remaining eight analyses, there was one significant finding. Psychological therapies with a focus on parents were found to significantly improve child symptom reporting for painful conditions. There were no other effects of parent-focused treatment in any other condition for any other outcome that could be analysed.

Individual psychological therapies for combined illness conditions-Second, we analysed data by each treatment class across all medical conditions, giving 48 possible analyses. There were no effects for follow-up data, leaving 24 possible analyses (Table 3 ). For nine of the 24 analyses, there were insufficient data to attempt a meta-analysis and so the findings are unknown (i.e. one or no studies available within a given outcome domain). Six analyses were inconclusive because the total number of studies entering the metaanalysis was two. However, we have included these six analyses in this review for transparency; all six had no effect. Of the remaining nine analyses, there were three significant findings. CBT had a significant effect on child symptom reporting, and PST had a positive effect on parent behaviour and on parent mental health outcomes.

We did not present data in the form of numbers needed to treat because of the limited number of effects identified; therefore, presenting continuous data in a categorical format would not have been useful. None of the significant effects were strong and these results could be strengthened or overturned with additional trials; therefore we did not calculate a failsafe N. Furthermore, it was not possible to conduct subgroup analyses regarding comparisons of parent-only interventions versus family-based interventions, intervention effects within specific illnesses, and intervention effects across specific types of psychological interventions due to the small number of trials.

\section{Quality of the evidence}

The overall study quality was adequate. However, the field continues to be hampered by the common practice of short and limited descriptions of treatment content, the insufficient reporting of results and a reliance on small samples.

Analysis of this evidence presented a number of challenges.

First, multiple measurement tools within a given domain are often employed in individual studies, and there is little agreement as to the preferred measurement tool across studies. In some cases measurement is relatively homogenous (e.g. pain intensity) whereas in others there is greater variety (e.g. family functioning scales in diabetes). These trials do not routinely a priori identify the primary outcome, and there is unusual variety of outcome reporting. For example, one study discussed parent judgement of child outcome when the more valid measure, but non-significant finding, of child report was available (Levy 2010). A posteriori selection of outcome measures is a significant problem in this field. As per our protocol we were uninfluenced by the primary reporting of measures and focused on the best measure available in each domain. This field needs to take account of reporting biases and establish standards to improve the reporting of a priori decisions regarding measurement.

Second, we attempted to review evidence of trials with a dominant parent intervention component. This meant we were inevitably going to combine trials with varying amounts of parenting content. Although we planned subgroup analyses, the data were not of sufficient quantity and quality to enable such an investigation. For some analyses we combined studies that were designed specifically with parents as the sole focus, and in others they were part of a combined treatment. Further, the philosophy of some treatments (e.g. MST) was antithetical to our strategy of determining an individual as a treatment target, however, we 
included them in this study. It should be noted that significant findings in this review emerged when there was homogeneity of approach, homogeneity of outcome measurement and a larger $n$.

Third, it should be noted that we had some difficulties in data retrieval due to incomplete and partial data reporting. Data were sometimes reported graphically, and ns, means and/or standard deviations were often missing. We wrote to all 31 first authors an average of two emails. Complete outcome data (i.e. sample size, means, standard deviations) were available from the published paper in 13 trials (Barakat 2010; Connelly 2006; Hoekstra-Weebers 1998; Kashikar-Zuck 2005; Kashikar-Zuck 2012; Laffel 2003; Ng 2008; Palermo 2009; Seid 2010; Stehl 2009; Wade 2006; Wade 2006b; Wade 2011). Seven authors provided data in response to our requests (Ambrosino 2008; Askins 2009; Celano 2012; Levy 2010; Niebel 2000; Sahler 2002; Sahler 2005). Other authors were unable or unwilling to provide additional data or did not respond. The non-production of data is a problem in science (Data's shameful neglect 2009), and has been particularly discussed in psychology (Wicherts 2006; Wicherts 2011). We support the general move toward central registries for all trial data.

Fourth, piecemeal and repeat publication was found in five cases where multiple manuscripts were published from the same trial. In particular, one study (Ellis 2005) was reported six times in five different journals while another trial (Wysocki 1999) was reported five times in four different journals, with variable citation of previous publications in later publications. Such practices are unhelpful, create confusion and increase unnecessary labour (American Psychological Association 2011). Many journals now have policies regarding publication of multiple manuscripts from the same trial, including a detailed description of previous publications from that trial and a statement regarding the unique contribution of the present manuscript (e.g. Drotar 2010).

Finally, replication by other research teams independent to the therapy progenitors is uncommon. For example, Ellis and colleagues are the only group who have evaluated MST in young people with diabetes (Ellis 2004; Ellis 2005). Similarly, PST for children and adolescents with TBI has not been evaluated by any research team outside of Wade and colleagues (Wade 2006; Wade 2006b; Wade 2011). Finally, some therapy approaches have been used exclusively within an illness group. Most notably, CBT was the only intervention evaluated for children with chronic pain.

\section{Potential biases in the review process}

This review was limited to the analysis of 14 conditions. Other studies in other conditions may be instructive. As is common practice within the Cochrane Pain, Palliative and Supportive Care Group ( $\mathrm{PaPaS}$ ), we did not searched grey literature. It is always possible that trials of parent-focused interventions were undertaken but unreported in peer-reviewed publications. We consider it unlikely that any such trials exist in the grey literature but this should be acknowledged. Only RCTs were included in this review. However, therapists were not blind to the therapy being delivered. Bias is most likely due to small sample sizes. Unpublished studies are always possible but unlikely given that there appear to be few barriers to publishing small, negative or poor quality studies. Bias in the field may be due largely to the lack of available studies.

\section{Agreements and disagreements with other studies or reviews \\ Agreements and disagreements with other reviews: combined psychological therapies for each illness condition-Only a handful of reviews have also} investigated psychological interventions for parents of children with a chronic illness. Our 
results are consistent with a previous meta-analysis regarding the effectiveness of CBT in reducing child symptoms in young people with chronic pain (Eccleston 2009a). Our results were somewhat consistent with a meta-analysis of psychological paediatric oncology interventions, which showed no effects on child behaviour or child mental health but positive effects for parent mental health and parent behaviour (Pai 2006). Our results are not consistent with previous reviews of psychological interventions that included parents of children with diabetes, which reported positive effects on child symptoms and family functioning (Armour 2005; Grey 2000; Harris 2010; McBroom 2009). Previous reviews of psychological interventions that included parents of children with asthma or skin diseases were inconclusive due to lack of trials that met inclusion criteria (Ersser 2007; Yorke 2009). Notably, disagreements between the present meta-analysis and previous reviews may be attributed to differences in inclusion criteria, selection of outcome measures and/or selection of comparator group.

\section{Agreements and disagreements with other reviews: individual psychological therapies for combined illness conditions-One prior review indicated that} psychological interventions which included coping skills training for adolescents and young adults with chronic illness (cancer, diabetes, juvenile idiopathic arthritis, sickle cell disease and asthma) and their parents/families had mixed effects on child psychosocial functioning and family functioning (Sansom-Daly 2011). We were unable to find any previous reviews that compared results from individual psychological therapies across chronic illness conditions for parent outcomes or child symptoms. Therefore, we cannot draw conclusions regarding consistency of our results by treatment type for parent outcomes or child symptoms with previous reviews.

\section{Authors' conclusions}

\section{Implications for practice}

More work is needed to develop and provide psychological interventions that directly target parents of children with chronic illness. Few interventions included in this review provided intensive treatment to parents that specifically targeted parent outcomes. We suggest that interventions which target specific strategies aimed at parent mental health and behaviour (e.g. problem solving skills training) are more likely to achieve those effects than interventions which include parents but do not purposefully target strategies in these outcome domains. Targeted relapse prevention strategies have not been attempted, and may be necessary to maintain treatment effects in the long term.

\section{Implications for research}

There are relatively few studies of psychological interventions that target parents of children with a chronic illness. For example, there were no studies of children with gynaecological disorders or irritable bowel diseases that met criteria for inclusion in this review. There was also only one study of children with skin diseases that met the inclusion criteria, meaning we were not able to conduct any meta-analyses for this condition. Furthermore, studies in this area need to be conducted to a higher level of quality so that gaps in the evidence base can be filled and the effectiveness of psychological interventions for parents of children with chronic illness can be better understood. The next generation of trials should improve by taking account of the limitations identified in this review, including:

1. larger sample sizes;

2. following CONSORT guidelines (Schulz 2010);

3. the clearer identification of primary outcomes; 
4. designing treatment content to specifically target change in the primary outcomes;

5. more consistency of measurement and greater consensus within the field around appropriate measure use within and across illness groups;

6. lodging treatment manuals and data in a shared database to facilitate replication of intervention trials and re-analysis of results.

This review has also highlighted several future directions for research that examines interventions targeting parents of children with chronic illness. Problem solving therapy (PST) looks particularly promising for improving parent mental health and parent behaviour. Research is needed to evaluate this intervention in populations other than cancer and traumatic brain injury (TBI), such as chronic pain. Replication studies are also needed for interventions that have been evaluated by only one research team, such as multisystemic therapy for families of children with diabetes and PST for families of children with TBI. We recognise that this goal may be difficult to achieve given the high degree of competition for funding and lack of interest among funding agencies for replication studies. Research is also needed to evaluate interaction effects such as the impact of changes in parent outcomes on child outcomes, as well as evaluation of specific treatment characteristics such as the intensity of intervention delivered to children versus parents. We also do not know anything about the effects of the interventions included in this review on fathers or siblings, which is a common critique of the field of paediatric psychology.

Our final recommendation for future research in this area is in regards to duplication and piecemeal publication. Editorial policies are needed to inform authors regarding reporting standards for multiple publications from the same trial. Editors play a crucial role in creating and enforcing these policies, and need to take a pro-active approach to identifying such papers during the review process (Committee on Publication Ethics 2011; World Association of Medical Editors 2012).

\section{Acknowledgments}

We would like to thank Dr Zeinab Mousavi, Dr Gerrit Hirschfeld, Dr Anna Huguet, Dr Rikard Wicksell, Dr Jordi Miro and Megan Walker for their time in helping to translate papers and extract data.

We also thank all authors who responded to emails requesting further studies or data.

We would also like to thank Jane Hayes for all her help designing and carrying out the search strategies.

Sources of support

Internal sources: • University of Bath, UK

External sources: - National Institutes of Health/National Institutes for Child Health and Human Development, USA Grant number: R21HD065180 (PI: Palermo)

\section{Published notes}

\section{Characteristics of studies}

\section{Characteristics of included studies}

Allen 1998

Methods

Participants

RCT. 2 arms. Assessed pre-treatment, post-treatment, 3 months and 1 year.

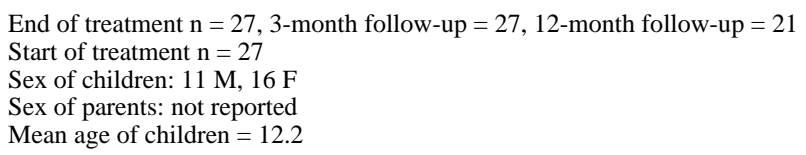


Mean age of parents $=$ not reported

Source $=$ referred by paediatricians and neurologists in the community and recruited by newspaper ad

Diagnosis of child = migraine headache

Mean years of illness $=4.4$ years

Interventions

Yates Quality Scale

Notes

Risk of bias table

Bias

Random sequence generation (selection bias)

Allocation concealment (selection bias)

Blinding of outcome assessment (detection bias)

Incomplete outcome data (attrition bias)

Selective reporting (reporting bias)

Ambrosino 2008

\section{Authors' judgement}

Unclear risk

Unclear risk

Unclear risk

High risk

High risk

\section{Support for judgement}

"Randomized, controlled group-outcome design, subjects were assigned to either thermal biofeedback intervention....., or the same biofeedback ntervention plus pain behavior management guidelines". Comment: method not described.

No description found in text. Comment: probably not done.

No description found in text. Comment: probably not done.

Attrition was not adequately described

Data were incompletely reported. Aims, measures and results were partially concordant. Comment: probably some reporting bias.
Methods

Participants

Interventions

RCT. 2 arms. Assessed pre-treatment, 1 month (end of treatment), 3 months, 6 months and 12 months post intervention.

End of treatment $\mathrm{n}=81$ children, 3-month follow-up $=79$ children, 6-month follow-up $=72$, 12-month follow-up $=72$

Start of treatment $\mathrm{n}=87$ parents and children received intervention at start

Sex of children: $34 \mathrm{M}, 53 \mathrm{~F}$

Sex of parents: $5 \mathrm{M}, 82 \mathrm{~F}$

Mean age of children $=9.91(+/-1.44)$

Mean age of parents $=40.01(+/-5.40)$

Source $=$ Yale Pediatric Diabetes Program

Diagnosis of child = type 1 diabetes

Mean years of illness $=3.71+/-2.91$ years

"Coping Skills Training (CST)" (CBT)

"Group Education (GE)"

Mode of delivery: groups, face to face, parents met separately

Intervention delivered by: mental health professionals

Training: not reported

Duration of intervention (child, hours) $=6 \times 1.5=9$ hours

Duration of intervention (parent, hours) $=6 \times 1.5=9$ hours

Outcomes

Child measures

Metabolic control*

Child Depression Inventory (CDI)*

Cochrane Database Syst Rev. Author manuscript; available in PMC 2013 August 15. 
Disease-related variables

Issues in Coping with IDDM - Child scale

Self-Efficacy for Diabetes Scale

Diabetes Quality of Life Scale for Youth (DQOL)

Diabetes Family Behavior Scale (DFBS)

Parent measures

Center for Epidemiologic Depression Scale (CES-D)*

Family Adaptability and Cohesion Scale (FACES II)*

Issues in Coping with IDDM - Parent scale

Diabetes Responsibility and Conflict Scale

Yates Quality Scale

Notes

Risk of bias table

Bias

Random sequence generation (selection bias)

Allocation concealment Low risk (selection bias)

Blinding of outcome assessment (detection bias)

Incomplete outcome data (attrition bias)

Selective reporting

(reporting bias)

Askins 2009

Methods

Participants

Interventions

Outcomes

Yates Quality Scale

Notes

Risk of bias table

\section{Authors' judgement}

Low risk

Unclear risk

Low risk

Unclear risk

\section{Support for judgement}

"Participants were randomised initially by a sealed envelope technique and later by computer to either the coping skills therapy of group eduction." Comment: probably done.

"Participants were randomised initially by a sealed envelope technique and later by computer to either the coping skills therapy of group eduction." Comment: probably done.

"All follow-up data were collected by trained research assistants." Comment: blinding unclear, probably not done.

Attrition was reported, no significant differences between completers and non-completers was described

Data were fully reported. Aims, measures and results were partially concordant. Comment: probably some reporting bias.

RCT. 2 arms. Assessed pre-treatment, post-treatment and at 3 months.

End of treatment $\mathrm{n}=131$ mothers, 3 -month follow-up $=123$ mothers

Start of treatment $n=197$ mothers

Sex of children: $103 \mathrm{M}, 94 \mathrm{~F}$

Sex of parents: $0 \mathrm{M}, 197 \mathrm{~F}$

Mean age of child $=8.1$

Mean age of parents $=36.3$

Source $=4$ paediatric cancer centres in USA

Diagnosis of child $=$ cancer

Mean years of illness = average 6 weeks since diagnosis, range 2 to 16 weeks from diagnosis

"Problem-Solving Skills Training" (PST)

"Problem-Solving Skills Training + Personal Digital Assistant"

Mode of delivery: individual, face to face

Intervention delivered by: therapists with graduate training in Clinical Psychology

Training: special training in PSST

Duration of intervention (child, hours) $=0$

Duration of intervention (parent, hours) $=8 \times 1=8$ hours

* Extracted measures

Parent measures

Social Problem-Solving Inventory-Revised (SPSI-R)*

Beck Depression Inventory-11 (BDI-II)*

Profile of Mood States (POMS)

Impact of Event Scale-Revised (IES-R)

Study quality (out of 35): 27 (high quality)

Treatment quality (out of 9): 9 (high quality)

Design quality (out of 26): 18 (high quality)

The comparison looks like a non

inferiority trial but it was not designed

in this way so we have included it

despite the lack of a control group

Cochrane Database Syst Rev. Author manuscript; available in PMC 2013 August 15. 


\section{Bias}

Random sequence generation (selection bias)

Allocation concealment (selection bias)

Blinding of outcome assessment (detection bias)

Incomplete outcome data (attrition bias)

Selective reporting (reporting bias)

Barakat 2010

Methods

Participants

Interventions

Outcomes

Yates Quality Scale

Notes

Risk of bias table

Bias

Random sequence generation (selection bias)

Allocation concealment (selection bias)

Blinding of outcome assessment (detection bias)

Incomplete outcome data (attrition bias)

Selective reporting (reporting bias)
Authors' judgement

Low risk

Low risk

Unclear risk

Unclear risk

Unclear risk

RCT. 2 arms. Assessed at pre-treatment, post-treatment and 12 months.

End of treatment $\mathrm{n}=37,12$-month follow-up $=34$

Start of treatment $n=42$ received session 1

Sex of children: $15 \mathrm{M}, 12 \mathrm{~F}$

Sex of parents: not reported

Mean age of child $=14.17(1.75)$

Mean age of parents $=$ not reported

Source = "Comprehensive sickle cell centre"

Diagnosis of child $=$ sickle cell disease

Mean years of illness $=$ lifetime

"Pain Management Intervention" (CBT)

"Disease Education Intervention"

Mode of delivery: individual families, face to face

Intervention delivered by: Clinical Psychology doctoral students

Training: not reported

Duration of intervention (child, hours) $=4 \times 90$ minutes $=6$ hours

Duration of intervention (parent, hours) $=4 \times 90$ minutes $=6$ hours

* Extracted measures

Child measures

Pain diary (\% days with pain and \% interference with activities)*

Coping Strategies Questionnaire

Family Cohesion Scale*

Health-related Hindrance Inventory

Health Service Use per Medical Chart Review

School Attendance Records

Study quality (out of 35): 27 (high quality)

Treatment quality (out of 9): 9 (high quality)

Design quality (out of 26): 18 (high quality)

\section{Support for judgement} cent arms was performed at the data

"Computerized randomisation to one of the three erms was performed at the data

No description found in text. Comment: probably not done.

Attrition was reported, but no data were presented describing equivalence between ters and non-completer

fully reported. Aims, measures and we partially concordant. Comment: probably some reporting bias. 
Methods

Participants

Interventions

Outcomes

Yates Quality Scale

Notes

Risk of bias table

Bias

Random sequence generation (selection bias)

Allocation concealment (selection bias)

Blinding of outcome assessment (detection bias)

Incomplete outcome data (attrition bias)

Selective reporting (reporting bias)

Celano 2012

Methods

Participants

Interventions

RCT. 2 arms. Assessed at pre-treatment, post-treatment and 3 months.

End of treatment $\mathrm{n}=29,3$-month follow-up $=29$

Start of treatment $n=36$

Sex of children: $10 \mathrm{M}, 19 \mathrm{~F}$

Sex of parents: not reported

Mean age of child $=9.4$

Mean age of parents $=$ not reported

Source $=$ ads in elementary schools and community health centres, referrals from

paediatricians and family physicians

Diagnosis of child $=$ headache

Mean years of illness $=2$ headaches/month

"Cognitive Behavioural Therapy" (CBT)

"Wait-list Control"'

Mode of delivery: group, face to face

Intervention delivered by: mental health professionals

Training: not reported

Duration of intervention (child, hours) $=2 \times 90$ minutes $=3$ hours

Duration of intervention (parent, hours) $=2 \times 90$ minutes $=3$ hours

* Extracted measure

Child measures

Pain diary*

Study quality (out of 35): 16 (low quality)

Treatment quality (out of 9): 5 (high quality)

Design quality (out of 26): 11 (low quality)

\section{Authors' judgement}

Unclear risk

High risk

Unclear risk

Unclear risk

High risk

\section{Support for judgement}

"Each parent-child pair was initially matched with another pair based on the child's age, sex and headache pain as indicated by the parents' ratings of average duration, frequency, and intensity of headaches. Subsequently, one of each of the matched parent-child pairs was randomly assigned to either the treatment condition or the waiting list control condition." Comment: method not described.

"Each parent-child pair was initially matched with another pair based on the child's age, sex and headache pain as indicated by the parents ratings of average duration, frequency, and intensity of headaches."

No description found in text. Comment: probably not done.

Attrition was reported, no significant differences between completers and non-completers was described

Data were not fully reported. Aims, measures and results were partially concordant. Comment: probably some reporting bias.

RCT. 2 arms. Assessed at pre-treatment, post-treatment and 6 months.

End of treatment $\mathrm{n}=40,6$-month follow-up $=37$

Start of treatment $n=43$

Sex of children: $26 \mathrm{M}, 15 \mathrm{~F}$

Sex of parents: $85 \%$ female

Mean age of child $=10.5(1.6)$

Mean age of parents $=$ not reported

Source $=$ urban children's hospital and residential camp for children with asthma

Diagnosis of child $=$ asthma

Mean years of illness = more than 1 year

"Home based family intervention"

"Enhanced treatment as usual"

Mode of delivery: individual families, face to face

Intervention delivered by: trained asthma counsellors, post-doctoral psychology fellow and respiratory therapist

Training: not reported

Cochrane Database Syst Rev. Author manuscript; available in PMC 2013 August 15. 
Outcomes

Yates Quality Scale

Notes

Risk of bias table

Bias

Random sequence generation (selection

bias)

Allocation concealment (selection bias)

Blinding of outcome assessment (detection bias)

Incomplete outcome data (attrition bias)

Selective reporting (reporting bias)

Connelly 2006

Methods

Participants

Yates Quality Scale

Notes

Risk of bias table

Duration of intervention (child, hours) $=4$ to 6 sessions, average 78 minutes per session Duration of intervention (parent, hours) $=4$ to 6 sessions, average 78 minutes per session

* Extracted measure

Child measures

Family Asthma Management System Scale

Metered Dose Inhaler Checklist

Cotinine/creatinine ratio

Number of school days missed

Asthma symptom days*

Urgent health care visits

Medical records reviewed

Parent measures

Family Asthma Management System Scale

Parenting Stress Index (PSI-SF)

Brief Symptoms Inventory (for parent distress)*

Study quality (out of 35): 19 (high quality)

Treatment quality (out of 9): 6 (high quality)

Design quality (out of 26): 13 (low quality)

Authors' judgement

Low risk

Unclear risk

Low risk

Unclear risk

Low risk

RCT. 2 arms. Assessed at pre-treatment, post-treatment and 2 months.

End of treatment $n=31,2$-month follow-up $=31$

Start of treatment $n=37$

Sex of children: $19 \mathrm{M}, 18 \mathrm{~F}$

Sex of parents: not reported

Mean age of child $=9.2(1.7)$

Mean age of parents $=$ not reported

Source = outpatient neurology clinic at a large children's hospital in Midwestern USA

Diagnosis of child $=$ headache

Mean years of illness $=2$ years 3 months ( 2 years 2 months)

"Headstrong CD ROM" (CBT)

"Wait-list Control"

Mode of delivery: computer and phone calls

Intervention delivered by: CD ROM

Training: not reported

Duration of intervention (child, hours) $=4 \times 1 \mathrm{hr}=4$ hours

Duration of intervention (parent, hours) $=1 \times 1 \mathrm{hr}=1$ hours

* Extracted measures

Child measures

Headache diary*

Pediatric Migraine Disability Assessment*

Parent measures

Headache diary

Pediatric Migraine Disability Assessment

Study quality (out of 35): 25 (high quality)

Treatment quality (out of 9): 7 (high quality)

Design quality (out of 26): 18 (high quality)

\section{Support for judgement}

"Randomisation....by blocked randomisation

No description found in text. Comment: probably not done

"Trained assistants blind to group assignment."

Attrition was reported, no significant differences described

Data were fully reported. Aims, measures and results were fully concordant. Comment: probably no reporting bias. " 


\section{Bias}

Random sequence generation (selection bias)

Allocation concealment (selection bias)

Blinding of outcome assessment (detection bias)

Incomplete outcome data (attrition bias)

Selective reporting (reporting bias)

Duarte 2006

Methods

Participants

Interventions

Outcomes

Yates Quality Scale

Notes

Risk of bias table

Bias

Random sequence generation (selection bias)

Allocation concealment (selection bias)

Blinding of outcome assessment (detection bias)

Incomplete outcome data (attrition bias)

Selective reporting (reporting bias)

Authors' judgement

Low risk

Low risk

Low risk

Unclear risk

Low risk

RCT. 2 arms. Assessed at first, second, third and fourth session (sessions were monthly).

End of treatment $\mathrm{n}=32$ children

Start of treatment $n=32$ children

Sex of children: $10 \mathrm{M}, 22 \mathrm{~F}$

Sex of parents: not reported

Mean age of children $=9.15(2.1)$

Mean age of parents $=$ not reported

Source $=$ Pediatric Gastroenterology Reference Service

Diagnosis of child $=$ recurrent abdominal pain

Mean years of illness $=25+/-17.5$ months

"Cognitive-behavioural family intervention" (CBT)

"Control group"

Mode of delivery: face to face (group/individual not reported)

Intervention delivered by: general health professionals

Training: not reported

Duration of intervention (child, hours) $=4 \times 50$ minutes $=3$ hours, 20 minutes

Duration of intervention (parent, hours) $=4 \times 50$ minutes $=3$ hours, 20 minutes

* Extracted measures

Child measures

Pain diary*

Visual analogue scale

Pressure Pain Threshold

Study quality (out of 35): 7 (low quality)

Treatment quality (out of 9): 4 (low quality)

Design quality (out of 26): 3 (low quality)

were fully reported. Aims, measures and esults were fully concordant. Comment: probably no reporting bias.

"Randomly assigned to one of two groups by a

earch assistant using a uniform random

"Randomly assigned to one of two groups by a umbers table." Comment: probably done.

Study neurologists remained blind to follow- unblinding were limited because following the initial assessment." Comment

A rition was reported, but no data were presented describing equivalence between completers and non-completers

Support for judgement

\section{Authors' judgement}

Unclear risk

Unclear risk

Unclear risk

High risk

Unclear risk

\section{Support for judgement}

"Randomly allocated to 2 groups." Comment: probably done but unclear method

No description found in text. Comment: probably not done.

No description found in text. Comment: probably not done.

Attrition was not adequately described

Data were incompletely reported. Aims, measures and results were fully concordant. Comment: probably some reporting bias.

Ellis 2004 
Methods

Participants

Interventions

Outcomes

Yates Quality Scale

Notes

Risk of bias table

Bias

Random sequence generation (selection bias)

Allocation concealment (selection bias)

Blinding of outcome assessment (detection bias)

Incomplete outcome data (attrition bias)

Selective reporting (reporting bias)

Ellis 2005

Methods

Participants

RCT. 2 arms. Assessed pre-treatment, 6 months after study entry (end of treatment).

End of treatment $=25$

Start of treatment $n=31$

Sex of children: $14 \mathrm{M}, 11 \mathrm{~F}$

Sex of parents: all female

Mean age of children $=13.6(1.6)$

Mean age of parents $=0 \mathrm{M}, 31 \mathrm{~F}$

Source $=$ endocrinology clinic within a tertiary care children's hospital

Diagnosis $=$ type 1 diabetes

Mean years of illness $=$ at least 1 year

"Multisystemic Therapy" (MST)

"Standard Care Control"

Mode of delivery: individual families, face to face and phone contact

Intervention delivered by: mental health professionals

Training:Completed 1 week MST training

Duration of intervention (child) = mean 6.5 months, 46 sessions

Duration of intervention (parent) $=$ mean 6.5 months, 46 sessions

* Extracted measures

Child measures

Metabolic control*

Twenty-Four Hour Recall Interview

Frequency of blood glucose testing from blood glucose meter

The Diabetes Management Scale (DMS)

Health Service Use per Medical Chart Review

Parent measures

Satisfaction with treatment

The Diabetes Management Scale (DMS)

Study quality (out of 35): 26 (high quality)

Treatment quality (out of 9): 9 (high quality)

Design quality (out of 26): 17 (high quality)

\section{Authors' judgement}

Unclear risk

Low risk

Low risk

Low risk

Unclear risk

\section{Support for judgement}

"Randomisation to treatment or control group was completed immediately after baseline data collection by the project statistician." Comment: no description provided.

"Randomisation to treatment or control group was completed immediately after baseline data collection by the project statistician." Comment probably done.

"All data was collected by a trained research assistant who was blind to the adolescent's treatment status." Comment: probably done.

Attrition was reported, no significant differences between completers and non-completers was described

Data were fully reported. Aims, measures and results were partially concordant. Comment: probably some reporting bias.

RCT. 2 arms. Assessed pre-treatment, 7 months after study entry (end of treatment), 12 months after study entry (6-month follow-up).

End of treatment $\mathrm{n}=110,6$-month follow-up $=85$

Start of treatment $n=127$ children and their families

Sex of children: $62 \mathrm{M}, 65 \mathrm{~F}$

Sex of parents: not reported

Mean age of children $=13.25(+/-1.95)$

Mean age of parents $=38.8(+/-6.8)$

Source $=$ endocrinology clinic within a tertiary care children's hospital

Diagnosis $=$ type 1 diabetes

Mean years of illness $=5.25(+/-4.35)$ years

"Multisystemic Therapy" (MST)

"Standard Care Control"

Mode of delivery: individual families, face to face and phone contact

Intervention delivered by: mental health professional

Training: 1-week training in MST and diabetes education

Cochrane Database Syst Rev. Author manuscript; available in PMC 2013 August 15. 
Duration of intervention (child) $=$ mean 5.7 months, 48 sessions

Duration of intervention (parent) $=$ mean 5.7 months, 48 sessions

Outcomes

Yates Quality Scale

Notes

Risk of bias table

Bias

Random sequence generation (selection bias)

Allocation concealment (selection bias)

Blinding of outcome assessment (detection bias)

Incomplete outcome data (attrition bias)

Selective reporting (reporting bias)

Grey 2011

Methods

Participants

\section{Authors' judgement}

Unclear risk

Unclear risk

Unclear risk

Low risk

Unclear risk

Extracted measures

Cxires

Diabetes Stress Questionnaire*

Family Relationship Index (FRI) of the Family Environment Scale (FES)*

Frequency of Blood Glucose Testing from blood glucose meter

enty-Four Hour Recall Interview

visits)

Diabetes Family Behavior Checklist (DFBC)

Diabetes Family Responsibility Questionnaire

Study quality (out of 35): 23 (high quality)

Treatment quality (out of 9): 8 (high quality)

Design quality (out of 26): 15 (high quality)

\section{Support for judgement}

"Random assignment to treatment group was completed after baseline data collection." Comment: no method described.

"To ensure equivalence across treatment conditions, random assignment was stratified according to HbA1c level at the baseline visit."

No description found in text. Comment: probably not done.

Attrition was reported, no significant differences between completers and non-completers was described

Data were incompletely reported. Aims, measures and results fully concordant. Comment: probably some reporting bias.

RCT. 2 arms. Assessed pre-treatment, 3 months, 6 months and 12 months post-treatment. Data came from 2 separate randomised clinical trials of coping skills training interventions: one trial included parents and their 8 to 12-year old children, and the other trial included parents of children under 8 years of age.

End of treatment $\mathrm{n}=129,3$ months $=121,6$ months $=120,12$ months $=112$

Start of treatment $n=129$

Sex of children: $53 \mathrm{M}, 74 \mathrm{~F}$

Sex of parents: not reported

Mean age of children $=8.0(2.8)$

Mean age of parents $=$ not reported

Source = paediatric diabetes clinic at a university-based medical centre

Diagnosis $=$ type 1 diabetes

Mean years of illness $=$ at least 6 months

Interventions

"Coping skills training group" (CBT)

"Group diabetes education"

Mode of delivery: group, face to face

Intervention delivered by: mental health professional

Training: not reported

Duration of intervention $($ child $)=$ not reported.

Duration of intervention (parent) $=1.5$ hours $\times 6$ sessions $=9$ hours (treatment), 1.5 hours $\times$

4 sessions $=6$ hours $($ control $)$

Outcomes

* Extracted measures

Child measures

HbA1c Levels

Parent measures

Issues in Coping with IDDM-Parent Scale

The Center for Epidemiologic Studies-Depression Scale

The Diabetes Responsibility and Conflict Scale 
The Parents Diabetes Quality of Life Questionnaire

\section{Yates Quality Scale}

Notes

Risk of bias table

\section{Bias}

Random sequence generation (selection bias)

Allocation concealment (selection bias)

Blinding of outcome assessment (detection bias)

Incomplete outcome data (attrition bias)

Selective reporting (reporting bias)

Hicks 2006

Methods

Participants

Interventions

Outcomes

Yates Quality Scale

Notes

Risk of bias table

Bias

Random sequence generation (selection bias)

Allocation concealment Unclear risk (selection bias)

Child measures

Pain diary*

Parent measures

\section{Authors' judgement}

Unclear risk

Low risk

Low risk

Unclear risk

High risk

\section{Support for judgement}

"Data from two separate randomised trials.. Participants were randomised using a sealed envelope technique" Comment: combined 2 studies together to produce results.

"Participants were randomised using a sealed envelope technique." Comment: probably done.

"Data were collected....by trained research assistants who were blinded to group assignment." Comment: probably done.

Attrition was reported, but no data were presented describing equivalence between completers and non-completers

Aims, measures and results were fully concordant, but data presented were combined Comment: probably some reporting bias.

RCT. 2 arms. Assessed pre-treatment, 1-month follow-up and 3-month follow-up.

End of treatment $n=37,1$-month follow-up $=37,3$-month follow-up $=32$

Start of treatment $n=47$

Sex of children: $17 \mathrm{M}, 30 \mathrm{~F}$

Sex of parents: not reported

Mean age of children $=11.7(2.1)$

Mean age of parents $=$ not reported

Source $=$ media, posters in physicians offices and advertisements in school newsletters

Diagnosis $=$ recurrent head or abdominal pain

Mean years of illness $=3$ years

"Online cognitive-behavioral treatment programme" (CBT)

"Wait list Control"

Mode of delivery: individual, online web programme, email and phone contact

Intervention delivered by: Internet and researcher

Training: not reported

Duration of intervention (child) $=$ mean 3 hours on the phone, duration to complete online programme not described

Duration of intervention (parent) $=$ not described

* Extracted measures

Pediatric Quality of Life Inventory

Treatment expectation

Treatment satisfaction

Pediatric Quality of Life Inventory

Treatment expectation

Treatment satisfaction

Study quality (out of 35): 24 (high quality)

Treatment quality (out of 9): 6 (high quality)

Design quality (out of 26): 18 (high quality)

\section{Authors' judgement}

Low risk

\section{Support for judgement}

"The 47 participants were stratified by age and pain severity and randomly assigned by blocks to either the treatment condition or the standard medical care wait-list condition." Comment: probably done.

"The 47 participants were stratified by age and pain severity and randomly assigned by blocks to

Cochrane Database Syst Rev. Author manuscript; available in PMC 2013 August 15. 
Blinding of outcome assessment (detection bias)

Incomplete outcome data (attrition bias)

Selective reporting (reporting bias)

Hoekstra-Weebers 1998

Methods

Participants

Interventions

Yates Quality Scale

Notes

Risk of bias table

Bias

Random sequence generation (selection bias)

Allocation concealment (selection bias)

Blinding of outcome assessment (detection bias)

Incomplete outcome data (attrition bias)

Selective reporting (reporting bias)

Kashikar-Zuck 2005

Methods

Participants

Unclear risk

Low risk

Unclear risk

RCT. 2 arms. Pre-treatment (at diagnosis), post-treatment, 6-month follow-up

End of treatment and 6-month follow-up $n=81$ parents, 41 children

Start of treatment $n=120$ parents, 61 children

Sex of parents: $40 \mathrm{M}, 41 \mathrm{~F}$

Sex of children: $23 \mathrm{M}, 18 \mathrm{~F}$

Mean age of parents $=36.6(5.4)$

Mean age of children $=6.4(4.7)$

Source $=$ paediatric oncology clinic

Diagnosis $=$ cancer

Mean years of illness $=2$ to 21 days post diagnosis

"Psychoeducational and Cognitive-Behavioral Intervention" (CBT)

"Standard Care Control"

Mode of delivery: individual, face to face

Intervention delivered by: Master's student in Psychology

Training: not reported

Duration of intervention $($ child $)=0$

Duration of intervention (parent) $=8 \times 90$ minutes $=12$ hours

* Extracted measures

Parent measures

Symptom Check List (SCL)*

State-Trait Anxiety Inventory-State*

Goldberg General Health Questionnaire (GHQ)

Social Support List-Discrepancies (SSL-D)

Intensity of emotions questionnaire designed by the authors

Study quality (out of 35): 20 (high quality)

Treatment quality (out of 9): 6 (high quality)

Design quality (out of 26): 14 (low quality)

Authors' judgement

Unclear risk

Unclear risk

Unclear risk

Low risk

Low risk

RCT. 2 arms. Assessed pre-treatment and post-treatment.

End of treatment $\mathrm{n}=27$

Start of treatment $n=30$

Cochrane Database Syst Rev. Author manuscript; available in PMC 2013 August 15. 
Interventions

Outcomes

Yates Quality Scale

Notes

Risk of bias table

Bias

Random sequence generation (selection bias)

Allocation concealment Low risk (selection bias)

Blinding of outcome assessment (detection bias)

Incomplete outcome data (attrition bias)

Selective reporting (reporting bias)

Kashikar-Zuck 2012

Methods

Participants

Interventions

Sex of children: $0 \mathrm{M}, 30 \mathrm{~F}$

Sex of parents: $3 \mathrm{M}, 27 \mathrm{~F}$

Mean age of children $=15.83(1.26)$

Mean age of parents $=$ not reported

Source $=$ paediatric rheumatology clinic, Midwestern USA

Diagnosis $=$ fibromyalgia syndrome

Mean years of illness $=$ over 2 years

"Cognitive Skills Training" (CBT)

"Self Monitoring"'

Mode of delivery: individual, face to face plus phone contact

Intervention delivered by: doctoral level paediatric psychology intern or psychology fellow Training: trained by principal investigator

Duration of intervention (child) $=6$ sessions, hours not reported

Duration of intervention (parent) $=3$ sessions, hours not reported

* Extracted measures

Child measures

Children's Depression Inventory* (CDI)

Functional Disability Inventory* (FDI)

Visual analogue scale (VAS)

Pain Coping Questionnaire (PCQ)

Tender point examination

Study quality (out of 35): 22 (high quality)

Treatment quality (out of 9): 8 (high quality)

Design quality (out of 26): 14 (low quality)

\section{Authors' judgement}

Low risk

Low risk

Unclear risk

Low risk

\section{Support for judgement}

"A computer generated pseudo-random number list was used. A simple randomisation technique was used with a 1:1 allocation ratio for 30 subjects as a single block." Comment: probably done.

"A computer generated pseudo-random number list was used. A simple randomisation technique was used with a 1:1 allocation ratio for 30 subjects as a single block." Comment: probably done.

"A research assistant who was blind to the study objectives and to the subjects' treatment assignment administered the self-report measures. The rheumatologist or occupational therapist who conducted the tender point assessments was blind to the subjects' treatment assignment." Comment: probably done.

Attrition was reported, but no data were presented describing equivalence between completers and non-completers

Data were fully reported. Aims, measures and results were fully concordant. Comment: probably no reporting bias.

RCT. 2 arms. Assessed pre-treatment, post-treatment, 6-month follow-up

End of treatment $\mathrm{n}=106$, follow-up $\mathrm{n}=100$

Start of treatment $n=114$

Sex of children: $9 \mathrm{M}, 105 \mathrm{~F}$

Sex of parents: not reported

Mean age of children $=15.0(1.8)$

Mean age of parents $=$ not reported

Source $=4$ paediatric rheumatology centres, Midwestern USA

Diagnosis $=$ fibromyalgia syndrome

Mean years of illness $=2$ years, 10 months ( 2 years, 6 months)

"Cognitive behavioural therapy" (CBT)

"Fibromyalgia education"

Mode of delivery: individual, face to face

Intervention delivered by: therapists with postdoctoral training in paediatric psychology

Training: 6 to 8-hour training by principal investigator

Duration of intervention (child) $=6$ hours

Cochrane Database Syst Rev. Author manuscript; available in PMC 2013 August 15 
Duration of intervention (parent) $=2$ hours, 15 minutes

Outcomes

Yates Quality Scale

Notes

Risk of bias table

Bias

Random sequence generation (selection bias)

Allocation concealment

Blinding of outcome assessment (detection bias)

Incomplete outcome data (attrition bias)

Selective reporting (reporting bias)

Kazak 2004

Methods

Participants

Interventions

Yates Quality Scale

Notes

Outcomes

* Extracted measures

Child measures

Child Depression Inventory* (CDI)

Functional Disability Inventory* (FDI)

Visual analogue scale* (VAS)

Pediatric Quality of Life Inventory (PedsQL)

Study quality (out of 35): 33 (high quality)

Treatment quality (out of 9): 9 (high quality)

Design quality (out of 26): 24 (high quality) (selection bias)
Authors' judgement

Low risk

Low risk

Low risk

Low risk

Low risk

\section{Support for judgement}

"Eligible patients were randomly assigned to 1 of the 2 treatment arms based upon a computergenerated randomisation list. Randomisation was stratified by site." Comment: probably done.

"When a patient was enrolled, the study therapist contacted the biostatistician to obtain the subject identification number and treatment allocation.' Comment: probably done.

"The principle investigator, study physicians, study coordinator, and assessment staff were all blinded to the patients' treatment condition throughout the trial. Patients were asked not to divulge what treatment they were receiving to the study physician." Comment: probably done.

Attrition was reported, no significant differences between completers and non-completers was described

Data were fully reported. Aims, measures and results were fully concordant. Comment: probably no reporting bias.

RCT. 2 arms. Assessed pre-treatment and 3 to 5 months post-treatment

End of treatment $\mathrm{n}=116$ children

Start of treatment $\mathrm{n}=150$ children

Sex of children: $73 \mathrm{M}, 77 \mathrm{~F}$

Sex of parents: $106 \mathrm{M}, 146 \mathrm{~F}$

Mean age of children $=14.61(2.4)$

Mean age of parents $=$ not reported

Source $=$ oncology tumour registry at the Children's Hospital of Philadelphia

Diagnosis $=$ childhood cancer survivor

Mean years of illness $=5.30(2.92)$ years post-treatment

"Surviving Cancer Competently Intervention Program SCCIP” (CBT)

"Wait-list Control"

Mode of delivery: group, face to face

Intervention delivered by: nurses, social workers, psychologists, graduate and postdoctoral psychology trainees

Training: 12 hours

Duration of intervention (child) $=5$ hours direct, 2 hours informal

Duration of intervention (parent) $=5$ hours direct, 2 hours informa

* Extracted measures

Child measures

Post-Traumatic Stress Disorder Reaction Index (PTSD-RI)*

Impact of Events Scale-Revised (IES-R)

Revised Children's Manifest Anxiety Scale (RCMAS)

Parent measures

Post-Traumatic Stress Disorder Reaction Index (PTSD-RI)*

Impact of Events Scale-Revised (IES-R)

State-Trait Anxiety Inventory (STAI)

Study quality (out of 35): 24 (high quality)

Treatment quality (out of 9): 9 (high quality)

Design quality (out of 26): 15 (high quality)

Cochrane Database Syst Rev. Author manuscript; available in PMC 2013 August 15. 
Risk of bias table

Bias

Random sequence generation (selection bias)

Allocation concealment (selection bias)

Blinding of outcome assessment (detection bias)

Incomplete outcome data (attrition bias)

Selective reporting (reporting bias)

Laffel 2003

Methods

Participants

Interventions

Outcomes

Yates Quality Scale

Notes

Risk of bias table

Bias

Random sequence generation (selection bias)

Allocation concealment (selection bias)

Blinding of outcome assessment (detection bias)

Incomplete outcome data (attrition bias)

\section{Authors' judgement}

Unclear risk

Unclear risk

Unclear risk

Unclear risk

Unclear risk

RCT. 2 arms. Assessed at pre-treatment and 1 year.

End of treatment $n=100$ children

Start of treatment $\mathrm{n}=105$

Sex of children: 53 M.47 F

Sex of parents: not reported

Mean age of children $=12.1(2.3)$

Mean age of parents $=$ not reported

Source = Joslin Diabetes Center Pediatric and Adolescent Uni

Diagnosis $=$ type 1 diabetes

Mean years of illness $=2.7$ years $+/-1.6$ years

"Teamwork Intervention" (FT)

"Standard Care"

Mode of delivery: individual families, face to face

Intervention delivered by: research assistant

Training: not reported

Duration of intervention $($ child $)=4$ sessions over 1 year (hours not reported)

Duration of intervention (parent) $=4$ sessions over 1 year (hours not reported)

* Extracted measure

Child measures

Glycemic Control (A1c)*

Diabetes Family Conflict Scale*

Clinician Report of Adherence to Diabetes Management Tasks

Diabetes Family Responsibility Questionnaire

Joint structured interview to assess parental involvement in diabetes management tasks

Pediatric Quality of Life Inventory (PedsQL)

Parent measures

Diabetes Family Conflict Scale*

Diabetes Family Responsibility Questionnaire

Joint structured interview to assess parental involvement in diabetes management tasks

Study quality (out of 35): 12 (low quality)

Treatment quality (out of 9): 1 (low quality)

Design quality (out of 26): 11 (low quality)

Authors' judgement

Unclear risk

Unclear risk

Unclear risk

High risk

\section{Support for judgement}

"Patients were randomly assigned according to age and duration." Comment: method not described.

No description found in text. Comment: probably not done.

No description found in text. Comment: probably not done.

Attrition not adequately described

Cochrane Database Syst Rev. Author manuscript; available in PMC 2013 August 15 
Selective reporting Low risk (reporting bias)

Lask 1979

Methods

Participants

Notes

Risk of bias table

Bias

Random sequence generation (selection bias)

Allocation concealment (selection bias)

Blinding of outcome assessment (detection bias)

Incomplete outcome data (attrition bias)

Selective reporting (reporting bias)

Lehmkuhl 2010

Methods

Participants

RCT. Assessed at pre-treatment, post-treatment and 1 year follow-up.

End of treatment $\mathrm{n}=37$ children, 33 families Start of treatment $n=37$ children, 33 families

Sex of children: not reported

Sex of parents: not reported

Mean age of children $=$ range 4 to 14 years, mean not reported

Mean age of parents $=$ not reported

Source $=$ not reported

Diagnosis $=$ asthma

Mean years of illness $=$ not reported

"Family psychotherapy" (FT)

Standard care control group

Mode of delivery: individual families, face to face

Intervention delivered by: mental health professional

Training: not reported

Duration of intervention (child) $=6 \times 1 \mathrm{hr}$ family psychotherapy $=6$ hours

Duration of intervention (parent) $=6 \times 1 \mathrm{hr}$ family psychotherapy $=6$ hours

* Extracted measures

Child measures

Diary cards*

Peak expiratory flow rate (PEFR)

Forced expiratory volume (FEV)

Thoracic gas volume (TGV)

Study quality (out of 35): 10 (low quality)

Treatment quality (out of 9): 2 (low quality)

Design quality (out of 26): 8 (low quality)

Data were fully reported. Aims, measures and results were fully concordant. Comment: probably no reporting bias.

\section{Authors' judgement}

Unclear risk

Unclear risk

Unclear risk

High risk

High risk

RCT. 2 arms. Assessed pre and posttreatment.

End of treatment $\mathrm{n}=22$

Start of treatment $n=32$

Sex of children: $9 \mathrm{M}, 23 \mathrm{~F}$

Sex of parents: $2 \mathrm{M}, 27 \mathrm{~F}, 3$ unknown

Mean age of children $=13.66(2.43)$

Mean age of parents $=41.53(8.14)$

Source $=$ university-affiliated paediatric endocrinology clinic

Diagnosis $=$ type 1 diabetes

Mean years of illness $=$ over 6 months

"Telehealth Behavioral Therapy" (CBT)

"Wait list control"

Mode of delivery: individual, phone calls

Intervention delivered by: psychologists and Clinical Psychology interns

Training: not reported

Duration of intervention (child) $=36$ phone calls, 9 to 12 hours

Duration of intervention (parent) $=36$ phone calls, 9 to 12 hours
"Families were then randomly allocated to the experimental (group A) or control group (group B)." Comment: method not described.

No descript

No description found in text. Comment: probably not done.

Attrition was not adequately described

Data were incompletely reported. Aims, measures and results were partially concordant. Comment: probably some reporting bias. 
Outcomes

Yates Quality Scale

Notes

Risk of bias table

Bias

Random sequence generation (selection bias)

Allocation concealment (selection bias)

Blinding of outcome assessment (detection bias

Incomplete outcome data (attrition bias)

Selective reporting (reporting bias)

Levy 2010

Methods

Participants

Interventions

Outcomes

* Extracted measures

Child measures

A1c Now*

Diabetes Family Behavior Scale, Abbreviated (DFBS)*

Diabetes Self-Management Profile (DSMP)

Diabetes Family Behavior checklist (DFBC)

Diabetes Family Responsibility Questionnaire

Parent measures

Diabetes Self-Management Profile (DSMP)

Diabetes Family Behavior checklist (DFBC)

Diabetes Family Responsibility Questionnaire

Clinician measures

Clinical Global Impression Scale (CGIS)

Clinical Global Improvement (CGI)

Study quality (out of 35): 20 (high quality)

Treatment quality (out of 9): 7 (high quality)

Design quality (out of 26): 13 (low quality)

Authors' judgement

Low risk

Unclear risk

Unclear risk

High risk

High risk

RCT. 2 arms. Assessed at pre-treatment, post-treatment, 3-month follow-up, 6-month follow-up.

End of treatment $\mathrm{n}=168,3$ months $=143,6$ months $=154$

Start of treatment $\mathrm{n}=200$

Sex of children: $55 \mathrm{M}, 145 \mathrm{~F}$

Sex of parent: $12 \mathrm{M}, 188 \mathrm{~F}$

Mean age of child $=11.21(2.55)$

Mean age of parent $=43.75(6.35)$

Source = paediatric G1 Clinics at Seattle Children's Hospital and the Atlantic Health System

in Morristown, New Jersey. Seattle area participants were also recruited via local clinics and community-posted flyers.

Diagnosis $=$ functional abdominal pain

Mean years of illness $=3+$ episodes of abdominal pain during a 3-month period

"Cognitive-behavioural treatment" (CBT)

"Educational intervention"

Mode of delivery: individual families, face to face

Intervention delivered by: therapists

Training: not reported

Duration of intervention (child) $=3 \times 75$ minutes $=4$ hours

Duration of intervention (parent) $=3 \times 75$ minutes $=4$ hours

* Extracted measures

Child measures

Functional Disability Inventory* (FDI)

Faces Pain Scale-Revised*

Child Depression Inventory* (CDI)

Child Somatization Inventory (CSI)

Multidimensional Anxiety Scale for Children (MASC)

Parent measures

Functional Disability Inventory (FDI)

Faces Pain Scale-Revised

Child Somatization Inventory (CSI)

\section{Support for judgement} list using a random numbers table." Comment: bably done.

"All assessments were conducted by an

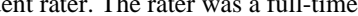
rater was blind.

were incompletely reported. Aims, measures and results were partially concordant. Comment: probably some reporting bias. 
Yates Quality Scale

Notes

Risk of bias table

Bias

Random sequence generation (selection bias)

Allocation concealment (selection bias)

Blinding of outcome assessment (detection bias)

Incomplete outcome data (attrition bias)

Selective reporting (reporting bias)

Ng 2008

Methods

Participants

Interventions

Outcomes

Yates Quality Scale

Notes

Risk of bias table

Bias

Random sequence generation (selection bias)

Study quality (out of 35): 27 (high quality)

Treatment quality (out of 9): 7 (high quality)

Design quality (out of 26): 20 (high quality)

Authors' judgement

Low risk

Low risk

Low risk

Unclear risk

Low risk

\section{Support for judgement}

"Randomisation was then performed by a different researcher using a computerised random-number generator, stratifying by age." Comment: probably done.

"Randomisation was then performed by a different researcher using a computerised random-number generator, stratifying by age." Comment: probably done.

"Nurse assessors were blind to the treatment assignment of the children." Comment: probably done.

Attrition was reported, but no data were presented describing equivalence between completers and non-completers

Data were fully reported after authors responded to data requests. Aims, measures and results were fully concordant. Comment: probably no reporting bias.

RCT. 2 arms. Assessed pre-treatment, post-treatment and 11 weeks follow-up.

End of treatment $\mathrm{n}=27$

Start of treatment $n=46$

Sex of children: $25 \mathrm{M}, 12 \mathrm{~F}$

Sex of parents: not reported

Mean age of child $=9.24(1.48)$

Mean age of parent $=$ not reported

Source $=$ paediatric chest clinic of the Prince of Wales Hospital Hong Kong

Diagnosis $=$ asthma

Mean years of illness $=5.70(2.41)$

"We Together-We Success Parallel Group for Children with Asthma and their Parents (WTWS)" (FT)

"Control Group" (wait list)

Mode of delivery: group, face to face

Intervention delivered by: not reported

Training: not reported

Duration of intervention $($ child $)=11 \times 2$ hours $=22$ hours

Duration of intervention (parent) $=11 \times 2$ hours $=22$ hours

* Extracted measures

Child measures

Exhaled nitric oxide (eNO)*

Spirometry

Parent measures

Anxiety Subscale of Chinese version Hospital Anxiety and Depression Scale (HADS)*

Caretakers' perceived efficacy in the management of child's asthma (self constructed)*

The Emotion Scale of Body-Mind-Spirit Well-Being Inventory (BMSWBI)

Standard Short Form 12 (SF-12) Chinese (Hong Kong) Version 1 measuring health-related quality of life

Patient's adjustment to asthma (self constructed)*

Study quality (out of 35): 16 (low quality)

Treatment quality (out of 9): 5 (high quality)

Design quality (out of 26): 11 (low quality)

Authors' judgement

Unclear risk

\section{Support for judgement}

"A randomised wait-list-controlled clinical trial design was adopted in this study". Comment: no method described.

Cochrane Database Syst Rev. Author manuscript; available in PMC 2013 August 15. 


\begin{tabular}{ll}
$\begin{array}{l}\text { Allocation concealment } \\
\text { (selection bias) }\end{array}$ & Unclear risk \\
$\begin{array}{l}\text { Blinding of outcome } \\
\text { assessment (detection } \\
\text { bias) }\end{array}$ & Unclear risk \\
$\begin{array}{l}\text { Incomplete outcome } \\
\text { data (attrition bias) }\end{array}$ & Unclear risk \\
\hline $\begin{array}{l}\text { Selective reporting } \\
\text { (reporting bias) }\end{array}$ & High risk
\end{tabular}

\section{Niebel 2000}

Methods

Participants

Interventions

\section{Outcomes}

Yates Quality Scale

Notes

Risk of bias table

Bias

Random sequence generation (selection bias)

Allocation concealment (selection bias)

Blinding of outcome assessment (detection bias)

Incomplete outcome data (attrition bias)

Selective reporting (reporting bias)

Olivares 1997

Methods

Participants

Interventions
No description found in text. Comment: probably not done.

No description found in text. Comment: probably not done.

Attrition was reported, but no data were presented describing equivalence between completers and non-completers

Data were fully reported. No aims or primary outcomes were described in the introduction. Comment: probably some reporting bias.

RCT. 2 arms. Assessed pre-treatment and post-treatment.

End of treatment $\mathrm{n}=47$

Start of treatment $n=57$

Sex of children: $5 \mathrm{M}, 47 \mathrm{~F}$

Sex of parents: $0 \mathrm{M}, 47 \mathrm{~F}$

Mean age of children $=3.9(2.43)$

Mean age of parents $=33.9(1.25)$

Source $=$ unknown

Diagnosis = eczema

Mean years of illness $=9.1$ years $(8.36)$

"Direct Behavioural Parental Education"

"Standardized Video-based Parental Education"

"Dermatologic Standard Treatment"

Mode of delivery: group and individual, face to face and video-based

Intervention delivered by: mental health professional

Training: not reported

Duration of intervention (child) $=0$

Duration of intervention (parent) $=10 \times 2=20$ hours $($ direct $), 1.67$ hours (video-based)

Study quality (out of 35): 11 (low quality)

Treatment quality (out of 9): 5 (high quality)

Design quality (out of 26): 6 (low quality)

\section{Authors' judgement}

Unclear risk

Unclear risk

Unclear risk

High risk

High risk

\section{Support for judgement}

No description found in text. Comment: probably not done.

No description found in text. Comment: probably not done.

No description found in text. Comment: probably not done.

Attrition was not adequately described

Data not fully reported. Comment: probably no reporting bias. Comment: probably no reporting bias.

RCT. 2 arms. Assessed at pre-treatment, post-treatment and 9-month follow-up.

End of treatment $\mathrm{n}=$ not reported

Start of treatment $n=36$

Sex of children: $19 \mathrm{M}, 17 \mathrm{~F}$

Sex of parents: $12 \mathrm{M} .23 \mathrm{~F}$

Mean age of children $=$ not reported

Mean age of parents = treatment group $=39.71(5.47)$, control group $=40.87(7.05)$

Source $=$ not reported

Diagnosis $=$ diabetes

Mean years of illness $=$ treatment group $=4.76(3.8)$ years, control group $=3.72(2.22)$ years

"Programme to modify parent behaviour" (CBT)

"Wait list control"

Cochrane Database Syst Rev. Author manuscript; available in PMC 2013 August 15. 
Mode of delivery: group, face to face

Intervention delivered by: not reported

Training: not reported

Duration of intervention $($ child $)=0$

Duration of intervention (parent) $=8$ sessions $\times 70 \mathrm{~min}=9$ hours $20 \mathrm{~min}$

Outcomes

Yates Quality Scale

Notes

Risk of bias table

Bias

Random sequence generation (selection bias)

Allocation concealment (selection bias)

Blinding of outcome assessment (detection bias)

Incomplete outcome data (attrition bias)

Selective reporting (reporting bias)

Palermo 2009

Methods

Participants

Outcomes

Yates Quality Scale

Notes

Risk of bias table

Bias

* Extracted measures

Knowledge about behaviour modification*

Responsibility for diabetes care*

Blood glucose level*

Study quality (out of 35): 16 (low quality)

Treatment quality (out of 9): 4 (low quality)

Design quality (out of 26): 12 (low quality)

Authors' judgement

Unclear risk

Unclear risk

Unclear risk

High risk

High risk

\section{Support for judgement}

No description found in text. Comment: probably not done.

No description found in text. Comment: probably not done.

No description found in text. Comment: probably not done.

Attrition was not adequately described

Data not fully reported. Comment: probably no reporting bias. Comment: probably no reporting bias.

RCT. 2 arms. Assessed at pre-treatment, post-treatment and 3-month follow-up

End of treatment $n=44$

Start of treatment $\mathrm{n}=48$

Sex of children: $13 \mathrm{M}, 35 \mathrm{~F}$

Sex of parents: 7:41

Mean age of children $=14.8(2.0)$

Mean age of parents $=$ not reported

Source $=$ academic health centre, Pacific Northwest USA

Diagnosis $=$ mixed pain conditions

Mean years of illness $=30$ months

"Internet-delivered family cognitive-behavioral therapy" (CBT)

"Wait list control group"

Mode of delivery: individual families, Internet

Intervention delivered by: Internet and online coach. Online coach was a $\mathrm{PhD}$ level postdoctoral psychology fellow.

Training: 1 year of experience delivering face-to-face CBT to children with chronic pain

Duration of intervention (child) $=4$ hours

Duration of intervention (parent) $=4$ hours

* Extracted measures

Child measures

Pain diary*

Child Activity Limitations Interview* (CALI)

Revised Child Anxiety and Depression Scale* (RCADS

Treatment Evaluation Inventory - Short Form

Parent measures

Adult Responses to Children's Symptoms* (ARCS)

Treatment Evaluation Inventory - Short Form

Study quality (out of 35): 30 (high quality)

Treatment quality (out of 9): 8 (high quality)

Design quality (out of 26): 22 (high quality)
Support for judgement 
Random sequence generation (selection bias)

Allocation concealment Low risk (selection bias)

\begin{abstract}
Blinding of outcome assessment (detection bias)
\end{abstract}

Incomplete outcome data (attrition bias)

Selective reporting (reporting bias)

Robins 2005

Methods

Participants

Interventions

Outcomes

Yates Quality Scale

Notes

Risk of bias table

Low risk

Low risk

Low risk entry.
"A fixed allocation randomisation scheme was used. Specifically, we used blocked randomisation with blocks of 10 to assign participants to the two treatment conditions during the course of randomisation. An online random number generator was used to produce the blocked randomisation. Group assignments were identified by ID number in sealed envelopes. Following completion of all pretreatment assessments, a research coordinator opened the sealed envelope to reveal the group assignment." Comment: probably done.

"A fixed allocation randomisation scheme was used. Specifically, we used blocked randomisation with blocks of 10 to assign participants to the two treatment conditions during the course of randomisation. An online random number generator was used to produce the blocked randomisation. Group assignments were identified by ID number in sealed envelopes. Following completion of all pretreatment assessments, a research coordinator opened the sealed envelope to reveal the group assignment." Comment: probably done.

Participants completed questionnaires online

Attrition was reported, no significant differences between completers and non-completers was described

Data were fully reported. Aims, measures and results were fully concordant. Comment: probably no reporting bias.

RCT. 2 arms. Assessed pre-treatment, post-treatment and 6 to 12 months following study

End of treatment $n=69$, follow-up $=69$

Start of treatment $\mathrm{n}=86$

Child sex: $30 \mathrm{M}, 39 \mathrm{~F}$

Parent sex: not reported

Mean age of children $=11.34(2.4)$

Mean age of parents $=$ not reported

Source $=$ community-based primary care physicians and hospital-based paediatric gastroenterologists

Diagnosis $=$ recurrent abdominal pain

Mean years of illness $=3+$ episodes over 3 months

"Standard Medical Care plus Short-Term Cognitive-Behavioral Family Treatment" (CBT) "Standard Medical Care"

Mode of delivery: group, face to face

Intervention delivered by: psychology post-doctoral fellow or pre-doctoral intern

Training: not reported

Duration of intervention $($ child $)=5$ sessions $\times 40$ minutes $=3$ hours 20 minutes

Duration of intervention (parent) $=3$ sessions $\times 40$ minutes $=2$ hours

* Extracted measures

Child measures

Abdominal Pain Index* (API)

Child Somatization Inventory* (CSI)

Functional Disability Inventory Child Version* (FDI)

School Absences obtained from school attendance records

Parent measures

Abdominal Pain Index (API)

Child Somatization Inventory (CSI)

Clinician measures

Health service use obtained from physician offices

Study quality (out of 35): 22 (high quality)

Treatment quality (out of 9): 6 (high quality)

Design quality (out of 26): 16 (high quality) 


\section{Bias}

Random sequence generation (selection bias)

Allocation concealment (selection bias)

Blinding of outcome assessment (detection bias)

Incomplete outcome data (attrition bias)

Selective reporting (reporting bias)

Sahler 2002

Methods

Participants

Notes

Risk of bias table

Bias

Random sequence generation (selection bias)

Allocation concealment Low risk (selection bias)

Blinding of outcome assessment (detection bias)

Incomplete outcome data (attrition bias)

Selective reporting (reporting bias)

Low risk
Authors' judgement

Unclear risk

Unclear risk

Unclear risk

High risk

RCT. 2 arms. Assessed pre-treatment, post-treatment and 3-month follow-up.

End of treatment $\mathrm{n}=81$

Start of treatment $n=92$

Sex of children: not reported

Sex of parents: OM, $92 \mathrm{~F}$

Mean age of children $=8.32(5.5)$

Mean age of mothers $=35.35$ (6.6)

Source $=6$ children's hospitals in USA

Diagnosis $=$ cancer

Mean years of illness $=2$ to 16 weeks from diagnosis

"Problem solving therapy" (PST)

"Standard psychosocial care"

Mode of delivery: individual, face to face

Intervention delivered by: mental health professional or doctoral candidate in psychology

Training: 3-day workshop

Duration of intervention (child) $=0$

Duration of intervention (parent) $=8$ sessions $\times 1 \mathrm{hr}=8$ hours

* Extracted measures

Parent measures

Social Problem-Solving Inventory-Cancer*

Profile of Mood States*

Study quality (out of 35): 23 (high quality)

Treatment quality (out of 9): 9 (high quality)

Design quality (out of 26): 14 (low quality) presented on significant differences between completers and non-completers

Data were incompletely reported. Aims, measures and results were Dartially concordant. Comment: probably some reporting bias. probably done.

No description found in text. Comment: probably

No description found in text. Comment: probably not done.

Attrition was reported, but no data were a coin-flip method." Comment:

\section{ly}


Sahler 2005

Methods

Participants

Interventions

Yates Quality Scale

Notes

Risk of bias table

\section{Bias}

Random sequence generation (lection bias)

Allocation concealment (selection Dias)

Blinding of outcome assessment (etection bias)

ncomplete outcome data (attrition Dias) (reporting bias)

Sanders 1994

Methods

Participants

RCT. 2 arms. Assessed pre-treatment, post-treatment and 6 months after T1.

End of treatment $n=407$

Start of treatment $n=430$

Sex of children: $219 \mathrm{M}, 210 \mathrm{~F}$

Sex of parents: 0M.429 F

Mean age of children at diagnosis $=7.6$

Mean age of mothers $=35.5$

Source $=7$ sites is USA +1 site in Israel

Diagnosis $=$ cancer

Mean years of illness $=2$ to 16 weeks from diagnosis

"Usual psychosocial care plus problem-solving therapy" (PST)

"Usual psychosocial care"

Mode of delivery: individual, face to face

Intervention delivered by: not reported

Training: not reported

Duration of intervention $($ child $)=0$

Duration of intervention (parent) $=8 \times 1 \mathrm{hr}=8$ hours

* Extracted measure

Parent measures

Profile of Mood States (POMS)*

Beck Depression Inventory-1l (BDI-II)*

Social Problem-Solving Inventory-Revised (SPSI-R)*

NEO-Five Factor Inventory (NEO-FFI)

Impact of Event Scale-Revised (IES-R)

Study quality (out of 35): 15 (low quality)

Treatment quality (out of 9): 5 (high quality)

Design quality (out of 26): 10 (low quality)

Selective reporting
Authors' judgement

Unclear risk

Unclear risk

Unclear risk

Unclear risk

Unclear risk
Support for judgement

"Randomisation was performed centrally." Comment: method not described.

No description found in text. Comment: probably not done.

No description found in text. Comment: probably not done.

Attrition was reported, but no data were presented describing equivalence between completers and non-completers

Data were fully reported after authors responded to requests. Aims, measures and results were partially concordant. Comment: probably some reporting bias.

RCT. 2 arms. Assessed at pre-treatment, post-treatment, 6-month follow-up, 12-month follow-up.

End of treatment $\mathrm{n}=44$

Start of treatment $\mathrm{n}=44$

Sex of children: $16 \mathrm{M}, 28 \mathrm{~F}$

Sex of parents: not reported

Mean age of children $=9.22(1.9)$

Mean age of parents $=39.3(4.9)$

Source $=$ not reported

Diagnosis $=$ recurrent abdominal pain

Mean years of illness $=44$ months $(37.76)$

Interventions

"Standard paediatric care"

Mode of delivery: individual, face to face

Intervention delivered by: Clinical Psychologists

Training: not reported

Duration of intervention $($ child $)=6 \times 50$ minutes $=5$ hours

Duration of intervention (parent) $=6 \times 50$ minutes $=5$ hours

Cochrane Database Syst Rev. Author manuscript; available in PMC 2013 August 15. 
Outcomes

Yates Quality Scale

Notes

Risk of bias table

Bias

Random sequence generation (selection bias)

Allocation concealment (selection bias)

Blinding of outcome assessment (detection bias)

Incomplete outcome data (attrition bias)

Selective reporting (reporting bias)

Seid 2010

Methods

Participants

Interventions

Outcomes

Yates Quality Scale

Notes

Risk of bias table

Bias
* Extracted measures

Child measures

Pain diary*

Videotaped vignettes, assessment of children's self coping

Parent measures

Child Behavior Checklist CBCL*

Videotaped vignettes, assessment of maternal care giving*

Parent Observation Record (POR)

Treatment expectancie

Measures of relapse - interview

Satisfaction with treatment

Study quality (out of 35): 18 (high quality)

Treatment quality (out of 9): 5 (high quality)

Design quality (out of 26): 13 (low quality)

\section{Authors' judgement}

Unclear risk

Unclear risk

Unclear risk

High risk

Unclear risk

\section{Support for judgement}

"The study used a randomised group comparison design with two treatment conditions." Comment: method not described.

No description found in text. Comment: probably not done.

No description found in text. Comment: probably not done.

Attrition was not adequately described

Data were incompletely reported. Aims, measures and results were fully concordant. Comment: probably some reporting bias.
RCT. 3 arms. Assessed pre-treatment, post-treatment and 6-month follow-up.

End of treatment $\mathrm{n}=204,6$-month follow-up $\mathrm{n}=188$

Start of treatment $\mathrm{n}=252$

Sex of children: $154 \mathrm{M}, 98 \mathrm{~F}$

Sex of parents: 9 M.244F

Mean age of children $=7.37$ (3.07)

Mean age of parents $=$ not reported

Source = federally qualified health centres, a commercial HMO, school/daycare, local asthma initiatives and self referrals in San Diego, CA, USA

Diagnosis $=$ asthma

Mean length of illness $=44$ months (37.76)

"Problem-Solving Skills Training + Care Coordination" (PST + Asthma Education

"In Home Asthma Education + Care Coordination" (Asthma Education)

"Standard care wait-list control"

Mode of delivery: individual families, face to face

Intervention delivered by: Master's level health educator (PST), paraprofessional asthma home visitors (care co-ordination)

Training: 2-week training

Duration of intervention (PST + Asthma Education $)=6 \times 45$ to 60 minutes

Duration of intervention (Asthma Education) $=5 \times 45$ to 60 minutes

\section{* Extracted measures}

Child measures

Pediatric Quality of Life Inventory Asthma Module Asthma Symptoms Scale (PedsQL

Asthma)

Parent measures

Pediatric Quality of Life Inventory (PedsQL)*

Health Service Use self report

Study quality (out of 35): 30 (high quality)

Treatment quality (out of 9): 9 (high quality)

Design quality (out of 26): 21 (high quality)

Authors' judgement

Support for judgement

Cochrane Database Syst Rev. Author manuscript; available in PMC 2013 August 15. 
Random sequence generation (selection bias)

Allocation concealment Low risk (selection bias)

Blinding of outcome assessment (detection bias)

Incomplete outcome data (attrition bias)

Selective reporting

(reporting bias)

Stehl 2009

Methods

Participants

Interventions

Yates Quality Scale

Notes

Risk of bias table

Bias

Random sequence generation (selection bias)

Allocation concealment Low risk (selection bias)

Blinding of outcome assessment (detection bias)

Low risk

Low risk

Low risk
RCT. 2 arms. Assessed pre-treatment and 1 month post-treatment.

End of treatment $\mathrm{n}=48$ families, 92 caregivers

Start of treatment $n=76$ families, 152 caregivers received intervention

Sex of children: $41 \mathrm{M}, 35 \mathrm{~F}$

Sex of parents $=$ not reported

Mean age of children $=6$ years

Mean age of primary caregiver $=36$ years

Source $=$ oncology service

Diagnosis $=$ cancer

Mean years of illness $=$ after diagnosis

\#x0201C;Surviving Cancer Competently Intervention Program-Newly Diagnosed" (CBT) "Standard Psychosocial Care"

Mode of delivery: group, face to face, CD-ROM based multiple family discussion groups

Intervention delivered by: psychology fellows, psychology intern, Master's level

psychologist and doctoral-level nurse

Training: 18 hours of didactic and experiential training

Duration of intervention (children) $=3 \times 45$ minutes +3 booster sessions

Duration of intervention (parents) $=3 \times 45$ minutes +3 booster sessions

* Extracted measures

Parent measures

State Trait Anxiety Inventory* (STAI)

Impact of Event Scale-Revised (IES-R)

Acute Stress Disorder Scale (ASDS)

Programme Evaluation

Clinicians' measures

Social Work Activity Form

Child Life Activity Form

Intensity of Treatment Rating Scale (ITR-2)

Study quality (out of 35): 25 (high quality)

Treatment quality (out of 9): 8 (high quality)

Design quality (out of 26): 17 (high quality)
Authors' judgement

Low risk

Low risk nd disease severity was used. Prepared and assignment." Comment: probably done.

and disease severity was used. Prepared randomisation lists were created by the statistician and concealed until intervention

列

Attrition was reported, no significant differences described

fully reported. Aims, measures and results ere fully concordant. Comment: probably no reporting bias.

"Blocked randomisation, stratified by site of care the intervention group, administered surveys Comment: probably done. ion care

\section{Support for judgement}

"Randomization was completed by a predetermined concealed random assignment list maintained by a staff member unaware of patient identity." Comment: probably done.

"Randomization was completed by a predetermined concealed random assignment list maintained by a staff member unaware of patient identity." Comment: probably done.

"Add data collection took place at the hospital at a time and location of convenience for the family
Cochrane Database Syst Rev. Author manuscript; available in PMC 2013 August 15. 


\begin{tabular}{ll}
$\begin{array}{l}\text { Incomplete outcome } \\
\text { data (attrition bias) }\end{array}$ & Low risk \\
$\begin{array}{l}\text { Selective reporting } \\
\text { (reporting bias) }\end{array}$ & Low risk \\
\hline
\end{tabular}

Wade 2006

Methods

Participants

Outcomes

Yates Quality Scale

Notes

Risk of bias table

Bias

Random sequence generation (selection bias)

Allocation concealment Unclear risk (selection bias)

Blinding of outcome assessment (detection bias)

Incomplete outcome data (attrition bias)

Selective reporting (reporting bias)

Wade 2006b

Methods

Participants

"Usual Care"

Child measures

Parent measures

and was conducted by research assistants." Comment: probably done.

Attrition was reported, no significant differences between completers and non-completers was described

Data fully reported. Aims, measures and results are fully concordant. Comment: probably no reporting bias.

RCT. 2 arms. Assessed pre and post-treatment

End of treatment $n=32$ children and their parents Start of treatment $n=37$ children and their parents Sex of children: $21 \mathrm{M}, 11 \mathrm{~F}$

Sex of parents: not reported

Mean age of children $=10.83(2.94)$

Mean age of parents $=$ not reported

Source = trauma registry at Cincinnati Children's Hospital Medical Center

Diagnosis $=$ traumatic brain injury

Mean years of illness $=8.78(4.53)$

"Family-centered problem-solving intervention" (PST)

Mode of delivery: individual families, face to face

Intervention delivered by: 5th year Clinical Psychology graduate student

Training: 2 months

Duration of intervention (children) $=7 \times 75$ minutes $=8$ hours 45 minutes to 11 hours 40

minutes + up to 4 individualised sessions

Duration of intervention (parents) $=7 \times 75$ minutes $=8$ hours 45 minutes to 11 hours 40 minutes + up to 4 individualised sessions

* Extracted measures

Conflict Behavior Questionnaire*

Treatment satisfaction

Child Behavior Checklist* (CBCL)

Conflict Behavior Questionnaire* (CBQ)

Brief Symptom Inventory* (BSI)

Treatment satisfaction

Study quality (out of 35): 22 (high quality)

Treatment quality (out of 9): 9 (high quality)

Design quality (out of 26): 13 (low quality)

\section{Authors' judgement}

Low risk

High risk

Low risk

Unclear risk

\section{Support for judgement}

"Families were randomly assigned to the familycentred problem-solving intervention or usual care group using a random numbers table." Comment: probably done.

No description found in text. Comment: probably not done.

"Interviewers were also upper-level psychology graduate students who received extensive training." Comment: no suggestion that they were blinded.

Attrition was reported, no significant differences between completers and non-completers was described

Data were fully reported after authors responded to requests. Aims, measures and results were partially concordant. Comment: probably some reporting bias.

RCT. 2 arms. Assessed pre-treatment and at session 7 of 8 .

End of treatment $n=41$ (40 analysed)

Start of treatment $n=46$

Sex of children: $23 \mathrm{M}, 17 \mathrm{~F}$

Cochrane Database Syst Rev. Author manuscript; available in PMC 2013 August 15. 
Interventions

Outcomes

Yates Quality Scale

Risk of bias table

Bias

Random sequence generation (selection bias)

Allocation concealment (selection bias)

Blinding of outcome assessment (detection bias)

Incomplete outcome data (attrition bias)

Selective reporting (reporting bias)

Wade 2011

Methods

Participants

Interventions

Sex of parents: not reported

Mean age of children $=11.00(3.27)$

Mean age of parents $=$ not reported

Source = trauma registry at Cincinnati Children's Hospital Medical Center

Diagnosis $=$ traumatic brain injury

Mean years of illness $=13.73(7.10)$ months since injury

"Family Problem Solving" (PST)

"Internet Resources Control"

Mode of delivery: individual, online and video conferencing

Intervention delivered by: Clinical Psychology graduate student

Training: 2 months

Duration of intervention (children) $=8$ core modules, 6 supplementary modules, time not reported

Duration of intervention (parents) $=8$ core modules, 6 supplementary modules, time not reported

* Extracted measures

Parent outcomes

Family Assessment Device (FAD)

Family Burden of Injury Interview subscales (FBII)

Likert scales of global family problem-solving, communication and behaviour management

Child Behavior Checklist Internalizing Problems* (CBCL)

Home and Community Social Behavior Scale (HCSBS)

Social Problem-Solving Index (SPSI-short version)

Symptom Checklist-90-Revised (SCL-90-R)

Global Severity Index (GSI)

Center for Epidemiologic Studies Depression Scale* (CES-D)

Anxiety Inventory $(\mathrm{Al})$

Online usage questionnaire

Website Evaluation Questionnaire (WEQ)

Study quality (out of 35): 25 (high quality)

Treatment quality (out of 9): 8 (high quality)

Design quality (out of 26): 17 (high quality)

\section{Authors' judgement}

Low risk

Unclear risk

Low risk

Unclear risk

Unclear risk

\section{Support for judgement}

"Families were randomly assigned to family problem-solving or internet resources comparison via a computer programme." Comment: probably done

No description found in text. Comment: probably not done.

"Given the nature of the study, neither the participants nor the research assistant was blind to group assignment. The primary outcome measures were based on parent and child report and therefore not dependent on the judgments of the research staff." Comment: probably done.

Attrition was not reported, but no significant differences between completers and noncompleters was described

Data were fully reported after authors responded to requests. Aims, measures and results were partially concordant. Comment: probably some reporting bias.

RCT. 2 arms. Assessed pre-treatment and post-treatment.

End of treatment $\mathrm{n}=35$

Start of treatment $n=42$

Sex of children: $17 \mathrm{M} .23 \mathrm{~F}$

Sex of parents: not reported

Mean age of children $=14.25(2.29)$

Mean age of parents $=$ not reported

Source = inpatient rehabilitation unit of 2 urban children's hospitals

Diagnosis $=$ traumatic brain injury

Mean years of illness $=9.54(4.97)$ months since injury

"Teen Online Problem Solving" (PST)

"Internet Resource Comparison"

Mode of delivery: individual, internet and video conferencing 
Outcomes

Yates Quality Scale

Notes

Risk of bias table

Bias

Random sequence generation (selection bias)

Allocation concealment (selection bias)

Blinding of outcome assessment (detection bias)

Incomplete outcome data (attrition bias)

Selective reporting

(reporting bias)

Wysocki 1999

Methods

Participants

Interventions

Intervention delivered by: staff psychologist + Clinical Psychology graduate students Training: multi-day training

Duration of intervention (children) $=10$ core modules, 6 supplementary sessions, time not reported

Duration of intervention (parents) $=10$ core modules, 6 supplementary sessions, time not reported

* Extracted measures

Child measures

Youth Self Report* (YSR)

Interaction Behaviour Questionnaire* (IBQ)

Behavioral Rating Inventory of Executive Functioning

Parent measures

Child Behaviour Checklist* (CBCL)

Interaction Behaviour Questionnaire* (IBQ)

Behavioral Rating Inventory of Executive Functioning (BRIEF)

Study quality (out of 35): 22 (high quality)

Treatment quality (out of 9): 8 (high quality)

Design quality (out of 26): 14 (low quality)

Authors' judgement

Unclear risk

Unclear risk

ome

Low risk

Unclear risk

Unclear risk

\section{Support for judgement}

"Families were randomly assigned to either teen online problem-solving or internet resource group by use of a randomisation scheme that stratified participants on the basis of the adolescent's gender and race/ethnicity to ensure comparable diversity in each group." Comment: method is not fully described.

"Families were randomly assigned to either teen online problem-solving or internet resource group by use of a randomisation scheme that stratified participants on the basis of the adolescent's gender and race/ethnicity to ensure comparable diversity in each group."

"Given the nature of the study we were unable to conceal group assignment from the participants and research staff; however, the primary outcome measures were based on parent and teen report and therefore not dependent on judgments of research staff." Comment: non-blinding of participants and research staff justified.

Attrition was reported, no data were presented on equivalence between completers and noncompleters

Data were fully reported after authors responded to requests. Aims, measures and results were partially concordant. Comment: probably some reporting bias.

RCT. 3 arms. Assessed pre-treatment, 3 months (post-treatment), 6-month follow-up and 12month follow-up.

End of treatment $n=115$ (post-treatment), 113 (6-month follow-up), 108 (12-month followup)

Start of treatment $n=119$ children

Sex of children: $50 \mathrm{M}, 69 \mathrm{~F}$

Sex of parents: $82 \mathrm{M}, 117 \mathrm{~F}$

Mean age of children $=14.3(1.4)$

Mean age of parents $=$ not reported

Source = Missouri and Florida

Diagnosis $=$ type 1 diabetes

Mean years of illness $=5.0(3.8)$

"Behavioral Family Systems Therapy (BFST)" (FT)

"Education and Support Group" (ES)

"Standard Care"

Mode of delivery: individual for BFST, group for ES, face to face

Intervention delivered by licensed Clinical Psychologists

Training: 150 hours

Duration of intervention (children) $=10$ sessions, time not reported 
Duration of intervention (parents) $=10$ sessions, time not reported

Outcomes

Yates Quality Scale

Notes

Risk of bias table

Bias

Random sequence generation (selection bias)

Allocation concealment (selection bias)

Blinding of outcome assessment (detection bias)

Incomplete outcome data (attrition bias)

Selective reporting

(reporting bias)

Wysocki 2006

Methods

Participants

Interventions
* Extracted measures

Child measures

Parent-Adolescent Relationship Questionnaire (PARQ)*

Issues Checklist (IC)

24 Hour Recall Interview of Conflict Situations

Teen Adjustment to Diabetes Scale (TADS)*

Diabetes Responsibility and Conflict (DRC)

24 Hour Recall Interview of IDDM Self-Care

Self-Care Inventory (SCI)

Glycated haemoglobin*

Parent measures

Parent-Adolescent Relationship Questionnaire (PARQ)*

Issues Checklist (IC)

24 Hour Recall Interview of Conflict Situations

Teen Adjustment to Diabetes Scale (TADS)

Diabetes Responsibility and Conflict (DRC)

24 Hour Recall Interview of IDDM Self-Care

Self-Care Inventory (SCI)

Parent-reported health service use

Study quality (out of 35): 23 (high quality)

Treatment quality (out of 9): 8 (high quality)

Design quality (out of 26): 15 (high quality)

\section{Authors' judgement}

Unclear risk

Unclear risk

Unclear risk

Unclear risk

High risk

\section{Support for judgement}

"The research scientist at the opposing centre randomly assigned each family, without knowledge of the family's baseline status on any of the outcome measures to one of three conditions." Comment: method not fully described.

"Randomisation was stratified by the adolescent's gender and treatment centre so that each centre enrolled a similar number of boys and girls into the three groups.'

"A research assistant administered questionnaires at evaluation sessions; the research assistant completed telephone interviews during the 2 weeks preceding each of the four evaluations." Comment: blinding not described.

Attrition was reported, but no data were presented on equivalence between completers and non-completers

Data not fully reported. Aims, measures and results were partially concordant. Comment: probably some reporting bias.
RCT. 3 arms. Assessed at pre-treatment, 6 months (post-treatment), 12-month follow-up, 18month follow-up.

End of treatment $\mathrm{n}=92$ (post-treatment), 88 (12-month follow-up), 85 (18-month follow-up) Start of treatment $n=104$ children (number of caregivers not reported)

Sex of children: $57 \mathrm{M}, 47 \mathrm{~F}$

Sex of parents: not reported

Mean age of children $=14.2(1.9)$

Mean age of parents $=$ not reported

Source $=2$ paediatric centres in the Southeast and Midwest USA

Diagnosis = type 1 diabetes or insulin-treated type 2 diabetes

Mean years of illness $=5.5(3.4)$

"Behavioral Family Systems Therapy for Diabetes (BFST-D)" (FT)

"Educational Support Group"

"Standard Care"

Mode of delivery: individual families, face to face

Intervention delivered by: licensed Clinical Psychologist, Social Worker

Training: trained in BFST-D

Duration of intervention (BFST-D) $=12$ sessions, time not reported

Duration of intervention $(\mathrm{ES})=12 \times 1.5 \mathrm{hr}$ sessions 
Outcomes

Yates Quality Scale

Notes

Risk of bias table

Bias

Random sequence generation (selection bias)

Allocation concealment (selection bias)

Blinding of outcome assessment (detection

bias)

Incomplete outcome data (attrition bias)

Selective reporting (reporting bias)
* Extracted measures

Child measures

Parent-Adolescent Relationship Questionnaire (PARQ)*

Glycosylated haemoglobin (HbA1c)*

Diabetes Responsibility and Conflict (DRC)

Diabetes Self-Management Profile (DSMP)

Family problem solving discussions coded using Interaction Behavior Code

Parent measures

Parent-Adolescent Relationship Questionnaire (PARQ)*

Diabetes Responsibility and Conflict (DRC)

Diabetes Self-Management Profile (DSMP)

Family problem solving discussions coded using Interaction Behavior Code

Study quality (out of 35): 26 (high quality)

Treatment quality (out of 9): 8 (high quality)

Design quality (out of 26): 18 (high quality)
Authors' judgement

Unclear risk

Unclear risk

Low risk

Unclear risk

High risk

footnote

CBT: cognitive behavioural therapy; Gl: gastrointestinal; HMO: health maintenance organisation; MST: multisystemic therapy; PSST: problem solving skills training; PST: problem solving therapy; RCT: randomised controlled trial

\section{Support for judgement}

"A three-group, randomised treatments design was used." Comment: method not described fully.

"Families were stratified by HbA1c"

"Raters were unaware of the family's identity or group assignment or of when the recording was made." Comment: probably done.

Attrition was reported, but no data were presented on equivalence between completers and non-completers

Data were incompletely reported. Aims, Comment: probably some reporting bias. measures and results were partially concordant.

\section{Characteristics of excluded studies}

Aleman 1992

Reason for exclusion Insufficient psychotherapeutic content

Anderson 1999

Reason for exclusion Insufficient psychotherapeutic content

Betancourt 2004

Reason for exclusion Identified participants prospectively

Braga 2005

Reason for exclusion Insufficient psychotherapeutic content

Bruzzese 2008

Reason for exclusion Aim of study was irrelevant to this review

Burke 1997

Reason for exclusion Insufficient psychotherapeutic content

Burke 2001

Reason for exclusion Insufficient psychotherapeutic content

Cakan 2007

Reason for exclusion Aim of study was irrelevant to this review

Canino 2008

Reason for exclusion Aim of study was irrelevant to this review 
Carey 2008

\begin{tabular}{|c|c|}
\hline $\begin{array}{l}\text { Reason for exclusion } \\
\text { Chernoff } 2002\end{array}$ & Aim of study was irrelevant to this review \\
\hline $\begin{array}{l}\text { Reason for exclusion } \\
\text { Chiang } 2009\end{array}$ & Insufficient psychotherapeutic content \\
\hline $\begin{array}{l}\text { Reason for exclusion } \\
\text { Ellis } 2007\end{array}$ & Insufficient psychotherapeutic content \\
\hline $\begin{array}{l}\text { Reason for exclusion } \\
\text { Ellis } 2008\end{array}$ & Aim of study was irrelevant to this review \\
\hline $\begin{array}{l}\text { Reason for exclusion } \\
\text { Evans } 1999\end{array}$ & Aim of study was irrelevant to this review \\
\hline $\begin{array}{l}\text { Reason for exclusion } \\
\text { Field } 1998\end{array}$ & Insufficient psychotherapeutic content \\
\hline $\begin{array}{l}\text { Reason for exclusion } \\
\text { Forsander } 1995\end{array}$ & Insufficient psychotherapeutic content \\
\hline $\begin{array}{l}\text { Reason for exclusion } \\
\text { Forsander } 2003\end{array}$ & Aim of study was irrelevant to this review \\
\hline $\begin{array}{l}\text { Reason for exclusion } \\
\text { Garbutt } 2010\end{array}$ & Inadequate $\mathrm{n}$ : the number of patients in any treatment arm was fewer than 10 \\
\hline $\begin{array}{l}\text { Reason for exclusion } \\
\text { Gerber } 2010\end{array}$ & Insufficient psychotherapeutic content \\
\hline $\begin{array}{l}\text { Reason for exclusion } \\
\text { Giallo } 2008\end{array}$ & Aim of study was irrelevant to this review \\
\hline $\begin{array}{l}\text { Reason for exclusion } \\
\text { Glang } 2007\end{array}$ & Insufficient psychotherapeutic content \\
\hline $\begin{array}{l}\text { Reason for exclusion } \\
\text { Gustafsson } 1986\end{array}$ & Insufficient psychotherapeutic content \\
\hline $\begin{array}{l}\text { Reason for exclusion } \\
\text { Harris } 2001\end{array}$ & Inadequate $\mathrm{n}$ : the number of patients in any treatment arm was fewer than 10 \\
\hline $\begin{array}{l}\text { Reason for exclusion } \\
\text { Haus } 1976\end{array}$ & Aim of study was irrelevant to this review \\
\hline $\begin{array}{l}\text { Reason for exclusion } \\
\text { Hernandez } 1998\end{array}$ & Inadequate $\mathrm{n}$ : the number of patients in any treatment arm was fewer than 10 \\
\hline $\begin{array}{l}\text { Reason for exclusion } \\
\text { Hommel } 2012\end{array}$ & Inadequate $\mathrm{n}$ : the number of patients in any treatment arm was fewer than 10 \\
\hline $\begin{array}{l}\text { Reason for exclusion } \\
\text { Hovell } 1994\end{array}$ & Aim of study was irrelevant to this review \\
\hline $\begin{array}{l}\text { Reason for exclusion } \\
\text { Humphreys } 2000\end{array}$ & Insufficient psychotherapeutic content \\
\hline $\begin{array}{l}\text { Reason for exclusion } \\
\text { Ireys } 1996\end{array}$ & Insufficient psychotherapeutic content \\
\hline $\begin{array}{l}\text { Reason for exclusion } \\
\text { Ireys } 2001\end{array}$ & Insufficient psychotherapeutic content \\
\hline $\begin{array}{l}\text { Reason for exclusion } \\
\text { Jay } 1990\end{array}$ & Insufficient psychotherapeutic content \\
\hline
\end{tabular}




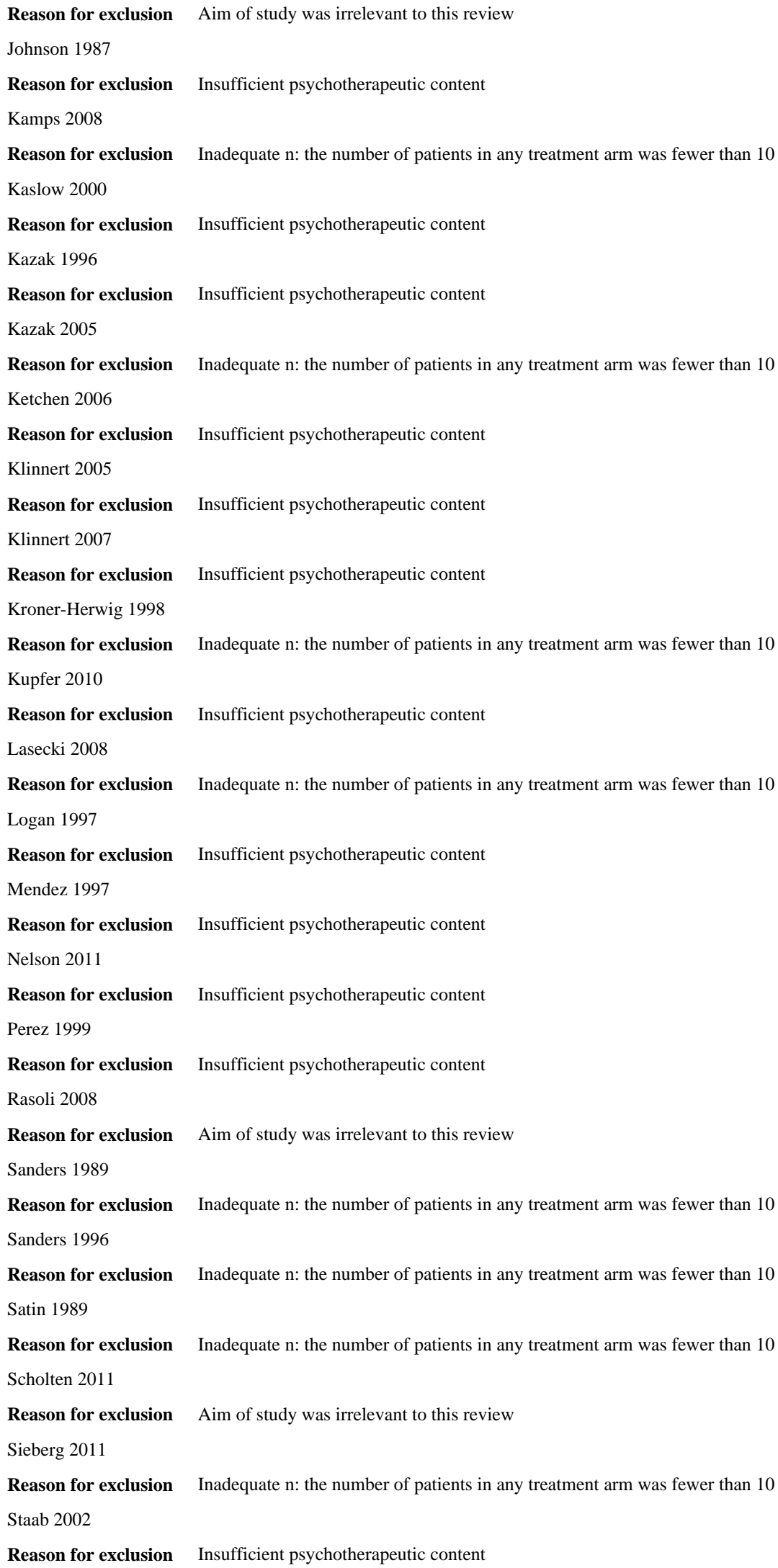

Reason for exclusion Insufficient psychotherapeutic content

Perez 1999

Reason for exclusion Insufficient psychotherapeutic content

Rasoli 2008

Reason for exclusion Aim of study was irrelevant to this review

Sanders 1989

Reason for exclusion Inadequate $n$ : the number of patients in any treatment arm was fewer than 10

Sanders 1996

Reason for exclusion Inadequate $\mathrm{n}$ : the number of patients in any treatment arm was fewer than 10 Satin 1989

Reason for exclusion Inadequate $\mathrm{n}$ : the number of patients in any treatment arm was fewer than 10 Scholten 2011

Reason for exclusion Aim of study was irrelevant to this review Sieberg 2011

Reason for exclusion Inadequate $\mathrm{n}$ : the number of patients in any treatment arm was fewer than 10 Staab 2002

Reason for exclusion Insufficient psychotherapeutic content 
Sullivan-Bolyai 2010

Reason for exclusion Insufficient psychotherapeutic content

Szczepanski 2010

Reason for exclusion Insufficient psychotherapeutic content

Wade 2010

Reason for exclusion Aim of study was irrelevant to this review

Walders 2006

Reason for exclusion Insufficient psychotherapeutic content

Walker 1996

Reason for exclusion Aim of study was irrelevant to this review

Warner 2011

Reason for exclusion Inadequate $\mathrm{n}$ : the number of patients in any treatment arm was fewer than 10

Wysocki 1997

Reason for exclusion Aim of study was irrelevant to this review

footnotes

Characteristics of studies awaiting classification

footnotes

Characteristics of ongoing studies

footnotes

\section{Other published versions of this review Classification pending references \\ Data and analyses}

1 Painful Conditions post treatment

\begin{tabular}{|c|c|c|c|c|}
\hline Outcome or Subgroup & Studies & Participants & Statistical Method & Effect Estimate \\
\hline 1.1 Parent Behaviour & 2 & 92 & $\begin{array}{l}\text { Std. Mean Difference(IV, } \\
\text { Random, 95\% CI) }\end{array}$ & $-0.34[-1.18,0.50]$ \\
\hline 1.2 Child Behaviour/Disability & 6 & 429 & $\begin{array}{l}\text { Std. Mean Difference(IV, } \\
\text { Random, 95\% CI) }\end{array}$ & $-0.18[-0.43,0.07]$ \\
\hline 1.3 Child Mental Health & 4 & 356 & $\begin{array}{l}\text { Std. Mean Difference(IV, } \\
\text { Random, 95\% CI) }\end{array}$ & $-0.02[-0.35,0.30]$ \\
\hline 1.4 Child Symptoms & 8 & 512 & $\begin{array}{l}\text { Std. Mean Difference(IV, } \\
\text { Random, 95\% CI) }\end{array}$ & $-0.29[-0.55,-0.03]$ \\
\hline \multicolumn{5}{|l|}{2 Painful Conditions Follow-up } \\
\hline Outcome or Subgroup & Studies & Participants & Statistical Method & Effect Estimate \\
\hline 2.1 Child Behaviour/Disability & 3 & 289 & $\begin{array}{l}\text { Std. Mean Difference(IV, } \\
\text { Random, 95\% CI) }\end{array}$ & $-0.06[-0.43,0.32]$ \\
\hline 2.2 Child Mental Health & 2 & 255 & $\begin{array}{l}\text { Std. Mean Difference(IV, } \\
\text { Random, 95\% CI) }\end{array}$ & $0.04[-0.21,0.28]$ \\
\hline 2.3 Child Symptoms & 6 & 391 & $\begin{array}{l}\text { Std. Mean Difference(IV, } \\
\text { Random, 95\% CI) }\end{array}$ & $-0.39[-0.86,0.08]$ \\
\hline \multicolumn{5}{|l|}{3 Cancer Post-treatment } \\
\hline Outcome or Subgroup & Studies & Participants & Statistical Method & Effect Estimate \\
\hline 3.1 Parent Behaviour & 4 & 629 & $\begin{array}{l}\text { Std. Mean Difference(IV, } \\
\text { Random, 95\% CI) }\end{array}$ & $-0.14[-0.35,0.07]$ \\
\hline 3.2 Parent Mental Health & 5 & 706 & $\begin{array}{l}\text { Std. Mean Difference(IV, } \\
\text { Random, 95\% CI) }\end{array}$ & $-0.15[-0.37,0.07]$ \\
\hline
\end{tabular}

4 Cancer Follow-up 


\section{Outcome or Subgroup}

4.1 Parent Behaviour

4.2 Parent Mental Health

5 Diabetes Post-treatment

Outcome or Subgroup

5.1 Child Mental Health

5.2 Child Symptoms

5.3 Family Functioning

6 Diabetes Follow-up

Outcome or Subgroup

6.1 Child Symptoms

7 Asthma Post-treatment

Outcome or Subgroup

7.1 Parent Mental Health

7.2 Child Symptoms

8 Asthma Follow-up

Outcome or Subgroup

8.1 Child Symptoms
Studies

4

Studies

2

6

4

Studies

3

Studies

2

3

170

Studies

2

9 Traumatic Brain Injury Post-treatment

$\begin{array}{lll}\text { Outcome or Subgroup } & \text { Studies } & \text { Participant } \\ \text { 9.1 Parent Mental Health } & 2 & 72 \\ \text { 9.2 Child Behaviour/Disability } & 2 & 72 \\ 9.3 \text { Family Functioning } & 2 & 67\end{array}$

10 Cognitive Behavioural Therapy Post-treatment

$\begin{array}{lll}\text { Outcome or Subgroup } & \text { Studies } & \text { Participants } \\ \text { 10.1 Parent Behaviour } & 4 & 166\end{array}$

10.2 Parent Mental Health $\quad 4 \quad 224$

10.3 Child Behaviour/Disability $7 \quad 459$

10.4 Child Mental Health $\quad 5$

10.5 Child Symptoms $\quad 11$

10.6 Family Functioning $\quad 3 \quad 211$

11 Cognitive Behavioural Therapy Follow-up

Outcome or Subgroup

Studies Participants

11.1 Parent Behaviour
85
Statistical Method

Std. Mean Difference(IV, Random, 95\% CI

Std. Mean Difference(IV, Random, 95\% CI)

Statistical Method

Std. Mean Difference(IV Random, 95\% CI)

Std. Mean Difference(IV, Random, 95\% CI)

Std. Mean Difference(IV, Random, 95\% CI)

Statistical Method

Std. Mean Difference(IV, Random, 95\% CI)

Effect Estimate

$-0.06[-0.27,0.15]$

$-0.12[-0.32,0.08]$

Effect Estimate

$-0.08[-0.63,0.47]$

$-0.18[-0.39,0.03]$

$0.01[-0.22,0.24]$

Effect Estimate

$-0.25[-0.55,0.06]$

Effect Estimate

$-0.20[-0.66,0.26]$

Std. Mean Difference(IV, Random, 95\% CI)

Std. Mean Difference(IV, Random, 95\% CI)

$0.23[-0.07,0.54]$

\section{Effect Estimate}

$-0.16[-0.72,0.40]$

Std. Mean Difference(IV, Random, 95\% CI)

\section{Effect Estimate}

$-0.49[-1.14,0.16]$

Std. Mean Difference(IV, Random, 95\% CI)

Std. Mean Difference(IV,

$-0.28[-1.12,0.56]$ Random, 95\% CI)

Std. Mean Difference(IV, Random, 95\% CI)

$-0.14[-0.94,0.67]$

\section{Statistical Method}

Std. Mean Difference(IV, Random, 95\% CI)

Std. Mean Difference(IV Random, 95\% CI)

Std. Mean Difference(IV, Random, 95\% CI)

Std. Mean Difference(IV, Random, 95\% CI)

Std. Mean Difference(IV, Random, 95\% CI)

Std. Mean Difference(IV, Random, 95\% CI)

\section{Effect Estimate}

$-0.02[-0.41,0.38]$

$0.14[-0.12,0.41]$

$-0.11[-0.38,0.15]$

$0.03[-0.23,0.29]$

$-0.25[-0.44,-0.06]$

$0.06[-0.22,0.33]$

Statistical Method

Effect Estimate

Std. Mean Difference(IV Random, 95\% CI) 


\begin{tabular}{|c|c|}
\hline 11.2 Parent Mental Health & 2 \\
\hline 11.3 Child Behaviour/Disability & 3 \\
\hline 11.4 Child Mental Health & 2 \\
\hline 11.5 Child Symptoms & 7 \\
\hline 11.6 Family Functioning & 2 \\
\hline
\end{tabular}

Outcome or Subgroup

12.1 Parent Mental Health

12.2 Child Behaviour/Disability 2

12.3 Child Symptoms

12.4 Family Functioning

4

2

13 Family Therapy Follow-up

Outcome or Subgroup

13.1 Child Symptoms

\section{Studies}

2

74

107

202

132
Std. Mean Difference(IV, Random, 95\% CI)

Std. Mean Difference(IV, Random, 95\% CI)

Std. Mean Difference(IV, Random, 95\% CI)

Std. Mean Difference(IV, Random, 95\% CI)

Std. Mean Difference(IV Random, 95\% CI)

Studies Participants

14 Problem Solving Therapy Post-treatment

Outcome or Subgroup

Studies

14.1 Parent Behaviour

3

14.2 Parent Mental Health

5

14.3 Child Behaviour/Disability 2

14.4 Family Functioning

2

15 Problem Solving Therapy Follow-up
Outcome or Subgroup

15.1 Parent Behaviour

Studies

556

557

16 Multisystemic Therapy Post-treatment

Outcome or Subgroup

16.1 Child Symptoms
Studies

2
Studies Participants
588

660

72

67
Statistical Method

Std. Mean Difference(IV

Std. Mean Difference(IV, Random, 95\% CI)

Std. Mean Difference(IV, Random, 95\% CI)

Std. Mean Difference(IV, Random, 95\% CI)

\section{Statistical Method}

Std. Mean Difference(IV, Random, 95\% CI)

\section{Statistical Method}

Std. Mean Difference(IV Random, 95\% CI)

Std. Mean Difference(IV, Random, 95\% CI)

Std. Mean Difference(IV, Random, 95\% CI) Random, 95\% CI)

\section{Statistical Method}

Std. Mean Difference(IV, Random, 95\% CI)

Std. Mean Difference(IV, Random, 95\% CI)

Statistical Method

Std. Mean Difference(IV, Random, 95\% CI) Random, 95\% CI)

Std. Mean Difference(IV,
$0.32[-0.18,0.82]$

$-0.06[-0.43,0.32]$

$0.03[-0.21,0.28]$

$-0.35[-0.73,0.04]$

$-0.16[-0.66,0.35]$

Effect Estimate

$-0.20[-0.66,0.26]$

$-0.87[-2.05,0.31]$

$0.13[-0.14,0.41]$

$-0.08[-0.42,0.26]$

Effect Estimate

$-0.02[-0.43,0.38]$

Effect Estimate

$-0.22[-0.38,-0.06]$

$-0.27[-0.53,-0.02]$

$-0.28[-1.12,0.56]$

$-0.14[-0.94,0.67]$

\section{Effect Estimate}

$-0.09[-0.31,0.14]$

$-0.13[-0.38,0.12]$

Effect Estimate

$-0.31[-0.64,0.03]$

\section{Summary of findings tables}

\section{Additional tables}




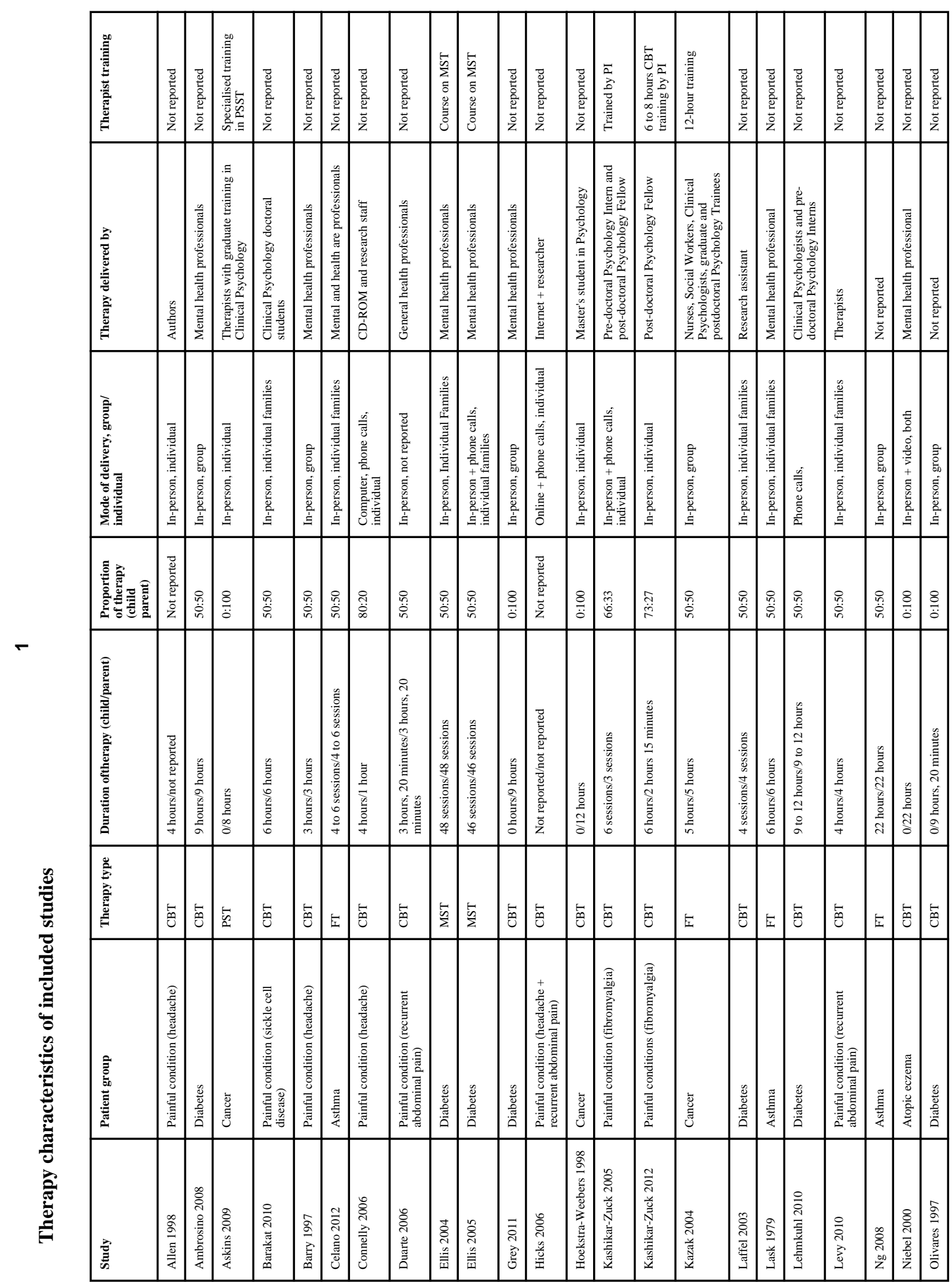

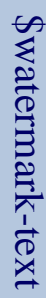




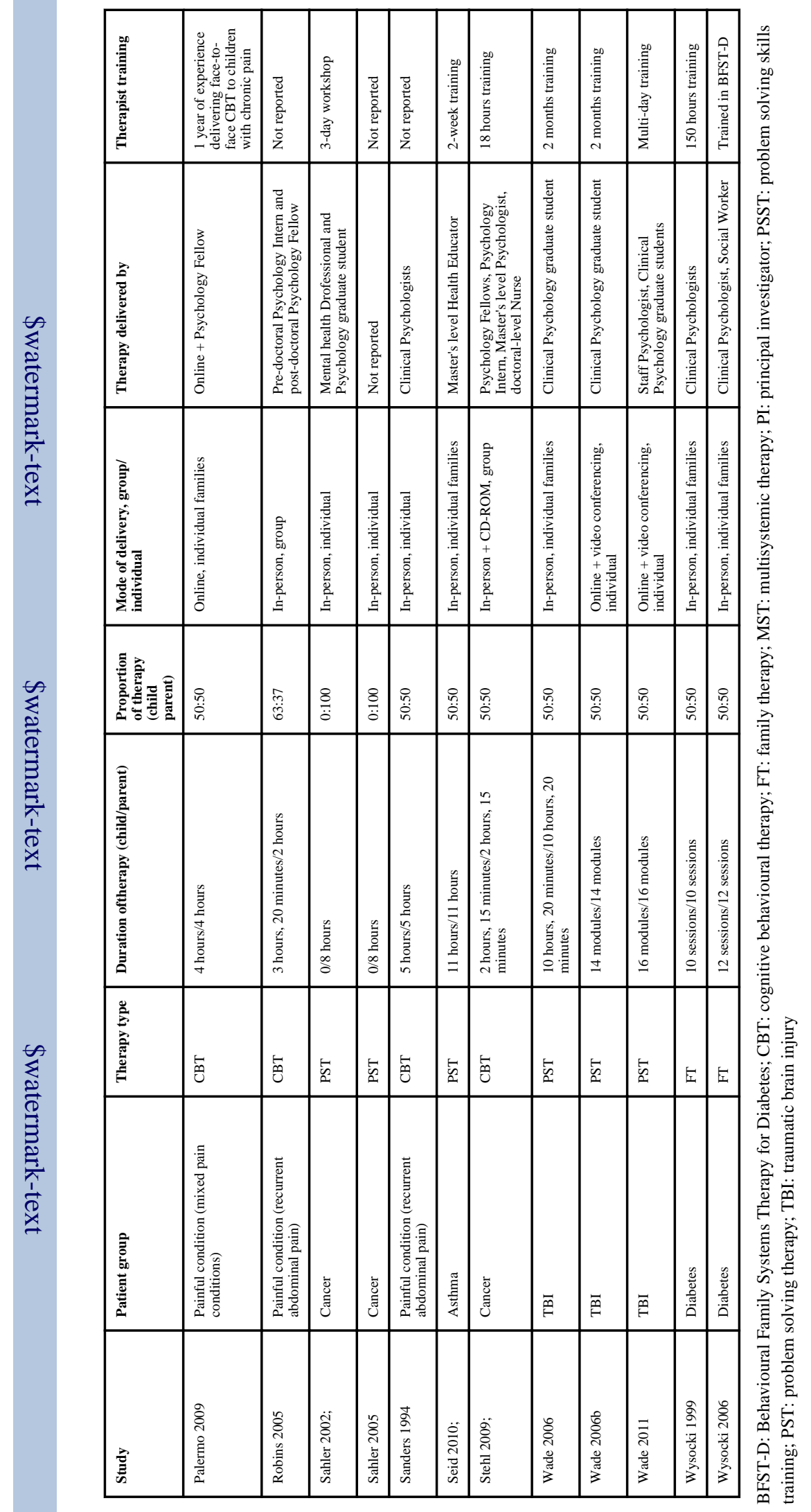

Cochrane Database Syst Rev. Author manuscript; available in PMC 2013 August 15. 


\section{2}

\section{Intervention content and therapy classification of included studies}

\begin{tabular}{|c|c|c|}
\hline Author & Therapy summary & Therapy type \\
\hline $\begin{array}{l}\text { Allen } 1998 \text { Painful condition } \\
\text { (migraine) }\end{array}$ & $\begin{array}{l}\text { Thermal biofeedback plus parent behaviour management. } \\
\text { Parents were provided with pain behaviour management } \\
\text { guidelines which focused on minimising attention to pain, } \\
\text { encouraging the child to participate in daily activities, and } \\
\text { praising practice of biofeedback. Children received thermal } \\
\text { biofeedback training. }\end{array}$ & CBT \\
\hline Ambrosino 2008 Diabetes & $\begin{array}{l}\text { Coping skills training. Parents and children received training } \\
\text { in communication skills, social problem solving, recognising } \\
\text { links between thoughts/feelings/behaviours, stress management } \\
\text { and conflict resolution. The focus of this intervention was to } \\
\text { improve participants' general ability to manage daily problems, } \\
\text { and did not directly address diabetes management. }\end{array}$ & CBT \\
\hline Askins 2009 Cancer & $\begin{array}{l}\text { PST + PDA. Mothers received problem solving training using } \\
\text { the Bright IDEAS framework: Be optimistic about solving } \\
\text { problems, Identify the problem, Determine options, Evaluate } \\
\text { options and choose one, Act and See if it worked. Mothers were } \\
\text { also provided a personal digital assistant (PDA) device that was } \\
\text { designed to review and practise problem solving steps and } \\
\text { record problems and solutions encountered between sessions. } \\
\text { Children did not receive any intervention. }\end{array}$ & PST \\
\hline $\begin{array}{l}\text { Barakat } 2010 \text { Painful condition } \\
\text { (SCD) }\end{array}$ & $\begin{array}{l}\text { Pain management intervention. Parents and children received } \\
\text { education about sickle cell disease (SCD) as well as training in } \\
\text { deep breathing, progressive muscle relaxation, cognitive } \\
\text { restructuring and guided imagery. }\end{array}$ & CBT \\
\hline $\begin{array}{l}\text { Barry } 1997 \text { Painful condition } \\
\text { (Headache) }\end{array}$ & $\begin{array}{l}\text { Cognitive behavioural group treatment. Parents received pain } \\
\text { education as well as training in relaxation, imagery and positive } \\
\text { parenting strategies. Children received pain education as well as } \\
\text { training in relaxation, imagery, distraction and cognitive } \\
\text { restructuring. }\end{array}$ & CBT \\
\hline Celano 2012 Asthma & $\begin{array}{l}\text { Home-based family intervention. Families received asthma } \\
\text { education regarding trigger control resources and feedback on } \\
\text { the child's lung functioning and metered does inhaler (MDI)/ } \\
\text { spacer technique, as well as psychosocial modules targeting } \\
\text { family rules and discipline, family communication and } \\
\text { caregiver mental health. }\end{array}$ & FT \\
\hline $\begin{array}{l}\text { Connelly } 2006 \text { Painful condition } \\
\text { (Headache) }\end{array}$ & $\begin{array}{l}\text { Headstrong programme. Using CD-ROMs, children and } \\
\text { parents jointly completed a module on management of pain } \\
\text { behaviours and creation of a pain-coping plan. Children } \\
\text { received headache education and training in guided imagery, } \\
\text { deep breathing, progressive muscle relaxation, cognitive } \\
\text { restructuring and problem solving. }\end{array}$ & CBT \\
\hline $\begin{array}{l}\text { Duarte } 2006 \text { Painful condition } \\
\text { (RAP) }\end{array}$ & $\begin{array}{l}\text { Cognitive-behavioural family intervention. Parents and } \\
\text { children received education about abdominal pain as well as } \\
\text { training in operant techniques with an emphasis on increasing } \\
\text { adaptive behaviours when in pain, deep breathing, physical } \\
\text { exercise, progressive muscle relaxation, thought stopping, } \\
\text { distraction and imagery. }\end{array}$ & CBT \\
\hline Ellis 2004 Diabetes & $\begin{array}{l}\text { Multisystemic therapy (MST). Families received an intensive, } \\
\text { family- and community-based intervention designed to target } \\
\text { problems related to adherence to diabetes treatment across the } \\
\text { multiple systems within which the child and their family } \\
\text { operated. A variety of psychological interventions were } \\
\text { employed depending on individual need, including cognitive } \\
\text { behavioural therapy, parent training and behavioural family } \\
\text { systems therapy. }\end{array}$ & MST \\
\hline Ellis 2005 Diabetes & Multisystemic therapy (MST). See Ellis 2004 above. & MST \\
\hline Grey 2011 Diabetes & $\begin{array}{l}\text { Coping skills intervention and training. Parents received } \\
\text { training in communication skills, social problem solving, }\end{array}$ & CBT \\
\hline
\end{tabular}




\begin{tabular}{|c|c|c|}
\hline Author & Therapy summary & Therapy type \\
\hline & $\begin{array}{l}\text { cognitive restructuring, stress management and conflict } \\
\text { resolution and were taught to apply these skills to thoughts, } \\
\text { feelings and behaviours related to diabetes management. } \\
\text { Children did not receive any intervention. }\end{array}$ & \\
\hline $\begin{array}{l}\text { Hicks } 2006 \text { Painful condition } \\
\text { (RAP) }\end{array}$ & $\begin{array}{l}\text { Online psychological treatment for paediatric recurrent } \\
\text { pain. Using a website, parents received training in ways to } \\
\text { promote healthy behaviour. Children received pain education as } \\
\text { well as training in deep breathing, relaxation, imagery, } \\
\text { cognitive strategies and healthy lifestyle choices. Children also } \\
\text { received a tape of personalised relaxation exercises and a } \\
\text { thought journal. Each week, families were contacted by a } \\
\text { researcher via phone or email to check progress and review } \\
\text { materials. }\end{array}$ & CBT \\
\hline Hoekstra-Weebers 1998 Cancer & $\begin{array}{l}\text { Intervention programme for parents of paediatric cancer } \\
\text { patients. Parents received education regarding the potential } \\
\text { impact of the child's illness on the child and family as well as } \\
\text { training in emotional expression, cognitive restructuring, } \\
\text { problem-focused coping skills, communication and } \\
\text { assertiveness skills. Children did not receive any intervention }\end{array}$ & CBT \\
\hline $\begin{array}{l}\text { Kashikar-Zuck } 2005 \text { Painful } \\
\text { condition (Fibromyalgia) }\end{array}$ & $\begin{array}{l}\text { Coping skills training. Parents received operant training with a } \\
\text { focus on encouraging active coping behaviour and independent } \\
\text { pain management. Children received education about } \\
\text { behavioural pain management as well as training in progressive } \\
\text { muscle relaxation, distraction, activity pacing, cognitive } \\
\text { techniques and problem solving. }\end{array}$ & $\mathrm{CBT}$ \\
\hline $\begin{array}{l}\text { Kashikar-Zuck } 2012 \text { Painful } \\
\text { condition (Fibromyalgia) }\end{array}$ & $\begin{array}{l}\text { Cognitive behavioural therapy (CBT) for the treatment of } \\
\text { juvenile fibromyalgia. This intervention is a revised version of } \\
\text { the Coping Skills Training program evaluated in Kashikar-Zuck } \\
\text { (2005) Parents received operant training with a focus on } \\
\text { encouraging independent pain management, maintaining a } \\
\text { normal routine, avoiding status checks and increasing their } \\
\text { child's use of coping skills learned in pe programme. Children } \\
\text { received education about behavioural pain management as well } \\
\text { as training in progressive muscle relaxation, distraction, activity } \\
\text { pacing, using self statements, problem solving and relapse } \\
\text { prevention strategies. }\end{array}$ & $\mathrm{CBT}$ \\
\hline Kazak 2004 Cancer & $\begin{array}{l}\text { Surviving Cancer Competently Intervention Programme } \\
\text { (SCCIP). Families received education about the link between } \\
\text { thoughts, feelings and behaviours and training in cognitive } \\
\text { restructuring. Families also participated in discussion groups } \\
\text { about the ways cancer has affected their family, recognising and } \\
\text { responding to distress in other family members, and } \\
\text { acknowledging and accepting their cancer experience. }\end{array}$ & CBT \\
\hline Laffel 2003 Diabetes & $\begin{array}{l}\text { Teamwork intervention. Parents and children received training } \\
\text { in communicating about diabetes and sharing blood glucose } \\
\text { results with family members, the need for teamwork between } \\
\text { parents end children in diabetes management during } \\
\text { adolescence, managing family members' responses to the child's } \\
\text { blood glucose levels, sharing diabetes management with family } \\
\text { members, and using a diary to help problem solve high and low } \\
\text { blood glucose levels. }\end{array}$ & FT \\
\hline Lask 1979 Asthma & $\begin{array}{l}\text { Family psychotherapy. This intervention aimed to improve the } \\
\text { psychological well-being of the family by focusing on attitudes } \\
\text { towards asthma and its treatment, fear of death and negative } \\
\text { emotions experienced by family members. }\end{array}$ & FT \\
\hline Lehmkuhl 2010 Diabetes & $\begin{array}{l}\text { Telehealth behavioural therapy. Using telephone contact, } \\
\text { families received diabetes education in addition to training in } \\
\text { specific skills targeting diabetes care and family functioning, } \\
\text { including problem solving, behavioural contracting, } \\
\text { communication skills, cognitive restructuring and family } \\
\text { structuring. }\end{array}$ & FT \\
\hline $\begin{array}{l}\text { Levy } 2010 \text { Painful condition } \\
\text { (FAP) }\end{array}$ & $\begin{array}{l}\text { Social learning and cognitive behavioural therapy. Children } \\
\text { and parents received pain education in addition training in deep } \\
\text { breathing, progressive muscle relaxation, imagery, operant }\end{array}$ & CBT \\
\hline
\end{tabular}




\begin{tabular}{|c|c|c|}
\hline Author & Therapy summary & Therapy type \\
\hline & $\begin{array}{l}\text { strategies, cognitive restructuring and relapse prevention } \\
\text { strategies. }\end{array}$ & \\
\hline Na 2008 Asthma & $\begin{array}{l}\text { We Together-We success Parallel Group for Children with } \\
\text { Asthma and their Parents (WTWS). Parents and children } \\
\text { received asthma education and discuss issues regarding mutual } \\
\text { respect between family members, psychosocial factors that may } \\
\text { impact asthma symptoms, applying concepts from traditional } \\
\text { Chinese medicine to asthma management, and fostering the } \\
\text { child's independence. }\end{array}$ & FT \\
\hline $\begin{array}{l}\text { Niebel } 2000 \text { Skin Diseases } \\
\text { (Eczema) }\end{array}$ & $\begin{array}{l}\text { Direct parental education in groups. Parents received asthma } \\
\text { education and training in operant strategies, scratch-control } \\
\text { techniques, stress management, progressive muscle relaxation, } \\
\text { how to poach their children in using progressive muscle } \\
\text { relaxation, how to conduct social skills training L/ith their } \\
\text { children and relapse prevention. Children did not participate in } \\
\text { the intervention. }\end{array}$ & CBT \\
\hline $\begin{array}{l}\text { Palermo } 2009 \text { Painful condition } \\
\text { (Mixed pain conditions) }\end{array}$ & $\begin{array}{l}\text { Web-based Management of Adolescent Pain (Web-MAP). } \\
\text { Using an internet program, parents received education about } \\
\text { chronic pain and training in recognising stress and negative } \\
\text { emotions, operant strategies, modelling, sleep hygiene and } \\
\text { lifestyle, communication and relapse prevention. Children } \\
\text { received education about chronic pain and training in } \\
\text { recognising stress and negative emotions, deep breathing and } \\
\text { relaxation, distraction, cognitive skills, sleep hygiene and } \\
\text { lifestyle, staying active and relapse prevention. }\end{array}$ & CBT \\
\hline $\begin{array}{l}\text { Robins } 2005 \text { Painful condition } \\
\text { (RAP) }\end{array}$ & $\begin{array}{l}\text { Short-term cognitive behavioural therapy. Children and } \\
\text { parents received education about pain and stress as well as } \\
\text { training in deep breathing, imagery, relaxation and operant } \\
\text { strategies. Children also training in tracking the antecedents and } \\
\text { consequences of pain episodes and cognitive restructuring. }\end{array}$ & CBT \\
\hline $\begin{array}{l}\text { Sanders } 1994 \text { Painful condition } \\
\text { (RAP) }\end{array}$ & $\begin{array}{l}\text { Cognitive-behavioural family intervention. Parents received } \\
\text { education about behavioural pain management, operant training } \\
\text { and relapse prevention. Children received education about } \\
\text { behavioural pain management, muscle relaxation, deep } \\
\text { breathing, imagery, cognitive restructuring, distraction and } \\
\text { relapse prevention. }\end{array}$ & CBT \\
\hline Sahler 2002 Cancer & $\begin{array}{l}\text { Problem solving skills training. Mothers received problem } \\
\text { solving training using the Bright IDEAS framework: Be } \\
\text { optimistic about solving problems, Identify the problem, } \\
\text { Determine options, Evaluate options and choose one, Act and } \\
\text { See if it worked. Children did not receive any intervention. }\end{array}$ & PST \\
\hline Sahler 2005 Cancer & Problem solving skills training. See Sahler 2002 above. & PST \\
\hline Seid 2010 Asthma & $\begin{array}{l}\text { Problem solving skills training + care co-ordination. Parents } \\
\text { received in-home asthma education, referrals to community } \\
\text { resources, co-ordination with medical providers and problem } \\
\text { solving training using the Bright IDEAS framework (see Sahler } \\
2002 \text { above). Children did not receive any intervention. }\end{array}$ & PST \\
\hline Stehl 2009 Cancer & $\begin{array}{l}\text { Surviving Cancer Competently Intervention Programme - } \\
\text { Newly diagnosed (SCCIP-ND). Parents received education } \\
\text { about the link between thoughts, feelings and behaviours, } \\
\text { training in cognitive restructuring, and discussion of beliefs } \\
\text { about the role cancer will play in the family's future. Parents } \\
\text { also watched a CD-ROM of other parents of children with } \\
\text { cancer discussing their experiences and responses to diagnosis. } \\
\text { Children did not receive any intervention. }\end{array}$ & CBT \\
\hline Wade 2006 TBI & $\begin{array}{l}\text { Family problem solving intervention. Families received } \\
\text { problem solving training using the ABCDE framework (Aim, } \\
\text { Brainstorm, Choose, Do It and Evaluate) and were encouraged } \\
\text { to have a positive attitude towards problem solving. Families } \\
\text { also received education on the effects of TBI on child } \\
\text { functioning as well as training in behavioural management, } \\
\text { communication skills and handling crises. }\end{array}$ & PST \\
\hline Wade 2006b TBI & $\begin{array}{l}\text { Family problem solving intervention. Using an internet } \\
\text { program and videoconferencing, families received training in }\end{array}$ & PST \\
\hline
\end{tabular}




\begin{tabular}{|l|l|l|}
\hline Author & Therapy summary & Therapy type \\
\hline & $\begin{array}{l}\text { problem solving, communication, behaviour management skills } \\
\text { and relapse prevention. Families could also complete } \\
\text { supplemental sessions if needed on stress management, working } \\
\text { with the school, sibling concerns, anger management, pain } \\
\text { management and marital communication. }\end{array}$ & \\
\hline Wade 2011 TBI & $\begin{array}{l}\text { Teen Online Problem Solving (TOPS). Using an internet } \\
\text { program and videoconferencing, families received training in } \\
\text { stress management, problem solving, planning and organisation, } \\
\text { communication and self regulation. Families could also } \\
\text { complete supplemental sessions if needed on stress } \\
\text { management, self care, marital communication, memory } \\
\text { difficulties, planning for after high school graduation, sibling } \\
\text { concerns, pain management and communication between teens } \\
\text { and parents. }\end{array}$ & PST \\
\hline Wysocki 1999 Diabetes & $\begin{array}{l}\text { Behavioural Family Systems Therapy (BFST). Families } \\
\text { received training in problem solving skills, communication } \\
\text { skills and cognitive restructuring as well as functional and } \\
\text { structural family therapy interventions targeting family systems } \\
\text { issues that may have interfered with effective problem solving } \\
\text { and communication skills. }\end{array}$ & FT \\
\hline Wysocki 2006 Diabetes & $\begin{array}{l}\text { Behavioural Family Systems Therapy for Diabetes (BFST- } \\
\text { D). This intervention is a revised version of the BFST } \\
\text { intervention evaluated in Wysocki 1999. Families received } \\
\text { training in problem solving, communication skills and cognitive } \\
\text { restructuring as well as functional and structural family therapy } \\
\text { interventions targeting family systems issues related to effective } \\
\text { problem solving and communication. Diabetes-specific } \\
\text { adaptations included targeting two or more barriers to diabetes } \\
\text { management in treatment, training in behavioural contracting, } \\
\text { education in how to improve diabetic control based on data } \\
\text { from self monitoring of blood glucose levels, simulation of } \\
\text { living with diabetes by parents for 1 week, and involvement of } \\
\text { peers/teachers/extended family in treatment as needed. }\end{array}$ & FT \\
\hline
\end{tabular}

BFST-D: Behavioural Family Systems Therapy for Diabetes; CBT: cognitive behavioural therapy; FT: family therapy; MST: multisystemic therapy; PST: problem solving therapy; TBI: traumatic brain injury 


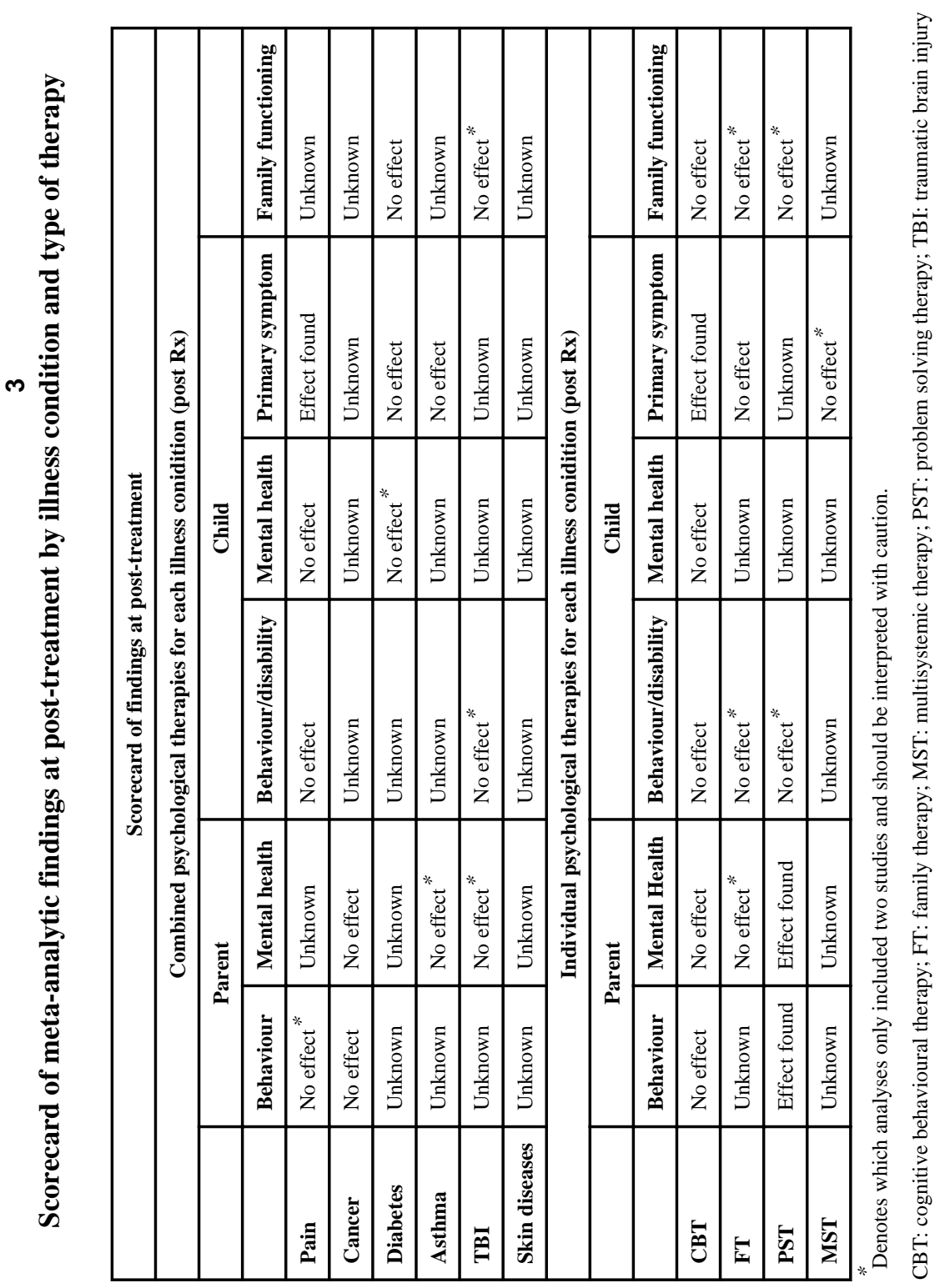

Cochrane Database Syst Rev. Author manuscript; available in PMC 2013 August 15. 


\section{Feedback: Appendices}

\section{MEDLINE search strategy}

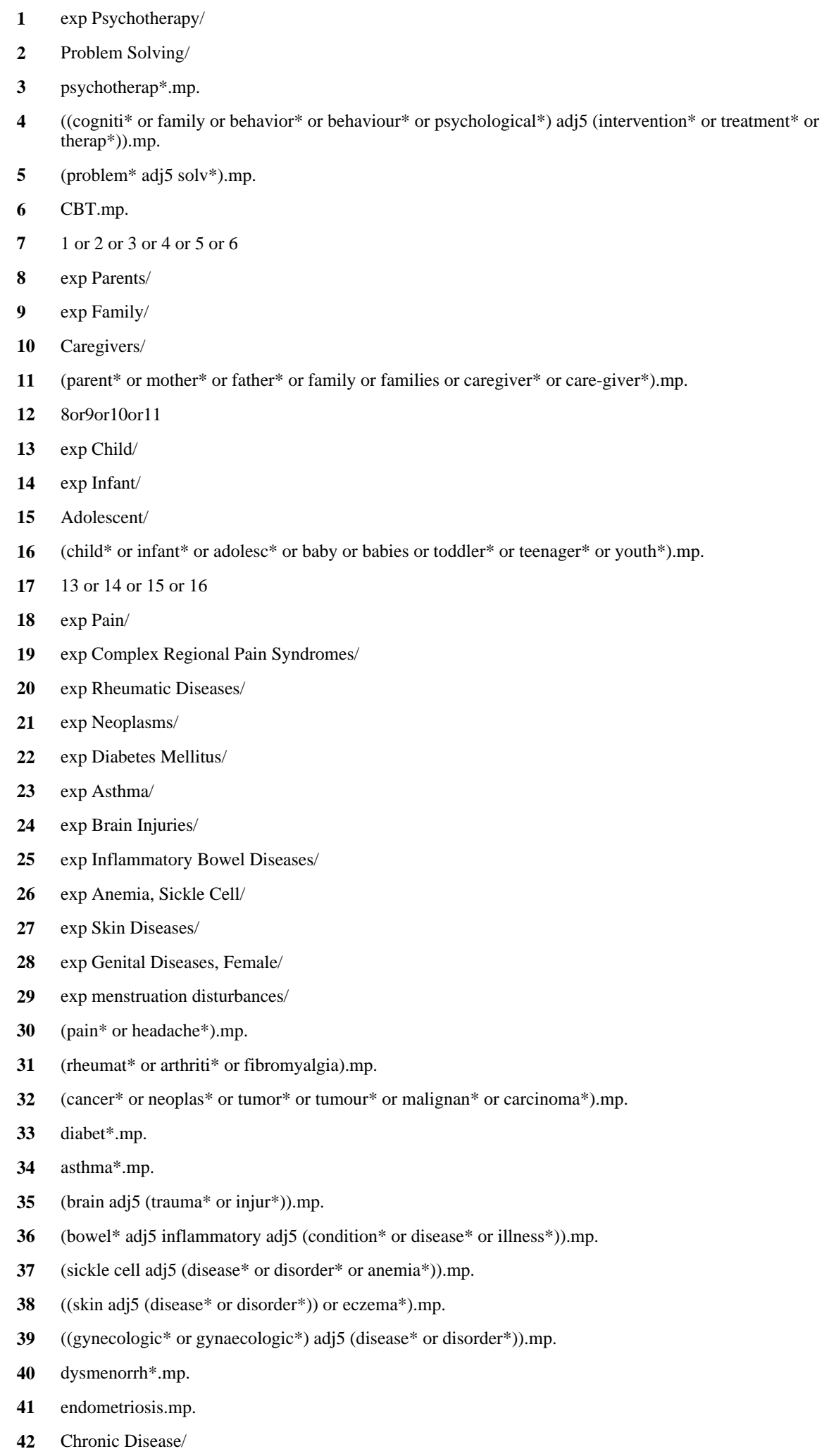




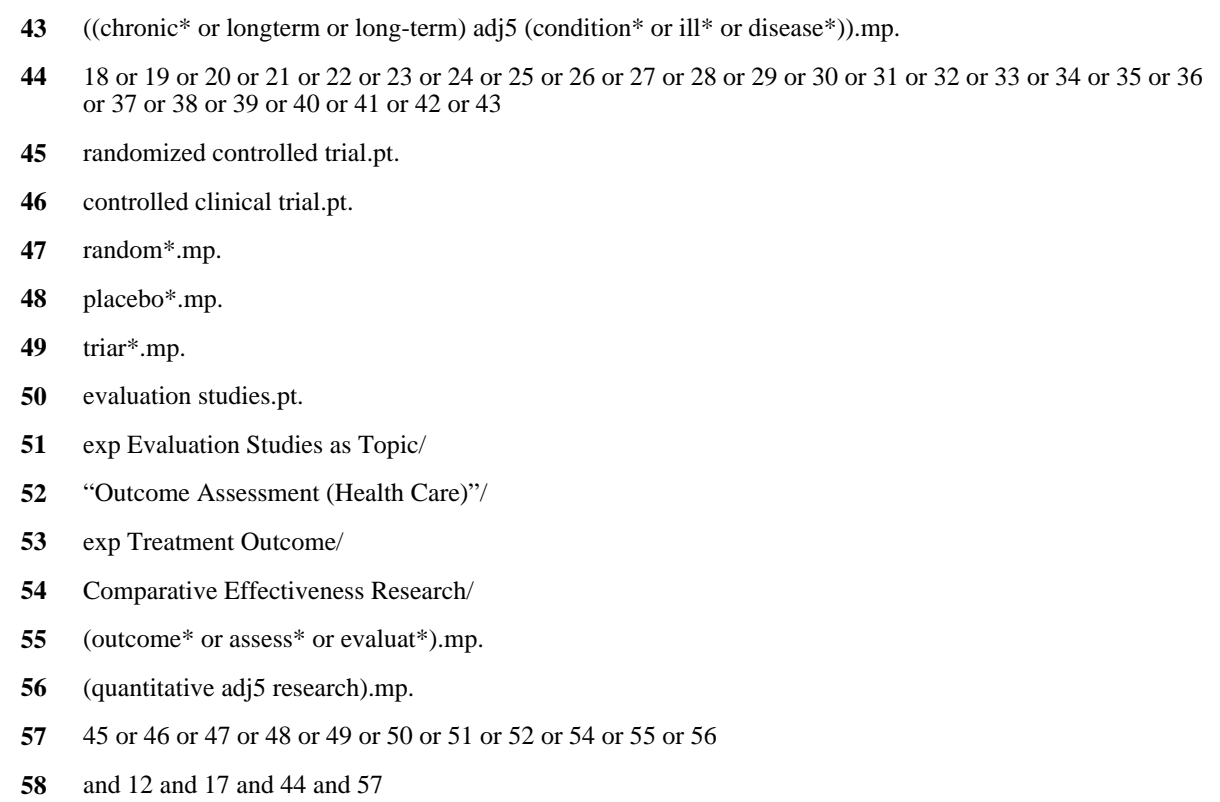

Key: $\mathrm{mp}=$ protocol supplementary concept, rare disease supplementary concept, title, original title, abstract, name of substance word, subject heading word, unique identifier, $\mathrm{pt}=$ publication type

\section{Other search strategies}

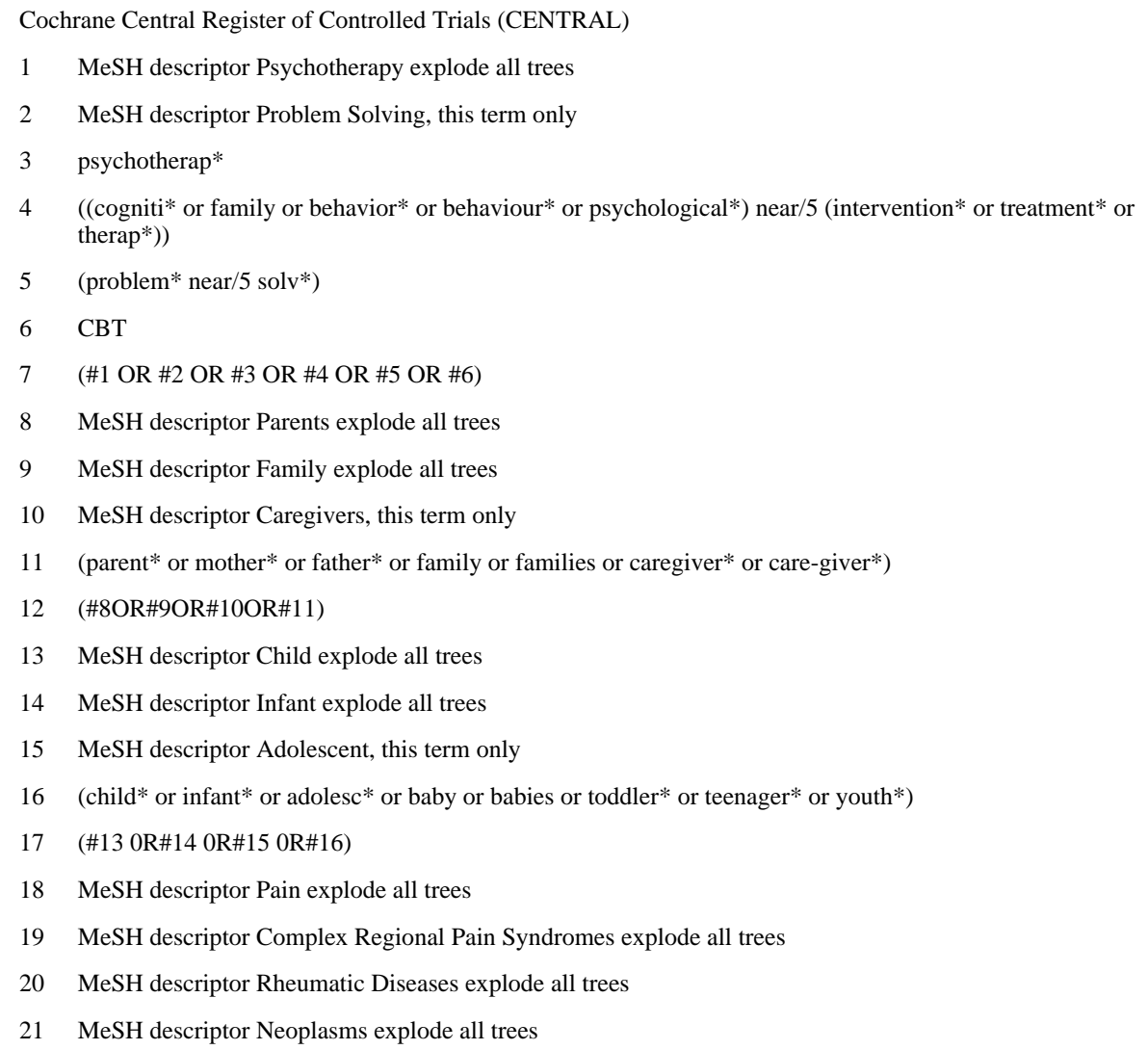


MeSH descriptor Diabetes Mellitus explode all trees

MeSH descriptor Asthma explode all trees

MeSH descriptor Brain Injuries explode all trees

MeSH descriptor Inflammatory Bowel Diseases explode all trees

MeSH descriptor Anemia, Sickle Cell explode all trees

MeSH descriptor Skin Diseases explode all trees

MeSH descriptor Genital Diseases, Female explode all trees

MeSH descriptor Menstruation Disturbances explode all trees

(pain* or headache*)

(rheumat* or arthriti* or fibromyalgia)

(cancer* or neoplas* or tumor* or tumour* or malignan* or carcinoma*)

diabet*

asthma*

(brain near/5 (trauma* or injur*))

(bowel* near/5 inflammatory near/5 (condition* or disease* or illness*))

(sickle cell near/5 (disease* or disorder* or anemia*))

((skin near/5 (disease* or disorder*)) or eczema*)

((gynecologic* or gynaecologic*) near/5 (disease* or disorder*))

dysmenorrh*

endometriosis

MeSH descriptor Chronic Disease, this term only

((chronic* or longterm or long-term) near/5 (condition* or ill* or disease*))

(\#18 OR \#19 OR \#20 OR \#21 OR \#22 OR \#23 OR \#24 OR \#25 OR \#26 OR \#27 OR \#28 OR \#29 OR \#30 OR \#31 OR \#32 OR \#33 OR \#34 OR \#35 OR \#36 OR \#37 OR \#38 OR \#39 OR \#40 OR \#41 OR \#42 OR \#43)

(\#7 AND \#12 AND \#17 AND \#44)

\section{EMBASE via Ovid}

exp psychotherapy/

exp problem solving/

psychotherap*.mp.

((cogniti* or family or behavior* or behaviour* or psychological*) adj5 (intervention* or treatment* or therap*)).mp.

5 (problem* adj5 solv*).mp.

6 CBT.mp.

$7 \quad 1$ or 2 or 3 or 4 or 5 or 6

8 exp parent/

9 exp family/

10 exp caregiver/

11 (parent* or mother* or father* or family or families or caregiver* or care-giver*).mp.

128 or 9 or 10 or 11

13 exp child/

14 exp infant/

5 exp adolescent/

16 (child* or infant* or adolesc* or baby or babies or toddler* or teenager* or youth*).mp.

17 13or14or15or 16

18 exp pain/

19 exp complex regional pain syndrome/

Cochrane Database Syst Rev. Author manuscript; available in PMC 2013 August 15. 

therap*)).mp.

6 (problem* adj5 solv*).mp.

7 CBT.mp.

exp rheumatic disease/

exp neoplasm/

exp diabetes mellitus/

exp asthma/

exp brain injury/

exp enteritis/

exp sickle cell anemia/

exp skin disease/

exp gynecologic disease/

exp menstruation disorder/

(pain* or headache*).mp

(rheumat* or arthriti* or fibromyalgia).mp.

(cancer* or neoplas* or tumor* or tumour* or malignan* or carcinoma*).mp.

diabet*.mp

asthma*.mp.

(brain adj5 (trauma* or injur*)).mp.

(bowel* adj5 inflammatory adj5 (condition* or disease* or illness*)).mp.

(sickle cell adj5 (disease* or disorder* or anemia*)).mp.

((skin adj5 (disease* or disorder*)) or eczema*).mp.

((gynecologic* or gynaecologic*) adj5 (disease* or disorder*)).mp.

dysmenorrh*.mp.

endometriosis.mp.

exp chronic disease/

((chronic* or longterm or long-term) adj5 (condition* or ill* or disease*)).mp.

or 19 or 20 or 21 or 22 or 23 or 24 or 25 or 26 or 27 or 28 or 29 or 30 or 31 or 32 or 33 or 34 or 35 or 36 or 37 or 38 or 39 or 40 or 41 or 42 or 43

exp controlled clinical trial/

random*.mp.

trial*.mp.

placebo*.mp.

exp evaluation/

exp treatment outcome/

exp comparative effectiveness/

(outcome* or assess* or evaluat*).mp.

(quantitative adj5 research).mp.

45 or 46 or 47 or 48 or 49 or 50 or 51 or 52 or 53

7 and 12 and 17 and 44 and 54

\section{PsyclNFO via Ovid}

exp psychotherapy/

exp family therapy/

exp problem solving/

psychotherap*.mp.

cogniti* or family or behavior* or behaviour* or psychological*) adj5 (intervention* or treatment* or$$
\text { (1) }
$$

Cochrane Database Syst Rev. Author manuscript; available in PMC 2013 August 15. 
1 or 2 or 3 or 4 or 5 or 6 or 7

exp Parents/

exp Family/

exp Caregivers/

(parent* or mother* or father* or family or families or caregiver* or care-giver*).mp.

9 or 10 or 11 or 12

(child* or infant* or adolesc ${ }^{*}$ or baby or babies or toddler* or teenager* or youth*).mp.

exp pain/

exp Rheumatoid Arthritis/

exp Neoplasms/

exp Diabetes Mellitus/

exp Asthma/

exp traumatic brain injury/

exp Sickle Cell Disease/

exp skin disorders/

exp gynecological disorders/

(pain* or headache*).mp.

(rheumat* or arthriti* or fibromyalgia).mp.

(cancer* or neoplas* or tumor* or tumour* or malignan* or carcinoma*).mp.

diabet*.mp.

asthma*.mp.

(brain adj5 (trauma* or injur*)).mp.

(bowel* adj5 inflammatory adj5 (condition* or disease* or illness*)).mp.

( sickle cell adj5 (disease* or disorder* or anemia*)).mp.

((skin adj5 (disease* or disorder*)) or eczema*).mp.

((gynecologic* or gynaecologic*) adj5 (disease* or disorder*)).mp.

dysmenorrh*.mp.

endometriosis.mp.

((chronic* or longterm or long-term) adj5 (condition* or ill* or disease*)).mp.

15 or 16 or 17 or 18 or 19 or 20 or 21 or 22 or 23 or 24 or 25 or 26 or 27 or 28 or 29 or 30 or 31 or 32 or 33 or 34 or 35 or 36

exp Clinical Trials/

random*.mp.

placebo*.mp

trial*.mp.

exp treatment outcomes/

(outcome* or assess* or evaluat*).mp.

(quantitative adj5 research).mp.

38 or 39 or 40 or 41 or 42 or 43 or 44

8 and 13 and 14 and 37 and 45

\section{References to studies}

Included studies

Allen KD, Shriver MD. Role of parent-mediated pain behavior management strategies in biofeedback treatment of childhood migraines. Behaviour Therapy. 1998; 29:477-90. 
*. Ambrosino JM, Fennie K, Whittemore R, Jaser S, Dowd MF, Grey M. Short-term effects of coping skills training in school-age children with type 1 diabetes. Pediatric Diabetes. 2008; 9:74-82. [PubMed: 18540868]

Grey M, Whittermore R, Jaser S, Ambrosino J, Lindemann E, Liberti L, et al. Effects of coping skills training in school-age children with type 1 diabetes. Research in Nursing \& Health. 2009; 32:40518. [PubMed: 19488997]

Askins MA, Sahler OJ, Sherman SA, Fairclough DL, Butler RW, Katz ER, et al. Report from a multiinstitutional randomized clinical trial examining computer-assisted problem-solving skills training for English- and Spanish-speaking mothers of children with newly diagnosed cancer. Journal of Pediatric Psychology. 2008; 34(5):551-63. [PubMed: 19091804]

Barakat LP, Schwartz LA, Salaom KS, Radcliffe J. A family-based randomized controlled trial of pain intervention for adolescents with sickle cell disease. Journal of Pediatric Hematology Oncology. 2010; 32(7):540-7.

Barry J, von Baeyer CL. Brief cognitive-behavioral group treatment for child's headache. Clinical Journal of Pain. 1997; 13(3):215-20. [PubMed: 9303253]

Celano MP, Holsey CN, Kobrynski LJ. Home-based family intervention for low-income children with asthma: a randomized controlled pilot study. Journal of Family Psychology. 2012:1-8. Advance online publication. [PubMed: 22040353]

Connelly M, Rapoff MA, Thompson N, Connelly W. Headstrong: a pilot study of a CD-ROM intervention for recurrent pediatric headache. Journal of Pediatric Psychology. 2006; 31(7):737-47. [PubMed: 16861397]

Duarte MA, Penna FJ, Andrade EMG, Cancela CSP, Neto JCA, Barbosa TF. Treatment of nonorganic recurrent abdominal pain: cognitive-behavioral family intervention. Journal of Pediatric Gastroenterology and Nutrition. 2006; 43(1):59-64. [PubMed: 16819378]

Ellis DA, Naar-King S, Frey M, Templin T, Rowland M, Greger N. Use of multisystemic therapy to improve regimen adherence among adolescents with type 1 diabetes in poor metabolic control: a pilot investigation. Journal of Clinical Psychology in Medical Settings. 2004; 11(4):315-24.

*. Ellis DA, Frey MA, Naar-King S, Templin T, Cunningham P, Cakan N. The effects of multisystemic therapy on diabetes stress among adolescents with chronically poorly controlled type 1 diabetes: findings from a randomized, controlled trial. Pediatrics. 2005; 116(6):e826-32. [PubMed: 16322140]

Ellis DA, Frey MA, Naar-King S, Templin T, Cunningham P, Cakan N. Use of multisystemic therapy to improve regimen adherence among adolescents with type 1 diabetes in chronic poor metabolic control. Diabetes Care. 2005; 28(7):1604-10. [PubMed: 15983308]

Ellis DA, Templin T, Naar-King S, Frey MA, Cunningham PB, Podolski CL, et al. Multisystemic therapy for adolescents with poorly controlled type 1 diabetes: stability of treatment effects in a randomized controlled trial. Journal of Consulting and Clinical Psychology. 2007; 75(1):168-74. [PubMed: 17295576]

Ellis DA, Yopp J, Templin T, Naar-King S, Frey MA, Cunningham PB, et al. Family mediators and moderators of treatment outcomes among youths with poorly controlled type 1 diabetes: results from a randomized controlled trial. Journal of Pediatric Psychology. 2007; 32(2):194-205. [PubMed: 16675714]

Naar-King S, Ellis DA, Idalski A, Frey MA, Cunningham P. Multisystemic therapy decreases parental overestimation of adolescent responsibility for type 1 diabetes management in urban youth. Families, Systems \& Health. 2007; 25(2):178-89.

Grey M, Jaser SS, Whittemore R, Jeon S, Lindemann E. Coping skills training for parents of children with type 1 diabetes. Nursing Research. 2011; 60(3):173-81. [PubMed: 21522034]

Hicks CL, von Baeyer CL, McGrath PJ. Online psychological treatment for pediatric recurrent pain: a randomized evaluation. Journal of Pediatric Psychology. 2006; 31(7):724-36. [PubMed: 16093516]

Hoekstra-Weebers JEHM, Heuvel F, Jaspers JPC, Kamps WA, Klip EC. Brief report: an intervention program for parents of pediatric cancer patients: a randomized controlled trial. Journal of Pediatric Psychology. 1998; 23(3):207-14. [PubMed: 9640900] 
Kashikar-Zuck S, Swain N, Jones BA, Graham TB. Efficacy of cognitive-behavioral intervention for juvenile primary fibromyalgia syndrome. Journal of Rheumatology. 2005; 32(8):1594-602. [PubMed: 16078340]

Kashikar-Zuck S, Ting TV, Arnold LM, Bean J, Powers SW, Graham TB, et al. Cognitive behavioral therapy for the treatment of juvenile fibromyalgia. Arthritis and Rheumatism. 2012; 64(1):297305. [PubMed: 22108765]

Kazak AE, Alderfer MA, Streisand R, Simms S, Rourke MT, Barakat LP, et al. Treatment of posttraumatic stress symptoms in adolescent survivors of childhood cancer and their families: a randomized clinical trial. Journal of Family Psychology. 2004; 18(3):493-504. [PubMed: 15382974]

Laffel LMB, Vangsness L, Connell A, Goebel-Fabbri A, Butler D, Anderson BJ. Impact of ambulatory, family-focused teamwork intervention on glycemic control in youth with type 1 diabetes. Journal of Pediatrics. 2003; 142:409-16. [PubMed: 12712059]

Lask B, Matthew D. Childhood asthma. A controlled trial of family psychotherapy. Archives of Disease in Childhood. 1979; 54(2):116-9. [PubMed: 373642]

Lehmkuhl HD, Storch EA, Cammarata C, Meyer K, Rahman O, Silverstein J, et al. Telehealth behavior therapy for the management of type 1 diabetes in adolescents. Journal of Diabetes Science and Technology. 2010; 4(1):199-208. [PubMed: 20167185]

Levy RL, Langer SL, Walker LS, Romano JM, Christie DL, Youssef N, et al. Cognitive-behavioral therapy for children with functional abdominal pain and their parents decreases pain and other symptoms. American Journal of Gastroenterology. 2010; 105(4):946-56. [PubMed: 20216531]

Ng SM, Li AM, Lou WVQ, Tso IF, Wan PYP, Chan DFY. Incorporating family therapy into asthma group intervention: a randomized waitlist-controlled trial. Family Process. 2008; 47(1):115-30. [PubMed: 18411833]

Niebel G, Kallweit C, Lange I, Folster-Holst R. Direct versus video-aided parent education in atopic eczema in childhood as a supplement to specialty physician treatment. A controlled pilot study [Direkte versus videover-mittelte elternschulung bei atopishchem ekzem in kinderslater als erganzung facharztlicher behandlung: eine kontrollierte pilotstudie]. Hautarzt. 2000; 51:401-11. [PubMed: 10907154]

Olivares J, Mendez FX, Ros M, Bermejo RM. Effects of a training program for parents with diabetic children with obstacles to comply with therapy [El cuidado de la diabetes mellitus insulinodependiente: Efectos de un programa de modificacion de conducta en padres]. Psicologia Conductual. 1997; 5(2):219-35.

Palermo TM, Wilson AC, Peters M, Lweandowski A, Somhegyi H. Randomized controlled trial of an Internet delivered family cognitive behavioral therapy intervention for children and adolescents with chronic pain. Pain. 2009; 146(1-2):205-13. [PubMed: 19695776]

Robins PM, Smith SM, Glutting JJ, Bishop CT. A randomized controlled trial of a cognitivebehavioral family intervention for pediatric recurrent abdominal pain. Journal of Pediatric Psychology. 2005; 30(5):397-408. [PubMed: 15944167]

Sahler OJZ, Varni JW, Fairclough DL, Butler RW, Noll RB, Dolgin MJ, et al. Problem-solving skills training for mothers of children with newly diagnosed cancer: a randomized trial. Developmental and Behavioural Pediatrics. 2002; 23(2):77-86.

Sahler OJZ, Fairclough DL, Phipps S, Mulhern RK, Dolgin MJ, Noll RB, et al. Using problem-solving skills training to reduce negative affectivity in mothers of children with newly diagnosed cancer: Report of a multisite randomized trial. Journal of Consulting and Clinical Psychology. 2005; 73(2):272-83. [PubMed: 15796635]

Sandes MR, Shepherd RW, Cleghorn G, Woolford H. The treatment of recurrent abdominal pain in children: a controlled comparison of cognitive-behavioral family intervention and standard pediatric care. Journal of Consulting and Clinical Psychology. 1994; 62(2):306-14. [PubMed: 8201068]

Seid M, Varni JW, Gidwani P, Gelhard LR, Slymen DJ. Problem-solving skills training for vulnerable families of children with persistent asthma: report of a randomized trial on health-related quality of life outcomes. Journal of Pediatric Psychology. 2010; 35(10):1133-43. [PubMed: 20061311] 
Stehl ML, Kazak AE, Alderfer MA, Rodriguez A, Hwang WT, Pai ALH, et al. Conducting a randomized clinical trial of an psychological intervention for parents/caregivers of children with cancer shortly after diagnosis. Journal of Pediatric Psychology. 2009; 34(8):803-16. [PubMed: 19091806]

Wade SL, Michaud L, Brown TM. Putting the pieces together: preliminary efficacy of a family problem-solving intervention for children with traumatic brain injury. Journal of Head Trauma Rehabilitation. 2006; 21(1):59-67.

Wade SL, Carey J, Wolfe CR. An online family intervention to reduce parental distress following pediatric brain injury. Journal of Consulting and Clinical Psychology. 2006; 74(3):445-54. [PubMed: 16822102]

Wade SL, Carey J, Wolfe CR. The efficacy of an online cognitive-behavioral family intervention in improving child behavior and social competence following pediatric brain injury. Rehabilitation Psychology. 2006; 51(3):179-89.

Wade SL, Walz NC, Carey J, McMullen KM, Cass J, Mark E, et al. Effect on behavior problems of teen online problem-solving for adolescent traumatic brain injury. Pediatrics. 2011; 128(4):e94753. [PubMed: 21890828]

Wysocki T, Greco P, Harris MA, Bubb J, White NH. Behavior therapy for families of adolescents with diabetes: maintenance of treatment effects. Diabetes Care. 2001; 24:441-6. [PubMed: 11289465]

Wysocki T, Harris MA, Greco P, Bubb J, Danda CE, Harvey LM, et al. Randomized, controlled trial of behavior therapy for families of adolescents with insulin-dependent diabetes mellitus. Journal of Pediatric Psychology. 2000; 25(1):23-33. [PubMed: 10826241]

Wysocki T, Miller KM, Greco P, Harris MA, Harvey LM, Taylor A, et al. Behavior therapy for families of adolescents with diabetes: effects on directly observed family interactions. Behavior Therapy. 1999; 30:507-25.

Wysocki T, Harris MA, Buckloh LM, Mertlich D, Lochrie AS, Mauras N, et al. Randomized trial of behavioral family systems therapy for diabetes: maintenance of effects on diabetes outcomes in adolescents. Diabetes Care. 2007; 30:555-60. [PubMed: 17327320]

Wysocki T, Harris MA, Buckloh LM, Mertlich D, Lochrie AS, Taylor A, et al. Effects of behavioral family systems therapy for diabetes on adolescents' family relationships, treatment adherence, and metabolic control. Journal of Pediatric Psychology. 2006; 31(9):928-38. [PubMed: 16401678]

Wysocki T, Harris MA, Buckloh LM, Mertlich D, Lochrie AS, Taylor A, et al. Randomized, controlled trial of behavioral family systems therapy for diabetes: maintenance and generalization of effects on parent-adolescent communication. Behavior Therapy. 2008; 39:33-46. [PubMed: $18328868]$

\section{Excluded studies}

Aleman Mendez S, Palacios AS. An integrated approach to the psychological features of the asthmatic child [Un adordaje integral de los aspectos psicologicos del nino asmatico]. Allergologia et Immunopathologia. 1992; 20:240-5. [PubMed: 1296466]

Anderson BJ, Ho J, Brackett J, Laffel LMB. An office-based intervention to maintain parentadolescent teamwork in diabetes management: impact on parent involvement, family conflict, and subsequent glycemic control. Diabetes Care. 1999; 22(7):713-21. [PubMed: 10332671]

Betancourt GP, Gutierrez de Pineres Scarpetta C. Psychological intervention pre-postsurgical program for cardiovascular pediatric patients. Saludarte. 2004; 3(11):19-34.

Braga L, Da Paz A Junior, Ylvisaker M. Direct clinician-delivered versus indirect family-supported rehabilitation of children with traumatic brain injury: a randomized controlled trial. Brain Injury. 2005; 19(10):819-31. [PubMed: 16175842]

Bruzzese J, Unikel L, Gallagher R, Evans D, Colland V. Feasibility and impact of a school-based intervention for families of urban adolescents with asthma: results from a randomized pilot trial. Family Process. 2008; 47(1):95-113. [PubMed: 18411832]

Burke SO, Handley-Derry MH, Costello EA, Kauffmann E, Dillon MC. Stress-point intervention for parents of repeatedly hospitalized children with chronic conditions. Research in Nursing \& Health. 1997; 20(6):475-85. [PubMed: 9397127] 
Burke SO, Harrison MB, Kauffmann E, Wong C. Effects of stress-point intervention with families of repeatedly hospitalized children. Journal of Family Nursing. 2001; 7(2):128-58.

Cakan N, Ellis DA, Templin T, Frey M, Naar-King S. The effects of weight status on treatment outcomes in a randomized clinical trial of multisystemic therapy for adolescents with type 1 diabetes and chronically poor metabolic control. Pediatric Diabetes. 2007; 8:206-13. [PubMed: 17659062]

Canino G, Vila D, Normand ST, Acosta-Perez E, Ramirez R, Garcia P, et al. Reducing asthma health disparities in poor Puerto Rican children: the effectiveness of a culturally tailored family intervention. Journal of Allergy \& Clinical Immunology. 2008; 121(3):665-70. [PubMed: 18061648]

Carey JC, Wade SL, Wolfe CR. Lessons learned: the effect of prior technology use on web-based interventions. Cyber Psychology \& Behavior. 2008; 11(2):188-95.

Chernoff RG, Ireys HT, DeVet KA, Kim YJ. A randomized, controlled trial of a community-based support program for families of children with chronic illness: pediatric outcomes. Archives of Pediatrics and Adolescent Medicine. 2002; 156(6):533-9. [PubMed: 12038883]

Chiang L, Ma W, Huang J, Tseng L, Hsueh K. Effect of relaxation-breathing training on anxiety and asthma signs/symptoms of children with moderate-to-severe asthma: a randomized controlled trial. International Journal of Nursing Studies. 2009; 46(8):1061-70. [PubMed: 19246041]

Ellis DA, Naar-King S, Templin T, Frey MA, Cunningham PB. Improving health outcomes among youth with poorly controlled type 1 diabetes: the role of treatment fidelity in a randomized clinical trial of multisystemic therapy. Journal of Family Psychology. 2007; 21(3):363-71. [PubMed: 17874921]

Ellis D, Naar-King S, Templin T, Frey M, Cunningham P, Sheidow A, et al. Multisystemic therapy for adolescents with poorly controlled type 1 diabetes: reduced diabetic ketoacidosis admissions and related costs over 24 months. Diabetes Care. 2008; 31(9):1746-7. [PubMed: 18566340]

Evans R, Gergen PJ, Mitchell H, Kattan M, Kercsmar C, Crain E, et al. A randomized clinical trial to reduce asthma morbidity among inner-city children: results of the national cooperative inner-city asthma study. Journal of Pediatrics. 1999; 135(3):332-8. [PubMed: 10484799]

Field T, Henteleff T, Hernandez-Reif M, Martinez E, Mavunda K, Kuhn C, et al. Children with asthma have improved pulmonary functions after massage therapy. Journal of Pediatrics. 1998; 132(5): 854-8. [PubMed: 9602199]

Forsander G, Persson B, Sundelin J, Berglund E, Snellman K, Hellstom R. Metabolic control in children with insulin-dependent diabetes mellitus $5 \mathrm{y}$ after diagnosis. Early detection of patients at risk for poor metabolic control. Acta Paediatrica. 1998; 87:857-64. [PubMed: 9736234]

*. Forsander G. Family attitudes to different management regimens in diabetes mellitus. Practical Diabetes International. 1995; 12(2):80-5.

Forsander GA, Sundelin J, Persson B. Influence of the initial management regimen and family social situation on glycemic control and medical care in children with type I diabetes mellitus. Acta Paediatrica International Journal of Paediatrics. 2000; 89(12):1462-8.

Forsander GA, Sundelin J. Comparison of two therapeutic regimes for diabetes-stricken children Social and mental resources of the family are often crucial for the prognosis [Två behandlingsregimer vid diabetesdebut hos barn jämförda: Familjens sociala och mentalaresurser avöbr ofta prognosen]. Lakartidningen. 2001; 89:5484-9. [PubMed: 11769363]

Sundelin JG, Forsander G, Mattson SE. Family-oriented support at the onset of diabetes mellitus: a comparison of two group conditions during 2 years following diagnosis. Acta Paediatrica International Journal of Paediatrics. 1996; 85(1):49-55.

Forsander G, Malmodin B, Eklund C, Persson B. Relationship between dietary intake in children with diabetes mellitus type I, their management at diagnosis, social factors, anthropometry and glycaemic control. Scandinavian Journal of Nutrition/Naringsforskning. 2003; 47(2):75-84.

Garbutt JM, Banister C, Highstein G, Sterkel R, Epstein J, Bruns J, et al. Telephone coaching for parents of children with asthma: impact and lessons learned. Archives of Pediatrics and Adolescent Medicine. 2010; 164(7):625-30. [PubMed: 20603462]

Gerber W, Petermann F, Gerber-von Muller G, Dollwet M, Darabaneanu S, Niederberger U, et al. MIPAS-Family-evaluation of a new multi-modal behavioral training program for pediatric 
headaches: clinical effects and the impact on quality of life. Journal of Headache Pain. 2010; $11: 215-25$.

Gerber WD, Muller GG, Petermann U, Niederberger U, Petermann F. Do behavioral medicine approaches have an effect on the quality of life and everyday competence of children suffering from chronic headaches? [Verbessern verhaltensmedizinische behandlungsstrategien die lebensqualitat bei kindern mit chronischen kopfschmerzen?]. Zeitschrift fur Klinische Psychologie und Psychotherapie. 2009; 38(4):231-9.

Gerber WD, Petermann F, Muller G, Niederberger U, Rentmeister B, Siniatchkin M, et al. MIPASfamily: development and evaluation of a behavioural medicine programme for the treatment of chronic paediatric headaches. Verhaltenstherapie. 2008; 18(4):247-55.

Giallo R, Gavidia-Payne S. Evaluation of a family-based intervention for siblings of children with a disability or chronic illness. AeJAMH (Australian e-Journal for the Advancement of Mental Health). 2008; 7(2):1-13.

Glang A, McLaughlin K, Schroeder S. Using interactive multimedia to teach parent advocacy skills: an exploratory study. Journal of Head Trauma Rehabilitation. 2007; 22(3):196-203.

Gustafsson PA, Kjellman M, Cederblad M. Family therapy in the treatment of severe childhood asthma. Journal of Psychosomatic Research. 1986; 30(3):369-74. [PubMed: 2874221]

Harris MA, Greco P, Wysocki T, White TH. Family therapy with adolescents with diabetes: a litmus test for clinically meaningful change. Families, Systems \& Health. 2001; 19:159-68.

Haus BF, Thompson S. The effect of nursing intervention on a program of behavior modification by parents in the home. Journal of Psychiatric Nursing and Mental Health Services. 1976; 14(8):9-16. [PubMed: 59806]

Hernandez NE, Kolb S. Effects of relaxation on anxiety in primary caregivers of chronically ill children. Pediatric Nursing. 1998; 24(1):51-6. [PubMed: 9555445]

Hommel KA, Hente EA, Odell S, Herzer M, Ingerski LM, Guilfoyle SM, et al. Evaluation of a groupbased behavioral intervention to promote adherence in adolescents with inflammatory bowel disease. European Journal of Gastroenterology and Hepatology. 2012; 24(1):64-9. [PubMed: 21989119]

Hovell MF, Meltzer SB, Zakarian JM, Wahlgren DR, Emerson JA, Hofstetter CR, et al. Reduction of environmental tobacco smoke exposure among asthmatic children: a controlled trial. Chest. 1994; 106(2):440-6. [PubMed: 7774317]

Humphreys PA, Gevirtz RN. Treatment of recurrent abdominal pain: components analysis of four treatment protocols. Journal of Pediatric Gastroenterology and Nutrition. 2000; 31(1):47-51. [PubMed: 10896070]

Ireys HT, Sills EM, Kolodner KB, Walsh BB. A social support intervention for parents of children with juvenile rheumatoid arthritis: results of a randomized trial. Journal of Pediatric Psychology. 1996; 21(5):633-41. [PubMed: 8936893]

Ireys HT, Chernoff R, DeVet KA, Kim Y. Maternal outcomes of a randomized controlled trial of a community-based support program for families of children with chronic illnesses. Archives of Pediatrics and Adolescent Medicine. 2001; 155(7):771-7. [PubMed: 11434842]

Jay SM, Elliott CH. A stress inoculation program for parents whose children are undergoing painful medical procedures. Journal of Consulting and Clinical Psychology. 1990; 58(6):799-804. [PubMed: 2292629]

Johnson MR, Whitt JK, Martin B. The effect of fantasy facilitation of anxiety in chronically ill and healthy children. Journal of Pediatric Psychology. 1987; 12(2):273-84. [PubMed: 3612428]

Kamps JL, Rapoff MA, Roberts MC, Varela RE, Barnard M, Olson N. Improving adherence to inhaled corticosteroids in children with asthma: a pilot of a randomized clinical trial. Children's Health Care. 2008; 37(4):261-77.

Kaslow NJ, Collins MH, Rashid FL, Baskin ML, Griffith JR, Hollins L, et al. The efficacy of a pilot family psychoeducational intervention for pediatric sickle cell disease. Families, Systems, \& Health. 2000; 18(4):381-404.

Kazak AE, Penati B, Boyer BA, Himelstein B, Brophy P, Waibel K, et al. A randomized controlled prospective outcome study of a psychological and pharmacological intervention protocol for 
procedural distress in pediatric leukaemia. Journal of Pediatric Psychology. 1996; 21:615-31. [PubMed: 8936892]

Kazak AE, Simms S, Alderfer MA, Rourke MT, Crump T, McClure K, et al. Feasibility and preliminary outcomes from a pilot study of a brief psychological intervention for families of children newly diagnose with cancer. Journal of Pediatric Psychology. 2005; 30(8):644-55. [PubMed: 16260434]

Ketchen B, Hazzard A, Lassiter S, Barber N, Armistead L, Mentz R, et al. STARBRIGHT world: a pilot study of a home-based sickle cell psychoeducational intervention. Children's Health Care. 2006; 35(4):321-38.

Klinnert MD, Liu AH, Pearson MR, Ellison M, Budhiraja N, Robinson JL. Short-term impact of a randomized multifaceted intervention for wheezing infants in low-income families. Archives of Pediatric Adolescent Medicine. 2005; 159:75-82.

Klinnert MD, Liu AH, Pearson MR, Tong S, Strand M, Luckow A, et al. Outcome of a randomized multifaceted intervention with low-income families of wheezing infants. Archives of Pediatrics and Adolescent Medicine. 2007; 161(8):783-90. [PubMed: 17679661]

Kroner-Herwig B, Mohn U, Pothmann R. Comparison of biofeedback and relaxation in the treatment of pediatric headache and the influence of parent involvement on outcome. Applied Psychophysiology and Biofeedback. 1998; 23(3):143-57. [PubMed: 10384247]

Kupfer J, Gieler U, Diepgen TL, Fartasch M, Lob-Corzilius T, Ring J, et al. Structured education program improves the coping with atopic dermatitis in children and their parents - a multicenter, randomized controlled trial. Journal of Psychosomatic Research. 2010; 68(4):353-8. [PubMed: 20307702]

Lasecki K, Olympia D, Clark E, Jenson W, Heathfield LT. Using behavioral interventions to assist children with type 1 diabetes manage blood glucose levels. School Psychology Quarterly. 2008; 23(3):389-406.

Logan S. Emotionally focused therapy improves marital adjustment in parents of children with chronically ill children. Child: Care, Health and Development. 1997; 23(6):479-80.

Mendez FJ, Belendez M. Effects of a behavioral intervention on treatment adherence and stress management in adolescent with IDDM. Diabetes Care. 1997; 20(9):1370-5. [PubMed: 9283782]

Nelson KA, Highstein GR, Garbutt J, Trinkaus K, Fisher E, Smith SR, et al. A randomized controlled trial of parental asthma coaching to improve outcomes among urban minority children. Archives of Pediatric Adolescent Medicine. 2011; 165(6):520-6.

Perez MG, Feldman L, Caballero F. Effects of a self-management educational program for the control of childhood asthma. Patient Education and Counseling. 1999; 36:47-55. [PubMed: 10036559]

Rasoli R, Etemadi A, Shafidabadi A, Delavar A. Comparing effectiveness of individual and marital emotionally focused intervention based on decreasing relationship distress of couples with chronically ill children. Journal of Family Research. 2008; 3(3):683-96.

Sanders MR, Rebgetz M, Morrison M, Bor W, Gordon A, Dadds M, et al. Cognitive-behavioral treatment of recurrent nonspecific abdominal pain in children: an analysis of generalization, maintenance, and side effects. Journal of Consulting and Clinical Psychology. 1989; 57(2):294300. [PubMed: 2708618]

Sanders MR, Cleghorn G, Shepherd RW, Patrick M. Predictors of clinical improvement in children with recurrent abdominal pain. Behavioural and Cognitive Psychotherapy. 1996; 24:27-38.

Satin W, La Greca AM, Zigo MA, Skyler JS. Diabetes in adolescence: effects of multifamily group intervention and parent simulation of diabetes. Journal of Pediatric Psychology. 1989; 14(2):25975. [PubMed: 2754576]

Scholten L, Willemen AM, Grootenhuis MA, Maurice-Stam H, Schuengel C, Last BF. A cognitive behavioral based group intervention for children with a chronic illness and their parents: a multicentre randomized controlled trial. BMC Pediatrics. 2011; 11(65):1-8. [PubMed: 21214908]

Sieberg CB, Flannery-Schroeder E, Plante W. Children with co-morbid recurrent abdominal pain and anxiety disorders: results from a multiple-baseline intervention study. Journal of Child Health Care. 2011; 15(2):126-39. [PubMed: 21685228] 
Staab D, van Rueden U, Kehrt R, Erhart M, Wenninger K, Kamtsiuris P, et al. Evaluation of a parental training program for the management of childhood atopic dermatitis. Pediatric Allergy and Immunology. 2002; 13(2):84-90. [PubMed: 12000479]

Sullivan-Bolyai S, Bova C, Leung K, Trudeau A, Lee M, Gruppuso P. Social support to empower parents (STEP): an intervention for parents of young children newly diagnosed with type 1 diabetes. The Diabetes Educator. 2010; 36(1):88-97. [PubMed: 20016058]

Szczepanski R, Jaeschke R, Spindler T, Ihorst G, Forster J, ASEV Study Group. Preschoolers' and parents' asthma education trial (P2AET) - a randomized controlled study. European Journal of Pediatrics. 2010; 169(9):1051-60. [PubMed: 20300774]

Wade SL, Walz NC, Carey J, Williams KM, Cass J, Herren L, et al. A randomized trial of teen online problem solving for improving executive function deficits following pediatric traumatic brain injury. Journal of Head Trauma Rehabilitation. 2010; 25(6):409-15. [PubMed: 21076241]

Walders N, Kercsmar C, Schluchter M, Redline S, Lester Kirchner H, Drotar D. An interdisciplinary intervention for undertreated pediatric asthma. Chest. 2006; 129(2):292-9. [PubMed: 16478844]

Walker JG, Johnson S, Manion I, Cloutier P. Emotionally focused marital intervention for couples with chronically ill children. Journal of Consulting and Clinical Psychology. 1996; 64(5):1029_ 36. [PubMed: 8916632]

Warner CM, Ludwig K, Sweeney C, Spillane C, Hogan L, Ryan J, et al. Treating persistent distress and anxiety in parents of children with cancer: an initial feasibility trial. Journal of Pediatric Oncology Nursing. 2011; 28(4):224-30. [PubMed: 21646637]

Wysocki T, McDonell K, Harris MA, Elder Danda CL, Greco P, Bubb J, et al. Social validity of support group and behavior therapy interventions for families of adolescents with insulindependent diabetes mellitus. Journal of Pediatric Psychology. 1997; 22(5):635-49. [PubMed: 9383927]

\section{References}

Studies awaiting classification

Ongoing studies

Other references

Additional references

American Psychological Association. Publication Manual of the American Psychological Association. Washington: American Psychological Association; 2011.

Anie KA, Green J. Psychological therapies for sickle cell disease and pain. Cochrane Database of Systematic Reviews. 2012; (2) Art. No.: CD001916. 10.1002/14651858.CD001916.pub2

Armour TA, Norris SL, Jack L Jr, Zhang X, Fisher L. The effectiveness of family interventions in people with diabetes mellitus: a systematic review. Diabetic Medicine. 2005; 22:1295-305. [PubMed: 16176186]

Ashby FG, Isen AM, Turken AU. A neuropsychological theory of positive affect and its influence on cognition. Psychological Review. 1999; 106(3):529-50. [PubMed: 10467897]

Bandura, A. Social Learning Theory. New Jersey: Prentice-Hall; 1977.

Bandura A. Human agency in social cognitive theory. American Psychologist. 1989; 44(9):1175-84. [PubMed: 2782727]

Bargh JA, Morsella E. The unconscious mind. Perspectives on Psychological Science. 2008; 3(1):739. [PubMed: 18584056]

Beck, AR.; Rush, AJ.; Shaw, B.; Emery, G. Cognitive Therapy of Depression. New York: Guilford Press; 1979.

Bergin AE, Suinn RM. Individual psychotherapy and behavior therapy. Annual Review of Psychology. 1975; 26:509-56.

Bronfenbreener, U. The Ecology of Human Development: Experiments and Design and Nature. Massachusetts: Harvard University; 1979. 
Cohen J. A power primer. Psychological Bulletin. 1992; 112(1):155-9. [PubMed: 19565683]

Committee on Publication Ethics. [accessed 22 march 2012] Code of conduct and best practice guidelines for journal editors. http://publicationethics.org/

D'Zurilla, TJ.; Nezu. Social problem solving in adults. In: Kendall, PC., editor. Advances in CognitiveBehavioral Research and Therapy. New York: Academic Press; 1982. p. 202-74.

D'Zurilla TJ, Goldfried MR. Problem solving and behavior modification. Journal of Abnormal Psychology. 1995; 78:107-26. [PubMed: 4938262]

D'Zurilla, TJ.; Nezu, AM. Problem-Solving Therapy: A Social Competence Approach to Clinical Intervention. New York: Springer-Verlag; 1999.

D'Zurilla, TJ.; Nezu, AM. A positive approach to clinical intervention. New York: Springer; 2007. Problem-solving therapy.

National survey of children with special health care needs: current health conditions and functional difficulties. Data Resource Center for Child \& Adolescent Health. 2010

Data's shameful neglect. Vol. 461. Nature; 2009. Nature; p. 145

Drotar D. Editorial: Guidance for submission and review of multiple publications derived from the same study. Journal of Pediatric Psychology. 2010; 35(3):225-30.

Eccleston C, Palermo TM, Williams ACDC, Lewandowski A, Morley S. Psychological therapies for the management of chronic and recurrent pain in children and adolescents. Cochrane Database of Systematic Reviews. 2009; (2) Art. No.: CD003968. 10.1002/14651858.CD003968

Eccleston C, Williams ACDC, Morley S. Psychological therapies for the management of chronic pain (excluding headache) in adults. Cochrane Database of Systematic Reviews. 2009; (2) Art. No.: CD007407. 10.1002/14651858.CD007407

Ersser SJ, Latter S, Sibley A, Satherley PA, Welbourne S. Psychological and educational interventions for atopic eczema in children. Cochrane Database of Systematic Reviews. 2007; (3) Art. No.: CD000054. 10.1002/14651858.CD004054

Gilliom M, Shaw DS, Beck JE, Schonberg MA, Lukon JL. Anger regulation in disadvantaged preschool boys: strategies, antecedents, and the development of self-control. Developmental Psychology. 2002; 38:222-35. [PubMed: 11881758]

Grey M. Interventions for children with diabetes and their families. Annual Review of Nursing Research. 2000; 18(1):149-70.

Haley, J. Problem Solving Therapy. San Francisco: Jossey-Bass; 1976.

Halfon N, Newackeck PW. Evolving notions of childhood chronic illness. JAMA. 2010; 303(7):6656. [PubMed: 20159877]

Harris MA, Freeman KA, Duke DC. Getting (the most) out of the research business: interventions for youth with T1 DM. Current Diabetes Report. 2010; 10:406-14.

Henggeler, SW.; Lee, T. Multisystemic treatment of serious clinical problems. In: Kazdin, E.; Weisz, JR., editors. Evidence-based Psychotherapies for Children and Adolescents. Vol. 2003. New York: Guilford Press; p. 301-24.

Higgins, JPT.; Green, S., editors. The Cochrane Collaboration. Cochrane Handbook for Systematic Reviews of Interventions Version 5.1.0 [updated March 2011]. 2011. Available from www.cochrane-handbook.org

Huertas-Ceballos AA, Logan S, Bennett C, Macarthur C. Psychosocial interventions for recurrent abdominal pain (RAP) and irritable bowel syndrome (IBS) in childhood. Cochrane Database of Systematic Reviews. 2008; (1) Art. No.: CD03014. 10.1002/14651858.CD003014.pub2

James, W. The Principles of Psychology. New York: Henry Holt and Company; 1980.

Jordan AL, Eccleston C, Osborn M. Being a parent of the adolescent with complex chronic pain: an interpretative phenomenological analysis. European Journal of Pain. 2007; 11:49-56. [PubMed: 16458550]

Lewin S, Munabi-Babigumira S, Glenton C, Daniels K, Bosch-Capblanch X, van Wyk BE, et al. Lay health workers in primary and community health care for maternal and child health and the management of infectious diseases. Cochrane Database of Systematic Reviews. 2010; (3) Art. No.: CD004015. 10.1002/14651858.CD004015 
Linabery AM, Ross JA. Trends in childhood cancer incidence in the U.S (1992-2004). Cancer. 2007; 112(2):416-32. [PubMed: 18074355]

Logan DE, Scharff L. Relationships between family and parent characteristics and functional abilities in children with recurrent pain syndromes: an investigation of moderating effects on the pathway from pain to disability. Journal of Pediatric Psychology. 2005; 30(8):698-707. [PubMed: 16093517]

McBroom LA, Enriquez M. Review of family-centered interventions to enhance the health outcomes of children with type 1 diabetes. The Diabetes Educator. 2009; 35(3):428-38. [PubMed: 19299519]

McDougall J, King G, de Wit D, Miller LT, Honh S, Offord DR, et al. Chronic physical health conditions and disability among Canadian school-aged children: a national profile. Disability and Rehabilitation. 2004; 26(1):35-45. [PubMed: 14660197]

Minuchin, S. Families \& Family Therapy. Massachusetts: Harvard University; 1974.

Nock MK, Kazdin AE. Parent expectancies for child therapy: assessment and relation to participation in treatment. Journal of Child and Family Studies. 2001; 10(2):155-80.

Pai ALH, Drotar D, Zebracki K, Moore M, Youngstorm E. A meta-analysis of the effects of psychological interventions in pediatric oncology on outcomes of psychological distress and adjustment. Journal of Pediatric Psychology. 2006; 31(9):978-88. [PubMed: 16514049]

Palermo TM. Impact of recurrent and chronic pain on child and family daily functioning: a critical review of the literature. Developmental and Behavioral Pediatrics. 2000; 21(1):58-69.

Palermo TM, Chambers CT. Parent and family factors in pediatric chronic pain and disability: an integrative approach. Pain. 2005; 119:1-4. [PubMed: 16298492]

Palermo TM, Wilson AC, Peters M, Lewandowski A, Somhegyi H. Randomized controlled trial of an internet delivered family cognitive-behavioral therapy intervention for children and adolescents with chronic pain. Pain. 2009; 146:205-13. 10.1016/j.pain.2009.07.034. [PubMed: 19695776]

Palermo TM, Eccleston C. Parents of children and adolescents with chronic pain. Pain. 2009; 146(1-2): 15-7. [PubMed: 19482426]

Perrin JM, Bloom SR, Gortmaker SL. The increase of childhood chronic conditions in the United States. JAMA. 2007; 297(24):2755-9. [PubMed: 17595277]

Review Manager (RevMan) [Computer program]. Version 5.1. Copenhagen: The Nordic Cochrane Centre, The Cochrane Collaboration; 2011.

Robin, AL.; Foster, SL. Negotiating Parent Adolescent Conflict: A Behavioral-family Systems Approach. New York: Guilford; 1989.

Sansom-Daly UM, Peate M, Wakefield CE, Bryant RA, Cohn RJ. A systematic review of psychological interventions for adolescents and young adults living with chronic illness. Health Psychology. 2011 Advance online publication:1-15. [10.1037/a0025977].

Savage E, Beirne PV, Ni Chroinin M, Duff A, Fitzgerald T, Farrell D. Self-management education for cystic fibrosis. Cochrane Database of Systematic Reviews. 2011; (7) Art. No.: CD007641. 10.1002/14651858.CD007641

Schulz KF, Altman DG, Moher D, for the CONSORT Group. CONSORT 2010 Statement: updated guidelines for reporting parallel group randomised trials. BMJ. 2010; 340:698-702.

Shapiro B. Building bridges between body and mind: the analysis of an adolescent with paralyzing chronic pain. International Journal of Psychoanalysis. 2003; 84:547-61. [PubMed: 12873360]

Skinner, BF. Science and Human Behaviour. Toronto: The Macmillan Company; 1953. Chapter 5: Operant behavior.

Soo C, Tate R. Psychological treatment for anxiety in people with traumatic brain injury. Cochrane Database of Systematic Reviews. 2007; (3) Art. No.: CD005239. 10.1002/14651858.CD005239.pub2

Van Cleave J, Gortmaker SL, Perrin JM. Dynamics of obesity and chronic health conditions among children and youth. JAMA. 2010; 303(7):623-30. [PubMed: 20159870]

Van der Lee JH, Mokkink LB, Grootenhuis MA, Heymans HS, Offringa M. Definitions and measurement of chronic health conditions in childhood. JAMA. 2007; 297(24):2741-51. [PubMed: 17595275] 
Wegner DM. Ironic processes of mental control. Psychological Review. 1994; 101(1):34-52. [PubMed: 8121959]

World Health Organization. WHO Library Cataloguing-in-Publication Data. 2011. World Health Statistics.

Wicherts JM, Borsboom D, Kats J, Molenaar D. The poor availability of psychological research data for reanalysis. American Psychologist. 2006; 61(7):726-8. [PubMed: 17032082]

Wicherts JM, Bakker M, Molenaar D. Willingness to share research data is related to the strength of the evidence and quality of reporting of statistical results. PLoS ONE. 2011; 6(11):e26828. [PubMed: 22073203]

[accessed 22 March 2012] World Association of Medical Editors. Publication ethics policies for medical journals. http://www.wame.org

Wysocki T, Harris MA, Greco P, Bubb J, Danda CE, Harvey LM, et al. Randomized, controlled trial of behavior therapy for families of adolescents with insulin-dependent diabetes mellitus. Journal of Pediatric Psychology. 2000; 25(1):23-33. [PubMed: 10826241]

Yates SL, Morley S, Eccleston C, Williams A. A scale for rating the quality of psychological trials for pain. Pain. 2005; 117:314-25. [PubMed: 16154704]

Yorke J, Shuldham C. Family therapy for asthma in children. Cochrane Database of Systematic Reviews. 2009; (2) Art. No.: CD003272. 10.1002/14651858.CD003272.pub2 


\begin{tabular}{|c|c|c|c|c|c|}
\hline & 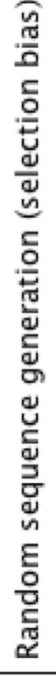 & 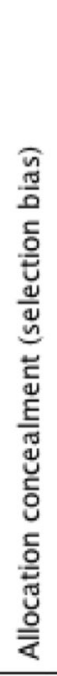 & 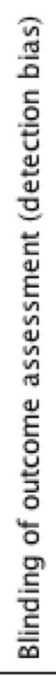 & 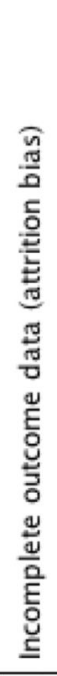 & 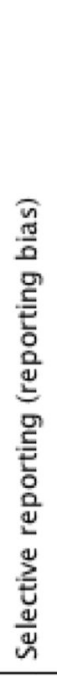 \\
\hline Allen 1998 & $?$ & $?$ & $?$ & - & $\odot$ \\
\hline Ambrosino 2008 & 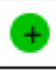 & + & $?$ & + & $?$ \\
\hline Askins 2009 & $\hookrightarrow$ & 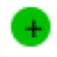 & $?$ & $?$ & ? \\
\hline Barakat 2010 & $?$ & $?$ & $?$ & 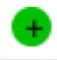 & $?$ \\
\hline Barry 1997 & $?$ & $\odot$ & $?$ & $?$ & $\odot$ \\
\hline Celano 2012 & 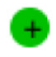 & $?$ & 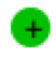 & $?$ & $\hookrightarrow$ \\
\hline Connelly 2006 & 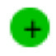 & 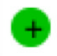 & 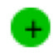 & $?$ & $\hookrightarrow$ \\
\hline Duarte 2006 & $?$ & $?$ & $?$ & O & $?$ \\
\hline Ellis 2004 & $?$ & 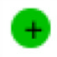 & 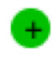 & 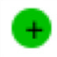 & $?$ \\
\hline Ellis 2005 & ? & $?$ & $?$ & 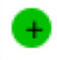 & $?$ \\
\hline Grey 2011 & $?$ & $\uparrow$ & $\uparrow$ & $?$ & $\odot$ \\
\hline Hicks 2006 & + & $?$ & $?$ & + & $?$ \\
\hline
\end{tabular}




\begin{tabular}{|c|c|c|c|c|c|}
\hline \multirow[b]{2}{*}{ Hoekstra-Weebers 1998} & \\
\hline & $?$ & $?$ & $?$ & $\odot$ & $\odot$ \\
\hline Kashikar-Zuck 2005 & $\hookrightarrow$ & 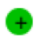 & $\hookrightarrow$ & $?$ & $\odot$ \\
\hline Kashikar-Zuck 2012 & 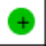 & $\hookrightarrow$ & 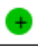 & $\odot$ & † \\
\hline Kazak 2004 & $?$ & $?$ & ? & $?$ & $?$ \\
\hline Laffel 2003 & $?$ & $?$ & ? & - & $\odot$ \\
\hline Lask 1979 & $?$ & $?$ & ? & - & 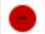 \\
\hline Lehmkuhl 2010 & $\oplus$ & $?$ & $?$ & - & - \\
\hline Levy 2010 & + & + & 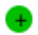 & $?$ & $\odot$ \\
\hline Ng 2008 & $?$ & $?$ & $?$ & $?$ & 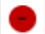 \\
\hline Niebel 2000 & $?$ & $?$ & ? & - & 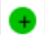 \\
\hline Olivares 1997 & $?$ & $?$ & $?$ & - & - \\
\hline Palermo 2009 & + & + & + & + & + \\
\hline Robins 2005 & 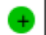 & $?$ & $?$ & $?$ & $\Theta$ \\
\hline Sahler 2002 & + & + & ? & 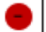 & + \\
\hline Sahler 2005 & $?$ & $?$ & $?$ & $?$ & $?$ \\
\hline Sanders 1994 & $?$ & $?$ & $?$ & - & $?$ \\
\hline Seid 2010 & $\oplus$ & 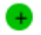 & 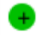 & $\odot$ & 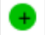 \\
\hline Stehl 2009 & + & + & + & + & + \\
\hline Wade 2006 & 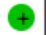 & $?$ & - & $\oplus$ & $?$ \\
\hline Wade $2006 \mathrm{~b}$ & $\oplus$ & $?$ & $\hookrightarrow$ & $?$ & $?$ \\
\hline Wade 2011 & $?$ & $?$ & 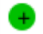 & $?$ & $?$ \\
\hline Wysocki 1999 & $?$ & $?$ & $?$ & $?$ & O \\
\hline Wysocki 2006 & ? & $?$ & $\hookrightarrow$ & $?$ & - \\
\hline
\end{tabular}

Figure 1.

'Risk of bias' summary: review authors' judgements about each risk of bias item for each included study. 


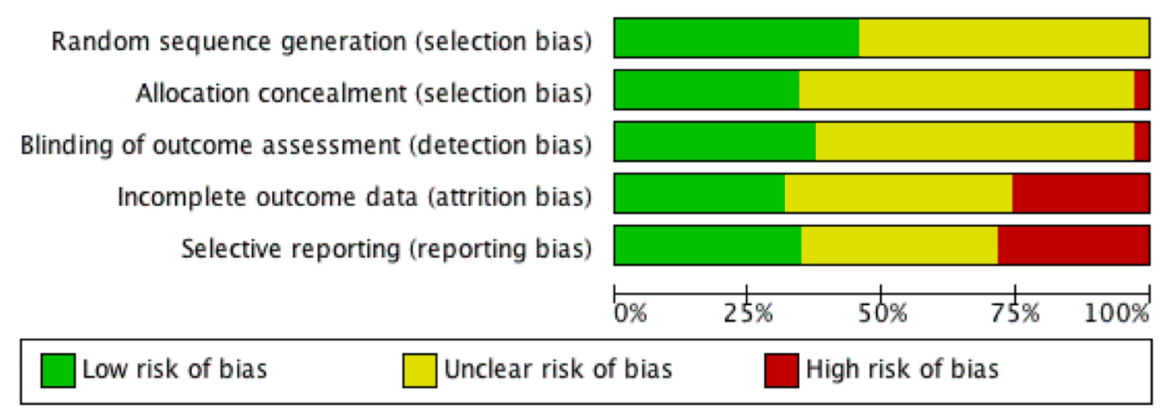

Figure 2.

'Risk of bias' graph: review authors' judgements about each risk of bias item presented as percentages across all included studies. 


\begin{tabular}{|c|c|c|c|c|c|c|c|c|c|}
\hline \multirow[b]{2}{*}{ Study or Subgroup } & \multicolumn{3}{|c|}{ Experimental } & \multicolumn{3}{|c|}{ Control } & \multicolumn{2}{|r|}{ Std. Mean Difference } & \multirow{2}{*}{$\begin{array}{l}\text { Std. Mean Difference } \\
\text { IV, Random, } 95 \% \mathrm{CI}\end{array}$} \\
\hline & Mean & SD & Total & Mean & SD & Total & Weight & IV, Random, $95 \% \mathrm{Cl}$ & \\
\hline Allen 1998 & 1.5 & 2.3 & 14 & 3.3 & 2.9 & 13 & $7.9 \%$ & $-0.67[-1.45,0.11]$ & \\
\hline Barakat 2010 & 16.6 & 16.57 & 17 & 17.29 & 23.21 & 20 & $10.2 \%$ & $-0.03[-0.68,0.61]$ & \\
\hline Connelly 2006 & 72.97 & 84.99 & 17 & 117.31 & 91.23 & 20 & $10.0 \%$ & $-0.49[-1.15,0.17]$ & \\
\hline Hicks 2006 & 3.4 & 2.4 & 21 & 4.7 & 2.2 & 16 & $9.9 \%$ & $-0.55[-1.21,0.11]$ & \\
\hline Kashikar-Zuck 2012 & 5.3 & 2.3 & 57 & 6 & 1.9 & 57 & $18.2 \%$ & $-0.33[-0.70,0.04]$ & \\
\hline Levy 2010 & 1.64 & 2.02 & 84 & 1.25 & 1.75 & 84 & $20.8 \%$ & $0.21[-0.10,0.51]$ & \\
\hline Palermo 2009 & 3.54 & 2.42 & 26 & 4.76 & 1.84 & 22 & $11.7 \%$ & $-0.55[-1.13,0.03]$ & \\
\hline Sanders 1994 & 3.27 & 8.33 & 22 & 6.67 & 7.04 & 22 & $11.3 \%$ & $-0.43[-1.03,0.17]$ & \\
\hline \multirow{2}{*}{\multicolumn{9}{|c|}{$\begin{array}{l}\text { Total }(95 \% \mathrm{Cl}) \\
\text { Heterogeneity: } \mathrm{Tau}^{2}=0.06 ; \mathrm{Ch}^{2}=12.80, \mathrm{df}=7(\mathrm{P}=0.08): \mathrm{I}^{2}=45 \%\end{array}$}} & \\
\hline & & & & & & & & & -1 \\
\hline
\end{tabular}

Figure 3 (Analysis 1.4).

Forest plot of comparison: 1 Painful Conditions Post-treatment, outcome: 1.4 Child Symptoms. 


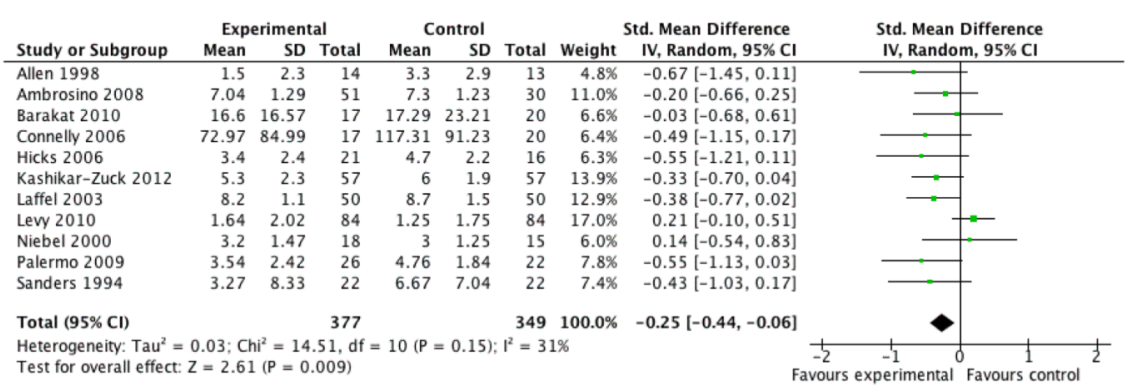

Figure 4 (Analysis 10.5).

Forest plot of comparison: 10 Cognitive Behavioural Therapy Post-treatment, outcome: 10.5 Child Symptoms. 


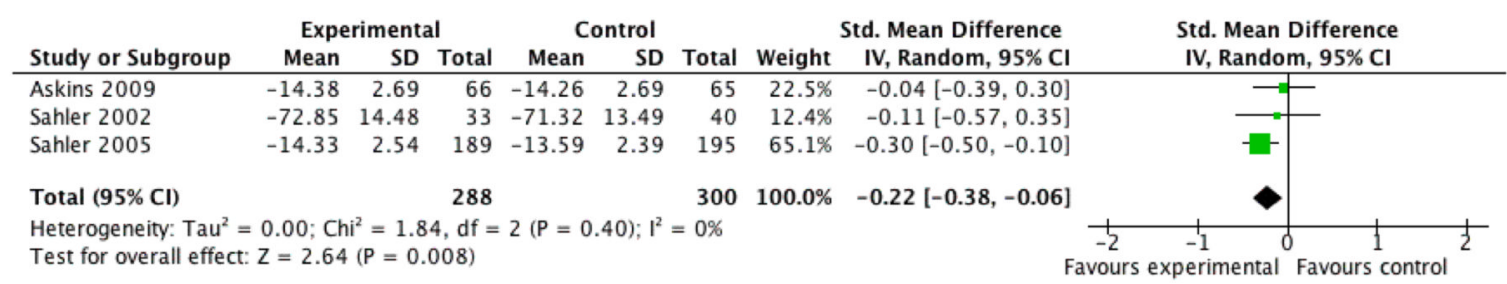

Figure 5 (Analysis 14.1).

Forest plot of comparison: 14 Problem Solving Therapy Post-treatment, outcome: 14.1

Parent Behaviour. 


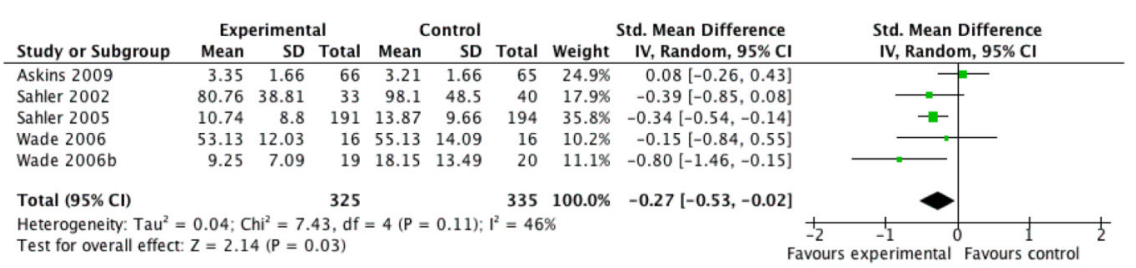

Figure 6 (Analysis 14.2).

Forest plot of comparison: 14 Problem Solving Therapy Post-treatment, outcome: 14.2 Parent Mental Health. 